NBER WORKING PAPER SERIES

\title{
TECHNOLOGICAL TRANSITIONS WITH SKILL HETEROGENEITY ACROSS GENERATIONS
}

\author{
Rodrigo Adão \\ Martin Beraja \\ Nitya Pandalai-Nayar \\ Working Paper 26625 \\ http://www.nber.org/papers/w26625
}

\author{
NATIONAL BUREAU OF ECONOMIC RESEARCH \\ 1050 Massachusetts Avenue \\ Cambridge, MA 02138 \\ January 2020
}

First version: May 2018 under title "Skill-Biased Technological Transitions." We are grateful to Masao Fukui, Agustin Gutierrez and Michelle Lam for excellent research assistance. We thank Christopher Tonetti for his superb discussion as well as all other participants at the NBER's EF\&G Fall meeting. For their valuable suggestions, we thank Daron Acemoglu, David Autor, Fernando Alvarez, Ariel Burstein, Juliette Caminade, V.V. Chari, Arnaud Costinot, Steve Davis, Dave Donaldson, Oded Galor, Erik Hurst, Greg Kaplan, Pablo Kurlat, Frank Levy, Simon Mongey, Fabrizio Perri, Aysegul Sahin, Dejanir Silva, Venky Venkateswaran, Gianluca Violante, and Fabrizio Zilibotti. We also thank seminar participants at Dartmouth, Duke, MIT, Northwestern, NYU, Notre-Dame, Philly Fed, Stockholm (IIES), UCLA, UCSD, U of Munich, USC Marshall, UT Austin, Yale, WashU/St. Louis Fed, the Barcelona GSE Summer Forum, and the NBER SI Income Distribution and Macroeconomics, and Micro Data for Macro Models groups for helpful comments. Data access was provided by the Research Data Centre (FDZ) of the German Federal Employment Agency (BA) at the Institute for Employment Research (IAB). We thank Peter Brown and Clare Dingwell of the Harvard Economics Department, for facilitating access to IAB data. All results based on IAB microdata have been cleared for disclosure. The views expressed herein are those of the authors and do not necessarily reflect the views of the National Bureau of Economic Research.

NBER working papers are circulated for discussion and comment purposes. They have not been peerreviewed or been subject to the review by the NBER Board of Directors that accompanies official NBER publications.

(C) 2020 by Rodrigo Adão, Martin Beraja, and Nitya Pandalai-Nayar. All rights reserved. Short sections of text, not to exceed two paragraphs, may be quoted without explicit permission provided that full credit, including $\odot$ notice, is given to the source. 
Technological Transitions with Skill Heterogeneity Across Generations

Rodrigo Adão, Martin Beraja, and Nitya Pandalai-Nayar

NBER Working Paper No. 26625

January 2020, Revised June 2020

JEL No. C0,E0,F0,J0,O0

\begin{abstract}
$\underline{\text { ABSTRACT }}$
We study how inequality, skills, and economic activity adjust over time to technological innovations. We develop a theory of technological transitions where economies adjust through two margins: (i) within-generation reallocation of workers with heterogeneous skills, and (ii) cross-generation changes in the skill distribution driven by entering generations investing in skills. We then characterize the equilibrium dynamics, showing that they resemble those of a qtheory of skill investment where $q$ is lifetime inequality. Technological transitions are slower and more unequal whenever innovations are biased towards economic activities intensive in skills which differ more from those used in the rest of the economy-i.e., technology-skill specificity is higher. This is because the first margin is weaker and the second stronger. Lastly, we document that recent cognitive-biased innovations caused responses in occupational composition and training which were strong for younger generations but weak for older ones. This evidence is consistent with high technology-skill specificity, implying that cognitive-biased transitions are particularly slow and unequal because they are mainly driven by changes in the skill distribution across generations.
\end{abstract}

\section{Rodrigo Adão}

Booth School of Business

University of Chicago

5807 South Woodlawn Avenue

Chicago, IL 60637

and NBER

rodrigo.adao@chicagobooth.edu
Nitya Pandalai-Nayar

Department of Economics

University of Texas at Austin

3.142 BRB, 2225 Speedway

Austin, TX 78713

and NBER

npnayar@utexas.edu

Martin Beraja

Department of Economics

MIT

50 Memorial Drive

Cambridge, MA 02142

and NBER

martinberaja@gmail.com

A online appendix is available at https://www.nber.org/data-appendix/w26625/ 


\section{Introduction}

In recent decades, developed economies have experienced rising inequality and large changes in relative employment across occupations and sectors (Acemoglu and Autor, 2011; Buera and Kaboski, 2012). These trends have resulted, in part, from technological innovations that were biased towards economic activities intensive in specific skills (Autor et al., 2003). However, these aggregate changes in relative employment can mask underlying differences across generations. For instance, Figure 1 documents that while the employment share of occupations intensive in cognitive skills increased in most developed economies, such changes were larger for younger than for older generations. ${ }^{1}$

In this paper, we study how economies adjust over time to technological innovations that are biased towards economic activities intensive in specific skills. We argue that the type of patterns in Figure 1 point to at least two margins through which this adjustment can occur: (i) existing workers reallocate towards these activities, provided their skills are more valuable in them, and (ii) new generations of workers invest more in the relevant skills, thus entering these activities in greater proportions. Because the first margin dominates the adjustment at shorter horizons and the second at longer ones, they shape the dynamics of the economy following technological innovations, in particular how slow and unequal these dynamics are. This implies that, if the strength of the two margins varies with the type of innovation, then technological transitions will vary in how slow and unequal they are as well. Motivated by this discussion, our goal is to provide answers to three questions: How do inequality, skills, and economic activity jointly adjust over time to technological innovations? What features of innovations and skills determine whether the adjustment is fast or whether it slowly plays out over many generations? Which types of evidence, even when only available over short horizons, point to an unequal and slow adjustment?

We begin by developing a theory of technological transitions where economies adjust through two margins: (i) within-generation reallocation of workers with heterogeneous skills (Roy, 1951), and (ii) cross-generation changes in the skill distribution driven by entering generations investing in different skills than previous ones (Chari and Hopenhayn, 1991). Using an approach that shares some parallels with Perla and Tonetti (2014) and Lucas and Moll (2014), we then show that the equilibrium dynamics resemble those of a $q$-theory of skill investment, where lifetime inequality $q$ overshoots its long-run level and the skill distribution slowly adjusts over time.

We use this characterization to establish our main insight: the type of technological innovation determines the relative strength of the two adjustment margins and, con-

\footnotetext{
${ }^{1}$ Murphy and Topel (1987) and Kim and Topel (1995) find similar patterns across broad sectors in the U.S. and Korea. Hobijn et al. (2019) and Porzio and Santangelo (2019) document them for many developed and developing countries. Autor and Dorn (2009) shows average age increases in middle-wage occupations in the U.S. in 1980-2005.
} 
Figure 1: Recent trends in cognitive-intensive employment growth in developed countries

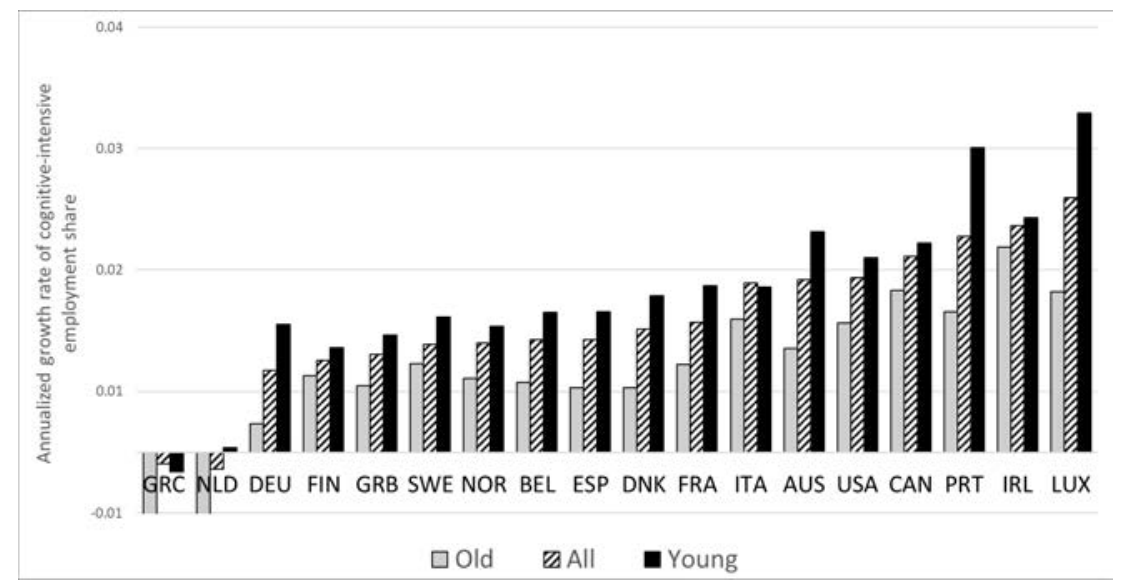

Note. Annualized log-change in cognitive-intensive occupation share in 1997-2017 for European countries, in 20002010 for U.S., and in 2001-2011 for Canada. Sample of males in two age groups: "Young" aged 15-39yrs and "Old" aged 40-64yrs. Cognitive-intensive occupations are the top 3 groups in cognitive intensity among the nine 2-digit ISCO occupation groups (Managers, Professionals, Technicians). Data comes from Eurostat for European countries and IPUMS International for U.S. and Canada. Cognitive intensity is the average across an ISCO group's occupations of time spent on analytical non-routine and interactive tasks as reported in the German BERUFNET dataset.

sequently, the joint equilibrium dynamics of inequality, the skill distribution, and economic activity. More precisely, we show that a technological transition is slower and more unequal whenever an innovation is biased towards economic activities intensive in skills which differ more from those used in other activities-i.e., whenever technologyskill specificity is higher. This is because, in this case, it is harder for existing workers to reallocate across activities (the first margin is weaker), which leads to a larger increase in inequality $q$ following the innovation. In turn, this causes new generations of workers to invest more in the skills that became more valuable, which leads to larger changes in the skill distribution along the transition (the second margin is stronger).

Lastly, in the context of Germany, we show that recent cognitive-biased innovations caused responses in occupational composition and training which were strong for younger generations but weak for older ones. These type of responses, even when observed over short horizons, indicate an economy featuring high technology-skill specificity. Through a counterfactual exercise, we then show that this implies that cognitivebiased transitions are particularly unequal and slow because they are mainly driven by changes in the skill distribution. As a result, naive extrapolations from observed responses at short horizons lead to overly pessimistic views about the welfare and distributional implications of cognitive-biased innovations. The reason is that they miss the increase in average living standards and the decline in inequality at longer horizons, which are yet unobserved and take many generations to fully materialize.

We next describe the theory in more detail and present the three main results which address, in turn, each of the three questions posed above. To formalize the withingeneration reallocation margin theoretically, we consider an economy with two technolo- 
gies that are combined to produce a final consumption good, as in Katz and Murphy (1992), Ngai and Pissarides (2007), and Buera et al. (2011). Workers are heterogeneous over a continuum of skill types that determine their technology-specific productivities, as in Roy (1951). Given the relative technology-specific wage at a point in time, there is an assignment threshold determining the allocation of workers with different skills to technologies. To formalize the cross-generation skill distribution changes margin, we introduce overlapping generations of workers with stochastic lifetimes, as in Yaari (1965) and Blanchard (1985). Workers make a costly forward-looking investment upon entry that determines their skill type for their lifetime, similar to Chari and Hopenhayn (1991), Caselli (1999) and Galor and Moav (2002). ${ }^{2}$ When faced with different paths of relative wages, the investment decisions of entering worker generations yield endogenous differences in skill distributions across generations.

Our first result characterizes the joint equilibrium dynamics of inequality, the skill distribution, and worker allocations following a skill-biased innovation that permanently increases the productivity of one of the technologies. This is the solution to a highdimensional, complex fixed-point problem in which the skill distribution is a state variable and can, in principle, only be tackled numerically (which we do in our numerical counterfactual exercises). Yet, we analytically characterize the approximate transitional dynamics by reducing the dimensionality of the problem. In particular, we establish that they can be approximated by a system of differential equations that resembles that of a $q$-theory of skill investment, where $q$ is the present value of the relative technologyspecific wage. This analytical characterization allows us to tell the story of the economy's adjustment through the two margins in the theory, as well as derive the theoretical and measurement insights that answer the questions posed in the beginning.

The economy's adjustment plays out as follows. On impact, the innovation raises the relative wage in the improved technology. Within existing generations, marginal skill types that were around the initial assignment threshold now reallocate into that technology. This rationalizes the observed changes in relative employment within older generations. For entering generations, the change in current and future relative wages (summarized in $q$ ) causes them to tilt their investment decisions towards skills more complementary to the improved technology. This rationalizes the stronger changes in occupation composition observed for younger generations. Along the transition, as younger generations replace older ones, the economy's overall skill distribution and worker allocations also tilt towards the improved skills and technology. This leads to a slow process of relative wage decline and relative output increase across technologies.

Our second result establishes our main insight about the determinants of technological transitions. We consider two separate thought experiments that speak to differences

\footnotetext{
${ }^{2}$ In an extension of our baseline model, we also let older generations invest in skills after a technological innovation.
} 
across episodes of adjustment in which the type of technological innovations might be different. The first compares two economies: one in which an innovation improves a technology intensive in skills which are markedly different from those used by the rest of the economy (a high technology-skill specificity economy) and another one in which they are more similar (a low technology-skill specificity economy). The second compares two other economies: one in which an innovation improves a technology intensive in skills which are harder to accumulate (a high cost of skill investment economy) and another one in which they are easier (a low cost of skill investment economy).

Higher technology-skill specificity leads to a slower, more back-loaded adjustment in inequality and economic activity following a skill-biased innovation. ${ }^{3}$ On impact, higher specificity weakens the within-generation reallocation of older generations with predetermined skills. This results in a stronger increase in inequality $(q)$, which then strengthens the incentives of younger generations to invest in those skills that are more complementary to the improved technology. Ultimately, a larger fraction of the overall adjustment happens along the transition because larger changes in the economy's skill distribution take place as younger generations replace older ones. In addition, a lower cost of skill investment for young generations strengthens the cross-generation margin by amplifying changes in the skill distribution for any given change in lifetime inequality. This makes the adjustment slower as well, both directly and by amplifying the importance of technology-skill specificity. Together, these results show that transitions are slower and more unequal whenever the adjustment is driven more by skill distribution changes than by the reallocation of older worker generations at impact.

Our third result connects the determinants of the two adjustment margins in our theory to the impact of technological innovations on labor market outcomes that are observed over short horizons. In particular, we link the degree of technology-skill specificity and the cost of skill investment to the type of responses for different generations shown in Figure 1. This result builds directly on the comparative statics described above. In the short-run, economies with higher technology-skill specificity exhibit weaker within-generation relative employment responses for older workers but larger cross-generation differences in relative employment responses of younger versus older workers. In contrast, a lower cost of skill investment for entering generations creates larger cross-generation differences in relative employment responses, but has no impact on the responses of older workers.

In the last part of the paper, we use our theory to analyze Germany's adjustment to cognitive-biased innovations. This has two advantages. First, we are able to provide

\footnotetext{
${ }^{3}$ Formally, we use the "discounted cumulative impulse response" (DCIR) to measure how slow the adjustment is. It captures how much of the overall (long-run) adjustment older generations born before the innovation expect to experience during their lifetime. In our model, we show that the DCIR of $q$ is an important determinant of the average and distributional welfare consequences of new technologies.
} 
causal evidence that confirms and extends the stylized patterns in Figure 1. Second, by exploiting our third theoretical result, we are able to use this evidence to discipline key structural parameters in our model and ask the following counterfactual question: if technological innovations had not been cognitive-biased and had instead been biased towards occupations or sectors intensive in skills which were more similar to those used in the rest of the economy, how different would the economy's adjustment have been?

We first investigate the evolution of labor market outcomes across narrowly defined occupations that differ in terms of cognitive intensity. We show that employment and payroll grew more in more cognitive-intensive occupations over recent decades. This effect is strong for younger generations but weak for older generations. These responses are similar when we control for a number of confounding factors, like exposure to immigration and international trade. We also explore the large-scale German vocational training program to document stronger growth in the number of trainees in more cognitive intensive occupations. This provides direct evidence for the theory's source of dynamics: entering generations tilt their investment decisions towards cognitive skills.

We then investigate the dynamic adjustment of labor market outcomes to a particular cognitive-biased innovation: the introduction of broadband internet in the early 2000s. Following Falck et al. (2014), we use pre-determined conditions of the German telephone network to obtain quasi-experimental variation across regions in the timing of adoption. By comparing late to early adopting regions, we estimate impulse response functions that show an increase in the relative employment and payroll of more cognitive-intensive occupations starting in 2005. We find that the impact on relative employment is small and non-significant for older generations over the entire period. In contrast, it is positive and statistically significant for younger generations. Thus, the expansion of cognitiveintensive occupations was entirely driven by the entry of younger generations.

Through the lens of our third theoretical result, the evidence indicates that cognitivebiased innovations are associated with an economy featuring high technology-skill specificity and that the supply of cognitive skills is elastic at longer horizons. Our counterfactual exercise shows that had recent technologies instead been biased towards economic activities intensive in skills which were more similar to those used in the rest of the economy (i.e., if technology-skill specificity had been lower), then the adjustment would have been less unequal and faster. In other words, cognitive-biased transitions are particularly unequal and slow to play out because they are mainly driven by skill distribution changes across generations. Moreover, we show that naively extrapolating from changes at short horizons leads to views regarding welfare and inequality that are too pessimistic. We conclude with suggestive evidence that technology-skill specificity was lower in the U.S. and German economies in the mid-twentieth century than in recent decades. ${ }^{4}$

\footnotetext{
${ }^{4}$ We document similar changes in occupational composition for young and old generations before 1990 in Germany
} 


\section{Related literature}

Our paper is related to the extensive literature analyzing the economic consequences of changes in relative demand for skills, sectors, or occupations. Recent papers have used static Roy-like assignment models with technology-skill interactions to study the impact of new technologies on relative wages and employment reallocation across occupations and sectors, e.g., Acemoglu and Autor (2011), Costinot and Vogel (2010), Hsieh et al. (2013), Burstein et al. (2016). A separate literature has studied how new technologies affect the economy through the entry of new generations with potentially different skills - e.g., Chari and Hopenhayn (1991) and Galor and Moav (2002). Finally, the literature on structural transformation has analyzed the reallocation of economic activity across sectors, focusing for the most part on sources of dynamics and notions of technology that abstract from interactions with skills altogether, e.g., Ngai and Pissarides (2007), Rogerson (2008), and, for a review, Herrendorf et al. (2014). ${ }^{5}$ Our theory builds on these literatures by endogenizing the dynamics of the skill distribution in assignment models through the forward-looking investment decisions of new generations on technology-specific skills. This allows us to study how the types of technologies and skills determine the reallocation of workers within a generation and changes in the skill distribution across generations and, consequently, the speed of reallocation of economic activity and the dynamics of inequality during technological transitions. Furthermore, we link our theoretical margins to causal short-run responses of labor market outcomes to technological innovations, which we then use to discipline counterfactual exercises on the impact of cognitive-biased innovations in Germany.

The only source of dynamics in our theory is the endogenous change in the distribution of skills across generations. This mechanism not only rationalizes the crossgeneration differences in occupation composition changes that we document, but it is also consistent with recent evidence on the impact of labor demand shocks on young individuals' decisions of educational attainment (Atkin, 2016 and Charles et al., 2018) and field of study (Abramitzky et al., 2019, Ghose, 2019). We add to this literature by documenting that cognitive-biased innovations cause higher training in cognitive-intensive occupations in Germany. Our paper is thus also related to the literature using quantitative frameworks with endogenous skill accumulation to study the impact of shocks to relative demand across skills, sectors and occupations - e.g., Lee and Wolpin (2006). This literature has by and large studied dynamics in environments with exogenous skillprices or without technology-specific skills, or focused on comparisons across long-run

and the U.S., which stands in sharp contrast with the strong differences across generations after 1990 (Figure 1).

${ }^{5}$ Exceptions considering workers with heterogenous skills are Buera and Kaboski (2012) and Lagakos and Waugh (2013). 
equilibria instead of transitional dynamics. ${ }^{6}$ By simplifying our theory along some dimensions, we are able to sharply characterize the economy's transitional dynamics in an environment with technology-specific skills and, thus, study how the type of innovations shape the endogenous dynamics of the skill distribution and skill-prices.

Several papers have proposed alternative sources of dynamics to study technological transitions, including technology diffusion across firms (Atkeson and Kehoe, 2007), firm-level investment in R\&D (Atkeson et al., 2018), endogenous creation of new tasks for labor in production (Acemoglu and Restrepo, 2018), sluggish labor mobility across sectors (Matsuyama, 1992; Dvorkin and Monge-Naranjo, 2019), and rising wealth inequality via permanent changes in the returns to wealth following increases in automation (Moll et al., 2019). We focus on dynamics arising from endogenous changes in the skill distribution across generations, which we show to be relevant in the context of Germany.

Finally, our paper is related to the extensive literature that has estimated the distributional consequences of shocks to the demand and supply of skills - for a review, see Acemoglu and Autor (2011). Our empirical analysis follows the literature studying the impact of new technologies on the demand of skills across occupations with different task intensity - e.g., Autor et al. (2003) and Acemoglu and Restrepo (2017). We extend the estimation strategy in this literature to establish that recent cognitive-intensive innovations caused relative employment responses that were strong for young workers but weak for older workers. ${ }^{7}$ Through the lens of our theory, this evidence suggests a slow transition process that takes several generations to materialize. Our results thus indicate that one should be cautions when extracting conclusions about the full impact of new technologies from evidence spanning less than a generation. ${ }^{8}$

\section{A Model of Skilled-biased Technological Transitions}

\subsection{Environment}

We consider a closed economy in continuous time. There is a single final good whose production uses the input of two intermediate goods. We denote the two inputs as

\footnotetext{
${ }^{6}$ One exception is Heckman et al. (1998), which numerically studies transitional dynamics in a model with technology-skill interactions, skill accumulation and endogenous inequality. Relative to this paper, we provide analytical characterizations of the transitional dynamics and use them to study what determines how unequal and slow technological transitions are.

${ }^{7}$ As Akerman et al. (2015), we estimate the labor market consequences of broadband internet adoption. While they focus on the impact of broadband internet adoption on educational composition of employment in Norwegian firms, we estimate the responses occupation-level outcomes across German local labor markets.

${ }^{8} \mathrm{~A}$ full account of inequality trends would require analyzing not only the impact of shocks to skill demand but also how the economy adjusts to shocks to the supply of skills, as in Katz and Murphy (1992) and Goldin and Katz (2009). For instance, Card and Lemieux (2001) show that generation-specific skill supply shocks are important determinants of inequality trends. Similarly, we incorporate skill differences across generations. However, while it would be possible to study the consequences of skill supply shocks in our theory, we focus on the consequences of shocks to skill demand when skill supply responds across generations.
} 
high-tech $(k=H)$ and low-tech $(k=L)$. Their production uses only labor. There is a continuum of worker skill types $i \in[0,1]$. The skill type determines the worker's productivity in the $H$ and $L$ production technologies. There are overlapping generations of workers. Workers consume the final good, self-select into a technology, and make a costly skill investment decision when they are born which determines their skill type for the remaining of their lifetime.

Final good. Production of the final good is a CES aggregator of the two inputs:

$$
Y_{t}=\left[\left(A_{t} X_{H t}\right)^{\frac{\theta-1}{\theta}}+\left(X_{L t}\right)^{\frac{\theta-1}{\theta}}\right]^{\frac{\theta}{\theta-1}}
$$

where $\theta>0$ is the demand elasticity of substitution between the low-tech and the hightech intermediate inputs, and $A_{t}$ is a shifter of the relative productivity of the high-tech input (as in Katz and Murphy, 1992).

Conditional on input prices, the cost minimization problem of firms producing the final good implies that the relative spending on the high-tech input is

$$
y_{t} \equiv \omega_{t} \frac{X_{H t}}{X_{L t}}=\left(\frac{\omega_{t}}{A_{t}}\right)^{1-\theta}
$$

where $\omega_{t} \equiv \omega_{H t} / \omega_{L t}$ is the relative price of the high-tech good. We normalize the price of the low-tech good to one, $\omega_{L t} \equiv 1$.

In a competitive environment with zero profits, the final good price is

$$
P_{t}=\left(1+y_{t}\right)^{\frac{1}{1-\theta}} .
$$

Assignment of skills to technologies. We assume that a worker's skill type determines her productivity with the two technologies in the economy. Specifically, the production functions of $L$ and $H$ are respectively

$$
\begin{gathered}
X_{L t}=\int_{0}^{1} \alpha(i) s_{L t}(i) d i, \\
X_{H t}=\int_{0}^{1} \alpha(i) \sigma(i) s_{H t}(i) d i,
\end{gathered}
$$

where $s_{k t}(i)$ is the density of workers employed with technology $k$ at time $t$. For a worker of type $i \in[0,1], \alpha(i)$ is the overall productivity and $\sigma(i)$ is her differential productivity in high-tech production. Therefore, $\alpha(i)$ governs vertical differences in the productivity across skill-types (i.e, absolute advantage) whereas $\sigma(i)$ governs horizontal differences across technologies for a given type (i.e., comparative advantage). Without loss of generality, we assume that $\sigma(i)$ is increasing in $i$ : we order types such that higher $i$ 
types have higher relative productivity in high-tech production. This implies that the skills of those workers indexed by higher $i$ types are more complementary to the $H$ technology than to the $L$ technology. The slope of $\sigma(i)$ governs the strength of this complementarity.

Online Appendix 1.1 provides one economic interpretation for a skill type. We show that (4)-(5) arise when production combines individual-level output of each worker's "cognitive" and "non-cognitive" task input. A type determines the differential ability to perform cognitive tasks.

We assume a competitive labor market where firms earn zero profits. In equilibrium, the wage of skill type $i$ with the $H$ and $L$ technologies are respectively

$$
w_{H t}(i)=\omega_{t} \sigma(i) \alpha(i) \text { and } \quad w_{L t}(i)=\alpha(i) .
$$

As in Roy (1951), workers self-select across technologies to maximize labor income. Thus, the labor income of a worker with skill type $i$ is

$$
w_{t}(i)=\max \left\{\omega_{t} \sigma(i), 1\right\} \alpha(i) .
$$

The technology-skill assignment in equation (7) plays a central role in determining the economy's adjustment to technological shocks. Equation (7) illustrates that such an assignment depends on the endogenous price $\omega_{t}$ defining the relative value of one unit of effective labor employed in $H$ production, as well as the exogenous function $\sigma(i)$ defining the differential productivity of type $i$ in $H$ production. In our theory, $\omega_{t}$ is a natural measure of inequality as it is the endogenous relative wage rate of skill types employed in different technologies conditional on their productivity. In what follows, we will refer to $\omega_{t}$ as the relative technology-specific wage or, sometimes, simply as the relative wage. ${ }^{9}$

At this point, it is worth discussing the three main advantages of our theory's Roy-like structure with skill heterogeneity defined over a continuum. First, as we discuss in detail later, this framework allows skill-biased technological innovations to cause endogenous changes in both relative wages and employment across technologies (conditional on the distribution of skills). Acemoglu and Autor (2011) show that this is important to rationalize the rich patterns of changes in inequality and occupation composition observed in developed economies. In fact, by mapping occupations to the technologies in our theory, this structure of skill heterogeneity implies that the theory can generate the type of within-generation worker reallocation documented in Figure $1 .{ }^{10}$ In contrast, such

\footnotetext{
${ }^{9}$ Note that changes in $\omega_{t}$ are not identical to changes in the relative average labor income of $H$ employees because of endogenous changes in the "selection" of skill types in H implied by (7) (Heckman and Honore, 1990).

${ }^{10}$ It is straight forward to extend our framework to have multiple worker groups defined in terms of observable attributes like education, race or gender - as in Hsieh et al. (2013) and Burstein et al. (2016). In this case, different groups may differ with respect to their distribution of skills. This creates different responses in worker allocations
} 
patterns cannot be generated by variants of the canonical model in Katz and Murphy (1992) that rely on a discrete number of skills specified in terms of observable attributes (Acemoglu and Autor, 2011).

Second, the presence of technology-skill complementarity allows us to formally study which features of technologies and skills are important determinants of the economy's adjustment to skill-biased innovations. In particular, the slope of $\sigma(i)$ measures how different skill types are in terms of relative productivity across technologies. Thus, through the self-selection decision in (7), it determines how much wages need to change to induce skill types to reallocate across technologies. In other words, the slope of $\sigma(i)$ captures the degree of transferability of skill types across technologies.

Third, from a mathematical tractability perspective, having a continuum of skill types is useful when combined with continuous time because it implies that the dynamic adjustment of all outcomes following technological innovations is smooth along the equilibrium path. This allows us to sharply characterize the transitional dynamics in a way that would not be possible with a discrete number of skill types. The reason for such smoothness is that any relative wage change triggers the reallocation of a positive mass of skill types through the self-selection condition (7).

Skill investment. We consider overlapping generations of workers whose birth and death follows a Poisson process with rate $\delta$. At each point in time, workers use their labor earnings to buy the final good. Utility is the present value of the log-utility flow discounted at rate $\rho$. At time $t$, the expected utility from consumption is

$$
V_{t}(i)=\int_{t}^{\infty} e^{-(\rho+\delta)(s-t)} \log \left(\frac{w_{s}(i)}{P_{s}}\right) d s .
$$

Crucially, we endogenize the distribution of skills by allowing workers to direct their skill investment decisions to target particular skill types. Given the future path for the wage distribution $\left\{w_{s}(i)\right\}_{s>t}$, workers born at time $t$ can pay a utility cost to select a lottery $\tilde{s}_{t}(i)$ over skill types. If they do not pay the cost, their type is drawn from an exogenous distribution of innate ability, $\bar{s}_{t}(i)$. A worker's type is then fixed during their lifetime. Formally, we assume that the cost of the lottery is proportional to the KullbackLeibler divergence between the lottery $\tilde{s}_{t}(i)$ and the baseline distribution $\bar{s}_{t}(i)$, so that workers of the cohort born at time $t$ solve the following skill investment problem:

$$
\max _{\tilde{s}_{t}(.): \int_{0}^{1} \tilde{s}_{t}(i) d i=1} \int_{0}^{1} V_{t}(i) \tilde{s}_{t}(i) d i-\frac{1}{\psi} \int_{0}^{1} \log \left(\frac{\tilde{s}_{t}(i)}{\bar{s}_{t}(i)}\right) \tilde{s}_{t}(i) d i .
$$

The skill investment problem in (9) for entering generations allows our model to raacross technologies after technological innovations. 
tionalize the differences across generations shown in Figure 1 (as well as similar patterns that we document for Germany in Section 7). Faced with different paths of relative wages upon entry, different worker generations will choose different optimal skill lotteries and, therefore, will have different skill distributions. In combination with the endogenous assignment in (7), this creates cross-generation differences in the allocation of workers across technologies. The positive parameter $\psi$ governs how easy it is for younger generations to adjust their skill investment in response to changes in the lifetime earnings of different skill types. In the limit when $\psi \rightarrow 0$, the economy's skill distribution is exogenous and equal to $\bar{s}_{t}(i)$.

A number of comments on these assumptions and their economic interpretation are in order. First, as shown in Fudenberg et al. (2015), the stochastic choice formulation in (9) is equivalent to the type of additive random utility model that is commonly used in the labor, trade, and industrial organization literatures. ${ }^{11}$ As we show in Lemma 3, it implies that the optimal skill lottery is a multinomial logit over a continuum. Therefore, one economic interpretation of this environment follows from its discrete-choice analog where the preference or innate ability of workers to invest in each skill type has an extreme-value distribution (e.g., McFadden, 1973). ${ }^{12}$ Under this interpretation, $\psi$ reflects the amount of variation across individuals in idiosyncratic additive random utility for specific skill types, with higher $\psi$ implying lower variability. The baseline distribution $\bar{s}_{t}(i)$ is then a skill-specific utility term that is common for all workers. An alternative interpretation for the uncertain skill type realization is that individuals with different unobservables may have heterogeneous returns to education and on-the-job training as documented by Carneiro et al. (2011). ${ }^{13}$

Second, our baseline model assumes that $\bar{s}_{t}(i)$ is exogenous and only entering generations invest in skills. These assumptions imply the optimal skill lottery is only a function of the future path of relative wages - see the problem in (9). This simplifies our analysis as the flow of new workers to a particular point in the skill distribution is independent of the current skill distribution. We relax both assumptions in Online Appendix 1.2 to show that our main results do not depend on either the cost of skill investment being infinite for older generations, nor on the skill investment technology being independent

\footnotetext{
${ }^{11}$ Entropy cost functions also have a long tradition in macroeconomics (Sims, 2003, Hansen and Sargent, 2008). Yet, the particular cost function is not crucial for our main results. This is because in later sections we take a log-linear approximation around the stationary equilibrium. What matters then is the curvature of the distance metric around the stationary equilibrium, similar to investment problems with a convex cost of adjustment.

${ }^{12}$ We do not follow this route for technical reasons: it is not possible to define independent innate ability draws over a continuum. The skill lottery together with the entropy cost function provides an equivalent alternative. In fact, Matějka and McKay (2015) give another interpretation for the multinomial logit choice structure. It arises when individuals choose actions with imperfect information about their payoffs while paying an entropy cost for signal acquisition.

${ }^{13}$ For our purposes, it is not important that workers are ex-ante identical but face uncertainty ex-post. It is easy to extend our model to introduce worker-groups that have ex-ante different observed attributes that only affect $\bar{s}(i)$ and $\psi$. The overall skill lottery would then be the average of lotteries across worker groups.
} 
of the economy's skill distribution. ${ }^{14}$

Our preferred economic interpretation of these assumptions is that changes in relative wages induce workers to move towards sectors or occupations that require similar skills and thus entail minimal retraining. That is, older workers may change the technology they work with, but do not change their skill type. Intuitively, they face a high cost of fundamentally changing career paths by acquiring completely different skills. For younger workers, such skill investments are less costly due to lower opportunity costs, higher ability to learn new skills, or longer work-life horizon - as in environments in the tradition of Ben-Porath (1967). Note, however, that the skill investment decision goes beyond traditional unidimensional decisions to acquire more human capital (or whether to attend college) that allow workers to vertically differentiate. Instead, it is a multidimensional decision to direct investments toward particular sets of skills, driven both by vertical considerations - expressed in absolute advantage $\alpha(i)$ and the relative wage $\omega_{t}$ - as well as horizontal considerations - expressed through comparative advantage $\sigma(i)$. As discussed above, this type of horizontal skill differentiation is central to capture changes in relative employment and wages within each generation. For tractability, we collapse into a one-time decision upon entry the skill investment that in reality occurs through formal schooling, major college choice, and/or on-the-job learning.

\subsection{Equilibrium}

We are now ready to define and begin to characterize the equilibrium of the economy introduced in Section 3.1. Because only new generations choose skill lotteries, the equilibrium skill distribution $s_{t}(i)$ follows the Kolmogorov-Forward equation,

$$
\frac{\partial s_{t}(i)}{\partial t}=-\delta s_{t}(i)+\delta \tilde{s}_{t}(i)
$$

Finally, the economy's equilibrium must satisfy market clearing for all $t$. By Walras' law, it suffices that relative demand and supply of the $H$ good are equal:

$$
y_{t}=\omega_{t} x_{t}
$$

where $y_{t}$ is given by (2) and $x_{t}$ is the ratio of $H$ to $L$ production given by (4)-(5).

We define the equilibrium as follows.

Definition 1 (Competitive Equilibrium) Given an initial skill distribution $s_{0}(i)$ and exogenous paths for $\left\{A_{t}, \bar{s}_{t}(i)\right\}_{t \geq 0}$, a competitive equilibrium is a path of the technology-skill as-

\footnotetext{
${ }^{14}$ Instead, what is important for mathematical tractability is that the skill investment decisions along the transition do not depend on the initial type of an individual. When this is the case, the dynamics of the overall skill distribution become much more complex. This independence could be violated if, for example, there was inter-generation transmission of skills, or skill acquisition had monetary costs and workers faced credit frictions.
} 
signment $\left\{G_{t}(i): i \in[0,1] \rightarrow\{H, L\}\right\}_{t \geq 0}$, the skill distribution $\left\{s_{t}(i)\right\}_{t \geq 0}$, the skill lottery $\left\{\tilde{s}_{t}(i)\right\}_{t \geq 0}$, the relative value of output $\left\{y_{t}\right\}_{t \geq 0}$, the relative wage and final price index $\left\{\omega_{t}, P_{t}\right\}_{t \geq 0}$, such that

1. Given $\left\{\omega_{t}\right\}_{t \geq 0},\left\{G_{t}(i), \tilde{s}_{t}(i)\right\}_{t \geq 0}$ are determined by (7) and (9).

2. Given $s_{0}(i)$ and $\left\{\tilde{s}_{t}(i)\right\}_{t \geq 0},\left\{s_{t}(i)\right\}_{t \geq 0}$ is determined by (10).

3. For all $t \geq 0$, the market clearing condition (11) is satisfied and $P_{t}$ is given by (3).

Static equilibrium conditions. The endogenous sorting decision in (7) determines the assignment of skill types to technologies. It implies that types self-select to work with the technology that yields the highest labor earnings. Thus, high- $i$ types receive higher relative earnings in $H$ and choose to be employed with that technology. Since $\sigma(i)$ is increasing, the assignment is described by a threshold $l_{t}$ characterizing the type that is indifferent between working with any of the two technologies. The following lemma formalizes this discussion.

Lemma 1 (Equilibrium Assignment) Worker types $i \leq l_{t}$ are employed in $L$ with labor income of $w_{t}(i)=\alpha(i)$. Worker types $i>l_{t}$ are employed in $H$ with labor income of $w_{t}(i)=$ $\omega_{t} \sigma(i) \alpha(i)$. The threshold is determined by the indifference condition,

$$
\omega_{t} \sigma\left(l_{t}\right)=1 \text {. }
$$

Lemma 1 links the relative wage $\omega_{t}$ to the allocation of skill types across technologies. Condition (12) is central to understand the impact of technological shocks on the allocation of workers across technologies. The slope of $\sigma($.$) at the threshold determines the$ strength of comparative advantage in $H$ of skill types slightly below $l_{t}$ compared to skill type $l_{t}$. Thus, the inverse elasticity of $\sigma(i)$ controls the subset of skill types that reallocate across technologies in response to relative wage changes. Formally, (12) implies

$$
\eta \equiv\left|\frac{\partial \log l_{t}\left(\omega_{t}\right)}{\partial \log \omega_{t}}\right|=\left(\frac{\partial \log \sigma\left(l_{t}\right)}{\partial \log l_{t}}\right)^{-1},
$$

where $l_{t}\left(\omega_{t}\right)$ is the implicit function defined by (12).

We will say that technology-skill specificity is higher when $\eta$ is lower because the productivity of skills associated with higher $i$ types decreases more when deployed to the $L$-technology rather than to the $H$-technology. Intuitively, a lower $\eta$ means that workers are less transferable across technologies because they require higher changes in relative wages to switch technologies in order to compensate them for their lower relative technology-specific productivity. It therefore directly governs the strength of the withingeneration reallocation adjustment margin in our theory. Technology-skill specificity is one of the features of the economy that we will vary in order to understand how it shapes the adjustment to skill-biased innovations. 
The technology-skill assignment in Lemma 1 together with equations (4)-(5) imply that the relative supply of high-tech production is

$$
x_{t}\left(l_{t}, s_{t}\right)=\frac{\int_{l_{t}}^{1} \sigma(i) \alpha(i) s_{t}(i) d i}{\int_{0}^{l_{t}} \alpha(i) s_{t}(i) d i} .
$$

The threshold $l_{t}$ is then uniquely determined by market clearing in (11).

Lemma 2 (Equilibrium Threshold) Given $s_{t}(i)$ and $A_{t}$, there is a unique equilibrium threshold $l_{t}$ that guarantees goods market clearing,

$$
A_{t}^{\theta-1} \sigma\left(l_{t}\right)^{\theta} \int_{0}^{l_{t}} \alpha(i) s_{t}(i) d i=\int_{l_{t}}^{1} \alpha(i) \sigma(i) s_{t}(i) d i .
$$

Proof. See Appendix A.1.

Dynamic equilibrium conditions. We now turn to the entrant's forward-looking problem of choosing their skill lottery $\tilde{s}_{t}(i)$ given the path of the relative wage $\left\{\omega_{s}\right\}_{s>t}$. The following lemma shows that the solution to the problem in (9) takes the form of a multinomial logit function over the continuum of types. In particular, the investment on high- $i$ types is a function of the present value of the relative wage in high-tech production as captured by $Q_{t}(i)$.

Lemma 3 (Optimal Lottery) Define $\log \left(Q_{t}(i)\right) \equiv \int_{t}^{\infty} e^{-(\rho+\delta)(s-t)} \max \left\{\log \left(\omega_{s} \sigma(i)\right), 0\right\} d s$. The optimal lottery is

$$
\tilde{s}_{t}(i)=\frac{\bar{s}_{t}(i) \alpha(i)^{\frac{\psi}{\rho+\delta}} Q_{t}(i)^{\psi}}{\int_{0}^{1} \bar{s}_{t}(j) \alpha(j)^{\frac{\psi}{\rho+\delta}} Q_{t}(j)^{\psi} d j} .
$$

Proof. See Appendix A.2.

As we have already intuitively discussed, the parameter $\psi$ governs the sensitivity of the optimal lottery to changes in relative lifetime earnings across technologies. We can now see this formally by writing

$$
\psi \equiv \frac{\partial \log \tilde{s}_{t}(i) / \tilde{s}_{t}\left(i^{\prime}\right)}{\partial \log Q_{t}(i) / Q_{t}\left(i^{\prime}\right)} .
$$

In the rest of the paper, we refer to $1 / \psi$ as the cost of skill investment. A higher cost implies a less elastic relative supply of skill types coming from entering worker generations since skill investment decisions are less sensitive to differences in $Q_{t}(i)$ across skills. As a result, the cost of skill investment crucially shapes the cross-generation adjustment margin in our theory. It is the other feature of the economy that we will vary in order to understand how it shapes the economy's adjustment to skill-biased innovations. 


\subsection{Skill distribution dynamics: A q-theory of skill investment}

We now combine the static and dynamic equilibrium conditions to solve for the equilibrium path of the skill distribution as well as all other variables, given an arbitrary initial skill distribution $s_{0}(i)$ and a constant path for $\left\{A_{t}, \bar{s}_{t}(i)\right\}_{t \geq 0}$. Our characterization guides the rest of the paper. It allows us to tell the story of the economy's adjustment through the two margins in the theory (Section 4), gain insights regarding how different features of technologies and skills determine the adjustment dynamics (Section 5), and transparently connect these determinants to the patterns we document across generations (Section 6).

In principle, the characterization of the equilibrium dynamics involves solving a complex infinite-dimensional fixed-point problem. To see this, consider a conjectured path for the relative wage $\left\{\omega_{t}\right\}_{t \geq 0}$. This path determines the skill investment decisions of new generations in (15) and, as such, the path for the skill distribution $\left\{s_{t}(i)\right\}_{t \geq 0}$ from (10) given $s_{0}(i)$. The relative wage path also determines the assignment threshold path $\left(\left\{l_{t}\right\}_{t \geq 0}\right)$ from the indifference condition (12). Taken together, the skill distribution and the assignment threshold determine the relative supply of the high-tech input $\left(\left\{x_{t}\right\}_{t \geq 0}\right)$ in (13). In an equilibrium, the relative supply of the high-tech input needs to be equal to its relative demand at the conjectured path for the relative wage - i.e., they need to be consistent with market clearing. Yet, in order to provide an analytical characterization of the equilibrium dynamics, we next approximate the solution of this fixed-point problem by considering a log-linear expansion around the stationary equilibrium. In Section 8 , we numerically solve this fixed-point problem and show that our main insights are not driven by the equilibrium approximation.

Theorem 1 establishes that the approximate equilibrium of this economy can be represented as that of a $q$-theory of skill investment, where $\log (q)$ refers to the present discounted value of the log-relative wage or, as we call it from now on, lifetime inequality:

$$
\log \left(q_{t}\right) \equiv \int_{t}^{\infty} e^{-(\rho+\delta)(s-t)} \log \left(\omega_{s}\right) d s .
$$

Specifically, we show that one does not need to keep track of the whole skill distribution to solve for the approximate equilibrium dynamics of $q_{t}$. Instead, changes in the threshold $l_{t}$ suffice to summarize the changes in the moments of the skill distribution that are relevant to solve for such dynamics. As a result, the approximate equilibrium dynamics of $q_{t}$ and $l_{t}$ are fully characterized by a system of linear differential equations. ${ }^{15}$

\footnotetext{
${ }^{15}$ This reduction in the dimensionality shares some parallels with the approaches in Perla and Tonetti (2014) and the special case with linear objectives in Lucas and Moll (2014) - who also characterize the dynamics of a distribution by tracking the evolution of a threshold - as well as that of Krusell and Smith (1998) - who show that aggregate dynamics in a Bewley-Huggett-Aiyagari economy with aggregate shocks can be approximated by tracking only a reduced set of
} 
Letting " ^ " denote variables in log-deviations from the stationary equilibrium, the following theorem presents the system of differential equations that, given $\hat{l}_{0}$, determines the equilibrium path of $\left\{\hat{q}_{t}, \hat{l}_{t}\right\}_{t}$ when $\left\{A_{t}, \bar{s}_{t}(i)\right\}_{t \geq 0}$ are constant over time. ${ }^{16}$ It then characterizes the skill distribution, skill lottery, and relative output.

Theorem 1 ( $q$-theory of skill investment) Suppose $\left\{A_{t}, \bar{s}_{t}(i)\right\}_{t \geq 0}$ is constant over time.

1. Given initial condition $\hat{l}_{0}$ and terminal condition $\lim _{t \rightarrow \infty} \hat{l}_{t}=0$, the equilibrium dynamics of $\left\{\hat{q}_{t}, \hat{l}_{t}\right\}$ are described by the system of differential equations

$$
\begin{aligned}
\frac{\partial \hat{l}_{t}}{\partial t} & =-\delta \hat{l}_{t}+\frac{\eta \psi}{\theta+\kappa \eta} \delta \hat{q}_{t} \\
\frac{\partial \hat{q}_{t}}{\partial t} & =(\rho+\delta) \hat{q}_{t}+\frac{1}{\eta} \hat{l}_{t}
\end{aligned}
$$

where $\kappa$ is a positive constant.

2. The equilibrium $\left\{\hat{q}_{t}, \hat{l}_{t}\right\}_{t \geq 0}$ is saddle-path stable with rate of convergence $\lambda$.

3. The equilibrium dynamics of the skill distribution $\hat{s}_{t}(i)$, the optimal lottery $\hat{\tilde{s}}_{t}(i)$, and the value of relative high-tech output $\hat{y}_{t}$ are determined by $\left\{\hat{q}_{t}, \hat{l}_{t}\right\}_{t \geq 0}$ and $\hat{s}_{0}(i)$.

\section{Proof. See Appendix A.3.}

The first part of the theorem presents a system that is a rather standard one in macroeconomics, with one control and one predetermined variable. The system is in fact mathematically isomorphic to the one in the $q$-theory of capital investment. In our model, $\hat{q}_{t}$ is the present discounted value of the log-relative wage in high-tech production, representing the shadow price of the human capital "asset" associated with having one additional unit of the high-tech good. Whenever this price is higher, the incentives to invest in high- $i$ skills are stronger and the skill distribution changes more. Similar to the seminal $q$-theory, we can see in (16) that parameters governing the "costs of adjustment" in the economy's skill distribution ( $\delta$ and $\psi$ ) affect the sensitivity of changes in the state variable $\left(\frac{\partial \hat{l}_{t}}{\partial t}\right)$ to the control variable $\left(\hat{q}_{t}\right)$. In fact, together with (17), this highlights how the dynamics of $\hat{l}_{t}$ suffice to summarize the relevant changes in the moments of the skill distribution which both feed back into and are caused by changes in $\hat{q}_{t}$. For example, if the skill distribution is exogenous and thus such changes are absent $(\psi=0$ or $\delta=0)$, then there are no transitional dynamics. Finally, our model also features both imperfect substitution of human capital across technologies and heterogeneous skills. Thus, the impact of $q_{t}$ on the evolution of $l_{t}$ also depends on the degree of technology-skill specificity (as controlled by $\eta$ ) and substitutability between goods (as measured by $\theta$ ).

moments of the wealth distribution.

${ }^{16}$ The initial $l_{0}$ is determined by the initial skill distribution $s_{0}(i)$ from the static equilibrium condition (14). 
The second part shows that (locally) the equilibrium exists and is unique-a consequence of saddle-path stability. The proof further shows that, given an initial condition $\hat{l}_{0}$, both $\hat{l}_{t}$ and $\hat{q}_{t}$ converge at a constant rate to the stationary equilibrium, where $-\lambda$ is the negative eigenvalue of the system of differential equations.

The last part of the theorem links the equilibrium path of the optimal skill lottery, the overall skill distribution and the relative value of output to the joint dynamics of $\left\{\hat{q}_{t}, \hat{l}_{t}\right\}$. The proof shows that the change in the optimal skill lottery along the transition depends centrally on the evolution of $\hat{q}_{t}$. Formally,

$$
\hat{\tilde{s}}_{t}(i)=\left(\mathbb{I}_{i>l}-\int_{l}^{1} s(i) d i\right) \psi \hat{q}_{t}+o_{t}(i),
$$

where $o_{t}(i)$ is such that $\int s(i) o_{t}(i) d i=0$. The parameter $\psi$ crucially shapes the extent to which a generation's skill distribution tilts towards skills associated with higher $i$ types when they face a higher $q_{t}$ at birth. The overall skill distribution is then a populationweighted average of the skill distributions of each generation. Finally, relative output is driven by changes in the relative wage, with $1 / \eta$ controlling how the latter responds to threshold changes.

The reduction in dimensionality in Theorem 1 is possible for three reasons. First, the dynamics of $s_{t}(i)$ only depend on $\log \left(Q_{t}(i)\right)$ via the optimal skill lottery. Yet, $\log \left(q_{t}\right)$ suffices to determine the value of most skill types in the investment decision - as opposed to the full path of $\omega_{t}$ in $\log \left(Q_{t}(i)\right)$ - because most workers never switch technologies along an equilibrium path if relative wages are close to their stationary level. Second, the market clearing condition (14) only contains integrals of $s_{t}(i)$. Because of the continuum of skill types, the effect of the marginal types that switch technologies along the transition are of second order when evaluating changes in these integrals. Taken together, the two observations imply that changes in $\hat{l}_{t}$ summarize the relevant changes in the moments of the skill distribution over time as a function of $\hat{q}_{t}$, as seen in (16). Finally, since condition (12) yields a mapping between $\omega_{t}$ and $l_{t}$, the dynamics of $\hat{q}_{t}$ can be written as a function of the path of $\hat{l}_{t}$, as seen in (17). ${ }^{17}$

\section{The Adjustment to Skill-biased Innovations}

We are now ready to answer the first question we posed at the beginning: how do inequality, skills, and economic activity jointly adjust over time to technological innovations? We first analytically characterize the dynamic adjustment of our economy to a permanent, unanticipated increase in the relative productivity $A$. We refer to this shock

\footnotetext{
${ }^{17}$ We conjecture that extending the model to multiple technologies is possible while keeping the $q$-theory representation (albeit in vector form) if skills and technologies satisfy the type of log-supermodularity assumption imposed by Costinot and Vogel (2010).
} 
as a skill-biased technological innovation since it increases the relative productivity of skill types $i$ sorted into the $H$ technology. We then discuss (i) how the economy's adjustment over different horizons is driven by the two margins in our theory (i.e., the reallocation of workers within a generation and changes in the skill distribution across generations), (ii) relate the adjustment dynamics to Samuelson's LeChatelier principle in a reduced-form representation of our theory, and (iii) present a formal measure of how slow the adjustment is. We conclude by connecting our measure of the adjustment's speed to the average and distributional welfare consequences of the skill-biased innovation.

\subsection{Dynamic responses of equilibrium outcomes}

We assume that immediately prior to the shock at time $t=0^{-}$the economy is in a stationary equilibrium. Let $\Delta \log (A)>0$ be the relative productivity shock. The following proposition characterizes the log-change in $\Delta \log \left(q_{t}\right) \equiv \log \left(q_{t} / q_{0^{-}}\right), \Delta \log \left(y_{t}\right) \equiv$ $\log \left(y_{t} / y_{0^{-}}\right)$, and $\Delta \log \left(l_{t}\right) \equiv \log \left(l_{t} / l_{0^{-}}\right)$.

Proposition 1 (Dynamic responses) Given a skill-biased technological innovation $\Delta \log (A)$, the dynamic responses $\Delta \log \left(l_{t}\right), \Delta \log \left(q_{t}\right)$ and $\Delta \log \left(y_{t}\right)$ are approximated by:

$$
\left[\begin{array}{c}
\Delta \log \left(l_{t}\right) \\
\Delta \log \left(q_{t}\right) \\
\Delta \log \left(y_{t}\right)
\end{array}\right]=\underbrace{\left[\begin{array}{c}
-\eta \\
\frac{1}{\rho+\lambda} \\
1+\kappa \eta
\end{array}\right] \frac{\theta-1}{\theta+\kappa \eta} \Delta \log (A)}_{\text {Short-run }}+\underbrace{\frac{\psi}{\chi}\left[\begin{array}{c}
\eta \\
\frac{-1}{\rho+\delta+\lambda} \\
\theta-1
\end{array}\right]\left(1-e^{-\lambda t}\right) \frac{\theta-1}{\theta+\kappa \eta} \Delta \log (A)}_{\text {Short- to long-run transition }}
$$

where $\chi \equiv\left(\theta+\kappa \eta+\frac{\psi}{\rho+\delta}\right)(\rho+\delta)$.

Proof. See Appendix A.4.

Figure 2 illustrates these dynamic responses together with the dynamics of the skill distribution and skill lottery. We do so for the case where the two technologies are substitutes in production $(\theta>1)$ and $\alpha(i)=1$.

The first term in (19) is the immediate impact of the shock represented by the responses at $t=0$ in Figure 2. In the short-run, there are increases in both relative output $\left(\Delta \log \left(y_{0}\right)>0\right)$ and lifetime inequality $\left(\Delta \log \left(q_{0}\right)>0\right)$. The higher relative wage in the $H$ technology induces the reallocation of skill types in the existing worker generations from the $L$ to the $H$ technology, as can be seen from the decline in the assignment threshold $l_{t}$. This reallocation further contributes to the relative output increase. Therefore, beyond the direct effect of the shock, the adjustment of the economy in the short-run is driven entirely by the first margin in the theory: the reallocation of workers within existing generations whose skills are predetermined. This is how the theory rationalizes the changes 
Figure 2: The economy's adjustment to a skill-biased technological innovation (when $\theta>1$ )
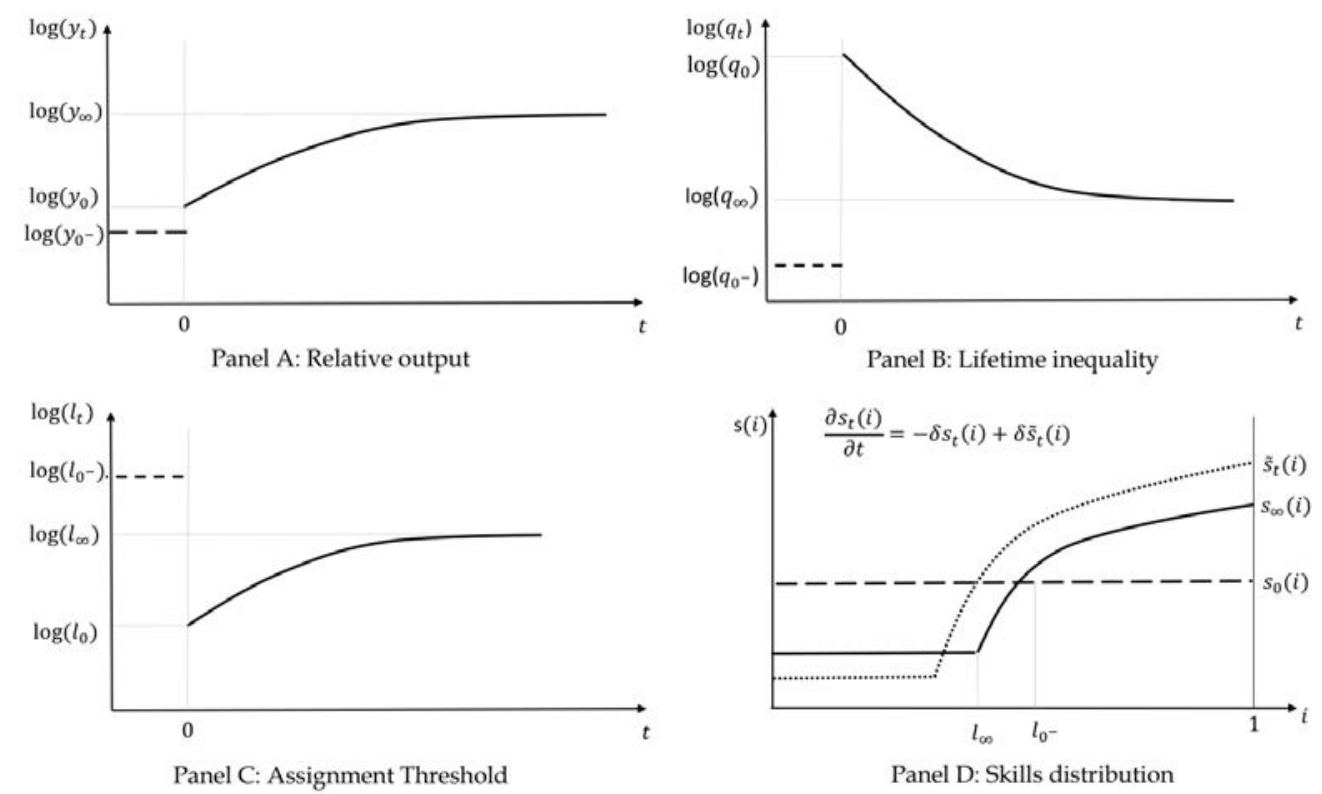

in inequality and occupational composition over short horizons following a skill-biased innovation.

The second term in (19) shows that, along the transition, all variables converge at rate $\lambda$. The increase in the relative lifetime wage in high-tech production causes entering worker generations to twist their skill lotteries $\tilde{s}_{\tau}(i)$ towards high-i types whose skills are more complementary to $H$ production (see bottom right panel of Figure 2). Such differences in the skill distribution across generations (and thus their assignment to different economic activites) is how the theory rationalizes observed cross-generation differences in relative employment following a skill-biased innovation. This triggers changes in the economy's overall skill distribution $s_{t}(i)$ as older generations are replaced with younger generations at rate $\delta$. Along the transition, the growing mass of high- $i$ types employed with the $H$ technology implies a continuing process of relative output increase and inequality decline. The rising relative high-tech output yields a decline in the consumption price index in (3). By reducing the relative wage, the arrival of more high- $i$ types in younger generations triggers the displacement of marginal $i$ types from $H$ production over time (i.e., $l_{t}$ increases along the transition).

In the long-run, the $H$ technology has higher relative wage, output and employment. The increase in $H$ employment is driven both by a skill distribution with higher mass in high- $i$ types and a lower assignment threshold of skill types employed in $H$. Finally, note that the only source of dynamics in our theory is the skill investment decision of generations born after the shock. Whenever incoming generations cannot invest in skills (i.e., $\psi=0$ ), the transitional dynamics term in (19) disappears and the responses in 
the long-run and short-run are identical. Therefore, the adjustment of the economy at longer horizons is also driven by the second margin in the theory: changes in the skill distribution across generations.

Samuelson's LeChatelier principle in a reduced-form model. To further provide intuition behind the economy's adjustment, we now connect the predictions of our theory to those of a reduced-form demand-supply framework. Appendix A.5 shows that our theory yields a reduced-form supply elasticity $\varphi_{t}$ such that relative output and wage solve

$$
\begin{aligned}
& \Delta \log \left(x_{t}\right)=(\theta-1) \Delta \log (A)-\theta \Delta \log \left(\omega_{t}\right), \\
& \Delta \log \left(x_{t}\right)=\varphi_{t} \Delta \log \left(\omega_{t}\right) .
\end{aligned}
$$

The main feature of our theory is an increasing supply elasticity of skills across technologies (i.e., $\varphi_{t}$ is positive and increasing over time). ${ }^{18}$ This arises from two sources. First, even if skills are exogenous $(\psi=0)$, the relative supply elasticity is positive because a fraction of the heterogeneous workers in the economy decides to reallocate across technologies in response to changes in the relative wage. Second, the change in the skill investment decision of generations born after the shock introduces an additional adjustment margin for relative supply. This margin becomes stronger over time as younger generations replace older ones, driving $\varphi_{t}$ upwards along the transition when $\psi>0$. Thus, our theory implies a form of Samuelson's LeChatelier principle: the relative supply of high-tech output is more elastic over longer horizons due to changes in the skill distribution.

Given that this simple reduced-form model captures the main intuition behind the economy's adjustment, why not use it instead of our micro-founded theory? There are two main advantages of micro-founding the dynamics of the relative supply elasticity $\varphi_{t}$. We explore both of them in the coming sections.

The first is that we can consider how the type of technologies and skills shape the economy's adjustment by affecting two features of the economy: technology-skill specificity and the cost of skill investment (see Section 5). In particular, Appendix A.5 shows that if either technology-skill specificity $(\eta)$ or the cost of skill investment $(\psi)$ are different, then the path of $\varphi_{t}$ will be different as well. This also points to a risk that arises when using reduced-form estimates of $\varphi_{t}$ in order to extrapolate to different contexts: a type of threat to external validity. To see this, consider a researcher that obtains estimates of the path of $\varphi_{t}$ from a particular technological transition. Suppose this researcher uses such estimates to make predictions about the dynamic consequences of a new technology in a different economy or historical context. The researcher will obtain biased predictions

\footnotetext{
${ }^{18}$ The canonical model of Katz and Murphy (1992) is a special case of our theory with $\varphi_{t}=0$.
} 
about the economy's adjustment at all horizons whenever technology-skill specificity or the cost of skill investment are different across episodes.

The second advantage is that we can use reduced-form responses to technological innovations that span short periods of time in order to learn about structural parameters (e.g., $\eta$ and $\psi$ ) that govern responses at longer horizons (see Section 6). This allows the proper computation of the full implications of new technologies for labor markets. It also points to a risk associated with naively extrapolating from estimated reduced-form responses in the economy over any given horizon. To see this, consider a researcher who knows $\theta$ and obtains $\varphi_{T}$ and $\Delta \log A$ from the estimated impact of a technological shock on relative output and wages at horizon $T$. Suppose this researcher then uses her estimates to analyze the consequences of skill-biased innovations. The time-varying nature of $\varphi_{t}$ implies that predictions will be biased for any period other than $T$. Specifically, the researcher's predictions will overestimate (underestimate) inequality changes and underestimate (overestimate) relative output changes for any period after (before) $T$.

How slow is the adjustment? We conclude this section by defining a measure that summarizes the importance of transitional dynamics and, therefore, gives a formal way of quantifying whether the economy's adjustment is fast or whether it slowly plays out over many generations. Specifically, we define the discounted cumulative impulse response (DCIR).

Intuitively, the DCIR is the answer to the question: from the point of view of generations alive just before the arrival of a technological innovation, how different is the adjustment they expect to see during their lifetime compared to the long-run adjustment? We will say that the economy's adjustment is slower when existing generations expect to miss more of the overall adjustment during their lifetime (i.e., the DCIR is larger).

Definition 2 (Discounted Cumulative Impulse Response) For any variable $z_{t}$ and innovation $\Delta \log (A)$, the discounted cumulative impulse response $D C I R(z)$ is:

$$
\operatorname{DCIR}(z)=\left|\int_{0}^{\infty} \delta e^{-\delta t} \frac{\Delta \log \left(z_{t}\right)}{\Delta \log (A)} d t-\frac{\Delta \log \left(z_{\infty}\right)}{\Delta \log (A)}\right| .
$$

Formally, the DCIR is the distance between the long-run response and the expected response of $\log \left(z_{t}\right)$ during the initial generations' lifetime, since all generations born before the innovation have exponentially distributed death probabilities with rate $\delta$. This is a convenient measure of the importance of transitional dynamics in our context for a number of reasons. First, it encodes not only the convergence rate $\lambda$, but also other relevant features of the impulse responses like how front-loaded they are. For instance, one could have an adjustment where the short- and long-run changes are almost identical-implying a DCIR close to zero—but the rate of convergence $\lambda$ from the short- to the 
long-run is very low. According to the DCIR, we would intuitively say that it is a fast adjustment since almost all of the overall adjustment is completed on impact, whereas looking at $\lambda$ alone suggests a slow adjustment. Second, the DCIR does not mechanically scale with the replacement rate of generations. If $\delta$ is higher, this mechanically increases $\lambda$ (making the adjustment faster) but it also decreases the expected lifetime of a generation. Finally, in the next sections, we show that this measure not only is relevant for analyzing the welfare consequences of skill-biased innovations, but also is tightly connected to the two adjustment margins in our theory.

\subsection{Changes in average welfare and lifetime welfare inequality}

We now compute the average and distributional welfare consequences of skill-biased innovations. Our welfare measure is the ex-ante expected utility of individuals born at each point in time (equation (9)). Given the log-utility assumption, the consumptionequivalent gain is the change in the ex-ante utility times $(\rho+\delta)$. From equations (7) and (9), the consumption-equivalent utility of cohort $\tau$ is

$U_{\tau} \equiv(\rho+\delta)\left(\int_{0}^{1} \tilde{s}_{\mathcal{\tau}}(i)\left(\log \left(\alpha(i)^{\frac{1}{\rho+\delta}} Q_{\tau}(i)\right)-\frac{1}{\psi} \log \frac{\tilde{s}_{\tau}(i)}{\bar{s}(i)}\right) d i-\int_{\tau}^{\infty} e^{-(\rho+\delta)(t-\tau)} \log P_{t} d t\right)$,

where $\tilde{s}_{\tau}(i)$ is the skill distribution of cohort $\tau, \log \left(Q_{\tau}(i)\right)$ is the present-discounted value of $\max \left\{\log \left(\omega_{t} \sigma(i)\right), 0\right\}$ defined in Lemma 3, and $P_{t}$ is the price index in (3).

The welfare of each generation has two components. The first is the average wage across skill types net of the skill lottery cost. This term depends on the relative wage $\omega_{t}$ through $\log \left(Q_{\tau}(i)\right)$ because a fraction of workers is employed in high-tech production. The second term is the consumption price index that equally affects all skill types. Importantly, due to the cost of good $H$, the price index in (3) is decreasing in high-tech productivity $A$ but increasing in $\omega_{t}$.

To obtain an average welfare measure across generations $\bar{U}$, we take an utilitarian approach by considering a weighted average of the ex-ante utility of different generations, where generation- $\tau^{\prime}$ s weight is $r e^{-r \tau}$ as in Calvo and Obstfeld (1988). To obtain a measure of average lifetime welfare inequality $\bar{\Omega}$, we first convert lifetime inequality for generation $\tau$ into a consumption-equivalent measure $(\rho+\delta) \log q_{\tau}$ and then aggregate all generations using the welfare weights. Then, average welfare and lifetime welfare inequality are

$$
\bar{U}=r \int_{0}^{\infty} e^{-r \tau} U_{\tau} d \tau \quad \text { and } \quad \bar{\Omega} \equiv(\rho+\delta) r \int_{0}^{\infty} e^{-r \tau} \log \left(q_{\tau}\right) d \tau .
$$

Appendix A.6 characterizes the first order changes in average welfare $\Delta \bar{U} \equiv \bar{U}-U_{0^{-}}$ and lifetime welfare inequality $\Delta \bar{\Omega} \equiv \bar{\Omega}-\log \left(q_{0^{-}}\right)$caused by $\Delta \log (A)$. We use this 
characterization to establish that the welfare consequences of technological innovations depend crucially on how slow the adjustment is.

Proposition 2 (Changes in average welfare and lifetime welfare inequality) Assume that the $H$ income share is larger than its employment share and that $r=\delta$. Then, for a given long-run elasticity $\frac{\Delta \log \left(q_{\infty}\right)}{\Delta \log (A)}$,

$$
\frac{\partial\left(\frac{\Delta \bar{U}}{\Delta \log (A)}\right)}{\partial D C I R(q)}<0 \text { and } \frac{\partial\left(\frac{\Delta \bar{\Omega}}{\Delta \log (A)}\right)}{\partial D C I R(q)}>0 .
$$

Proof. See Appendix A.6.

Intuitively, a higher $\operatorname{DCIR}(q)$ arises when the relative supply of $H$ goods increases more slowly over many generations. This then implies that, during their lifetimes, generations born before the shock expect to see a smaller fraction of the long-run increase in relative output and decline in the price index. Yet, they expect to experience even higher inequality compared to those generations born in the long-run (since $q$ remains high for longer). As a result, everything else equal, the average welfare increase will be smaller and the average lifetime welfare inequality increase will be larger. ${ }^{19}$

\section{Determinants of Skill-biased Transitions}

In this section, we establish how the type of innovations affect the relative strength of the two adjustment margins in the theory and, therefore, determine the dynamics of inequality, the skill distribution, and economic activity. Our main results focus on one summary measure of such dynamics: the discounted cumulative impulse response in Definition 2. They thus answer the second question we posed: what features of innovations and skills determine whether the adjustment is fast or whether it slowly plays out over many generations?

We show that a technological transitions is slower and more unequal whenever our theoretical economy features higher technology-skill specificity, i.e., whenever an innovation is biased towards economic activities intensive in skills which differ more from those used in the rest of the economy. In addition, the adjustment is slower if the cost of skill investment for entering generations is lower - for example, because the sets of skills used in the activities improved by the innovation are easier to learn. The reason is that, in both cases, the adjustment is driven more by the slow change in the skill distribution across generations as opposed to the fast reallocation of workers within a generation.

\footnotetext{
${ }^{19}$ Note also that, when the adjustment is slower and transitional dynamics more important, a researcher using reduced-form estimates of changes in inequality $\Delta \log \omega_{T}$ over some horizon $T$ will obtain more biased estimates of the true average and distributional welfare consequences of the shock. This is because she will wrongly conclude that the change in lifetime welfare inequality is $(\rho+\delta) \Delta \log q_{T}=\Delta \log \omega_{T}$, which may be higher or lower than $\Delta \bar{\Omega}$ depending on the estimation horizon $T$.
} 


\subsection{Comparative statics with respect to technology-skill specificity}

We now compare the dynamic adjustment of two economies featuring high and low technology-skill specificity. We interpret this as a comparison between two episodes of adjustment triggered by distinct types of skill-biased innovations that impact different sets of economic activities. In one episode, an innovation augments the productivity of the $H$ technology by $\Delta \log (A)$, where $H$ corresponds to occupations or sectors intensive in skills that are markedly different from those used in the rest of the economy (represented by the $L$ technology). That is, this episode is associated with a high technology-skill specificity economy where a worker skill type has a markedly different productivity in the $L$ and $H$ technologies. In the other episode, the productivity of the $H$ technology is again augmented by $\Delta \log (A)$ but $H$ instead corresponds to occupations or sectors intensive in similar skills to those used in the rest of the economy. That is, this episode is instead associated with a low technology-skill specificity economy.

Figure 3 illustrates the adjustment in these two economies. ${ }^{20}$ The black lines show the responses of an economy with a high value of $\eta$ (i.e., low technology-skill specificity). The blue lines show the responses of an economy with a low value of $\eta$ (i.e., high technology-skill specificity). In Appendix A.7, we support the graphical representation in Figure 3 with Proposition A.1 establishing how $\eta$ affects the short- and long-run responses, the cumulative impulse response, and the rate of convergence.

Figure 3: Comparative statics with respect to $\eta$
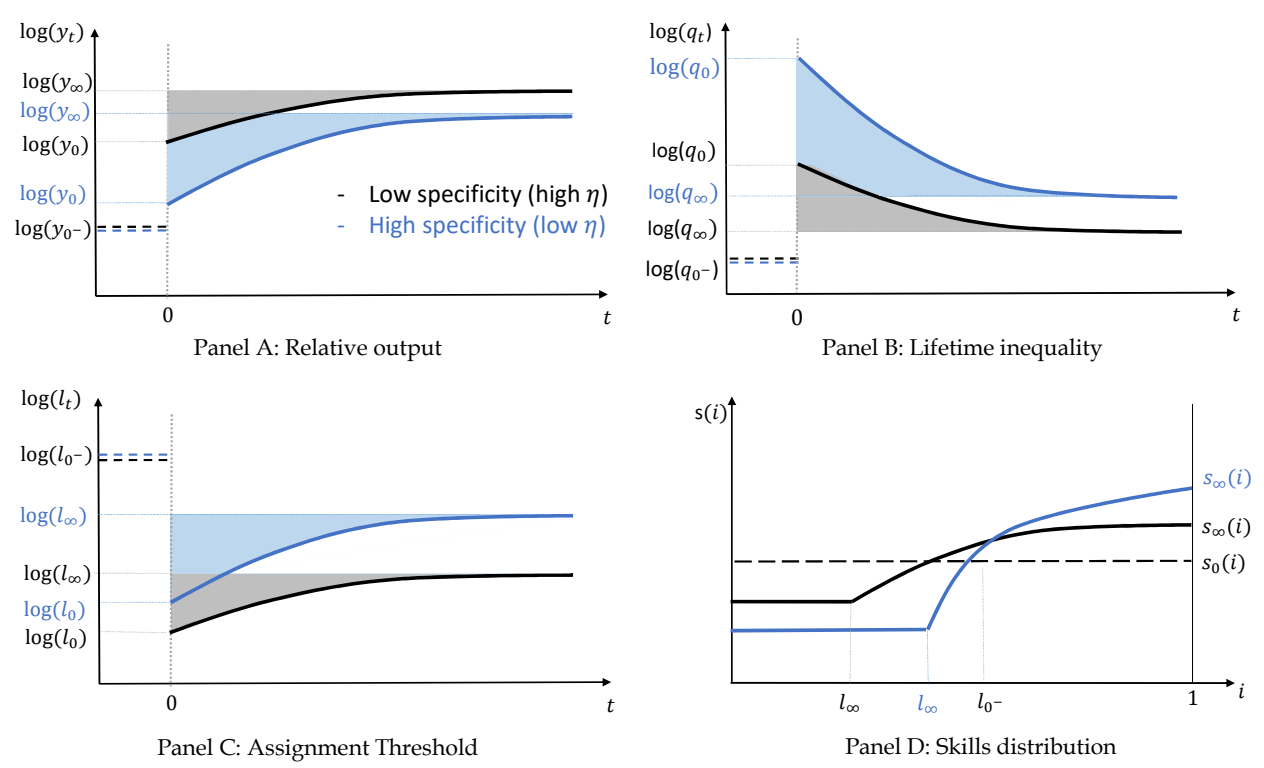

In the short-run, when technology-skill specificity is higher (lower $\eta$ ), a smaller mass of workers reallocate across technologies in response to the shock (i.e., $\frac{\partial\left|\Delta \log \left(l_{0}\right)\right|}{\partial \eta}>0$ ). That is, the within-generation adjustment margin is weaker. As a result, relative wages

\footnotetext{
${ }^{20}$ The figure shows the case where $\theta>1$ and the threshold's cumulative response increases with $\eta$.
} 
and lifetime inequality $q$ increase more in the short-run (i.e., $\frac{\partial\left|\Delta \log \left(q_{0}\right)\right|}{\partial \eta}<0$ ) whereas relative output increases less (i.e., $\frac{\partial\left|\Delta \log \left(y_{0}\right)\right|}{\partial \eta}>0$ ). The larger increase in $q$ then implies that younger entering generations have stronger incentives to invest in those skills that are more complementary to the $H$ technology. As a result, the optimal skill lotteries $\tilde{s}_{\tau}(i)$ are further tilted towards high $i$ skill types and there are larger differences in the skill distribution between old generations alive before the shock and young generations born after. $^{21}$ That is, the cross-generation adjustment margin becomes endogenously stronger. Ultimately, the overall magnitude of the adjustment of $y_{t}$ and $q_{t}$ that happens along the transition is larger because larger changes in the skill distribution take place as younger generations replace older generations. Formally, we measure this as the cumulative impulse response function being larger (e.g. $\left.\frac{\partial \int_{0}^{\infty} \hat{q}_{t} d t}{\partial \eta}<0\right)$ - graphically, the blue shaded areas being larger than the black shaded areas. ${ }^{22}$

To summarize, when the type of innovations and skills are such that an economy features high technology-skill specificity, technological transitions will be driven more by changes in the skill distribution across generations than the reallocation of workers within a generation. This is because the muted reallocation of workers at shorter horizons causes larger endogenous changes in the skill distribution along the transition due to the larger increases in lifetime inequality. ${ }^{23}$ The next theorem shows that, as result, the economy's adjustment will not only be more unequal but also slower.

Theorem 2.1 (DCIR comparative statics with respect to $\eta$ ) Following a skill-biased innovation $\Delta \log (A)$, lifetime inequality $(q)$ and relative output $(y)$ adjust slower in economies featuring higher technology-skill specificity (lower $\eta$ ). Formally,

$$
\frac{\partial \operatorname{DCIR}(q)}{\partial \eta}<0, \quad \frac{\partial \operatorname{DCIR}(y)}{\partial \eta}<0
$$

Proof. We have that $\operatorname{DCIR}(q)=\frac{\lambda \delta}{\lambda+\delta}\left|\frac{\int_{0}^{\infty} \hat{q}_{t} d t}{\Delta \log (A)}\right|$. From Proposition A.1 in Appendix A.7, we know that when $\eta$ is higher then $\lambda$ and $\left|\int_{0}^{\infty} \hat{q}_{t} d t\right|$ are both smaller. The proof for $y_{t}$ is analogous.

As a final remark, we point out that the slower adjustment in economies featuring higher technology-skill specificity does not mechanically follow from the fact that

\footnotetext{
${ }^{21}$ This follows directly from the fact that $\tilde{s}_{\tau}(i)$ is proportional to $\hat{q}_{\tau}$ in (18) and $\hat{q}_{\tau}$ is larger for all $\tau$ when technologyskill specificity is higher.

${ }^{22}$ Moreover, while the larger changes in the skill distribution could have implied a larger (smaller) overall long-run adjustment in relative output (lifetime inequality), it turns out that the smaller (larger) short-run response dominates. Thus, the long-run adjustment in relative output (lifetime inequality) is smaller (larger) in the economy with higher technology-skill specificity.

${ }^{23}$ We conjecture this intuition is more generally applicable. After a shock, economies with a less mobile stock of a factor experience stronger changes in the flow of entrants because of larger changes in relative prices - e.g., if old vintages of physical capital are less adaptable to a new sector, then the flow of firm entrants with newer capital vintages will be larger.
} 
reallocation is smaller in the short-run, or from the fact that old generations are replaced slowly at rate $\delta$. Instead, it follows from the skill distribution responding more to the stronger relative wage change. To make this point clear, Proposition 3 shows that technology-skill specificity has no effect on the DCIR of $q$ and $y$ when we shut down either changes in the skill distribution or inequality $(\psi \rightarrow 0$ or $\theta \rightarrow \infty)$.

Proposition 3 (Interaction of technology-skill specificity with $\psi$ and $\theta$ ) When the cost of skill investment is large $(\psi \rightarrow 0)$ or when $H$ and L are highly substitutable $(\theta \rightarrow \infty)$, then technology-skill specificity has no effect on how slow $q$ and $y$ adjust.

$$
\left.\frac{\partial D C I R(y)}{\partial \eta}\right|_{\psi \rightarrow 0}=\left.\frac{\partial D C I R(q)}{\partial \eta}\right|_{\psi \rightarrow 0}=0,\left.\quad \frac{\partial D C I R(y)}{\partial \eta}\right|_{\theta \rightarrow \infty}=\left.\frac{\partial D C I R(q)}{\partial \eta}\right|_{\theta \rightarrow \infty}=0
$$

Proof. See Appendix A.8.

\subsection{Comparative statics with respect to the cost of skill investment}

We now investigate the effect of the cost of skill investment for young generations on the economy's dynamic adjustment following the same skill-biased innovation $\Delta \log (A)$. We interpret this comparative static exercise as a comparison between episodes of adjustment where the sets of skills intensely used in the activities improved by a given type of innovation may have been harder or easier to learn. Or, alternatively, as a comparison between economies that differ in their educational systems, availability of vocational training for younger workers, or presence of retraining programs for older generations.

Figure 4 illustrates the responses of two economies. The blue lines depict the adjustment of an economy with a low cost of skill investment investment for young generations (i.e., high value of $\psi$ ). The black lines represent the responses of an economy with a high cost instead (i.e., low value of $\psi$ ). Proposition A.2 in Appendix A.7 supports this figure.

In the short-run, both economies exhibit identical responses in relative output and worker reallocation. This follows from the fact that $\psi$ does not affect the self-selection decisions of generations born before the shock. That is, it does not affect the withingeneration adjustment margin. However, a higher $\psi$ attenuates the short-run increase in lifetime inequality because future relative wages fall by more due to the larger increase in the future supply of high-i skills implied by the more responsive skill lottery in (18). The larger change in the skill distribution of the economy with a lower investment cost (i.e., higher $\psi$ ) has two important implications for its dynamic adjustment to the shock. First, in the long run, it implies that relative output (lifetime inequality) increases more (less). Second, as the following theorem shows, it implies a slower, more back-loaded adjustment in relative output and inequality. Intuitively, when the cost of skill investment for younger workers is lower, transitional dynamics become more important since 
Figure 4: Comparative statics with respect to $\psi$
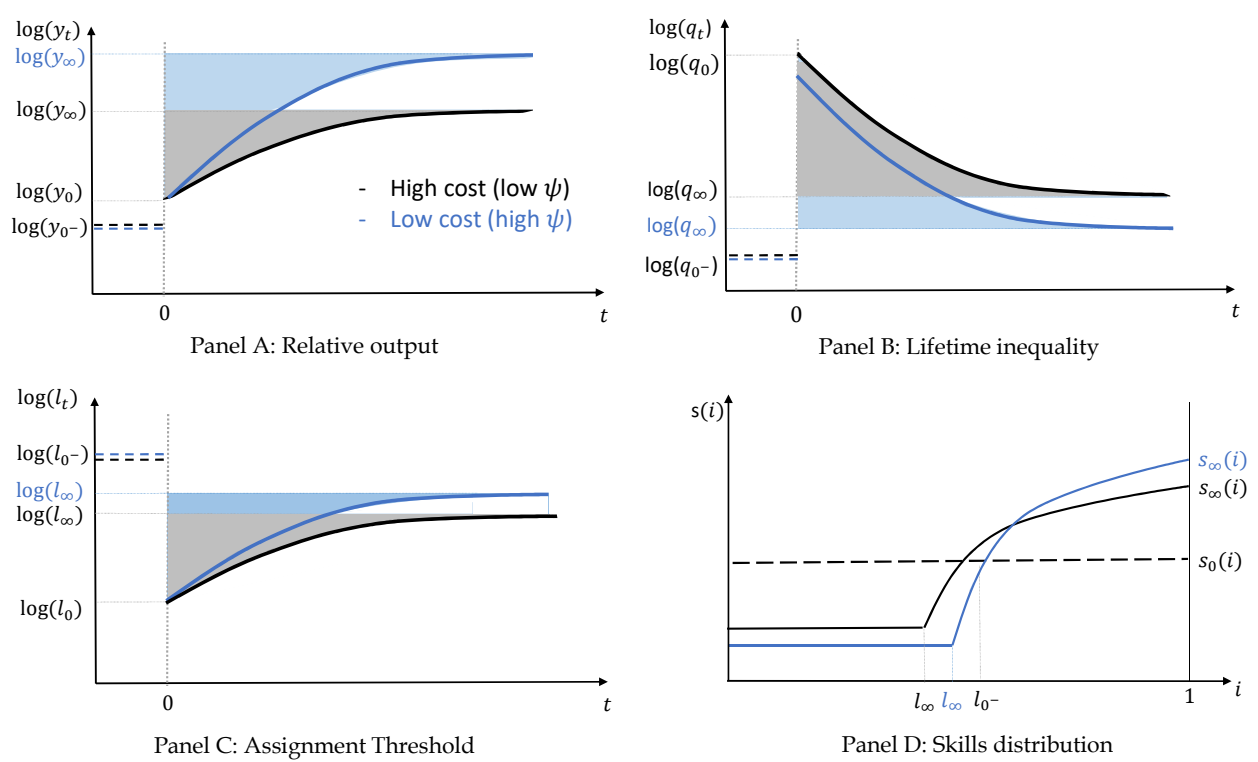

there are larger changes in the skill distribution. That is, the cross-generation adjustment margin is stronger.

Theorem 2.2 (DCIR comparative statics with respect to $\psi$ ) Following a skill-biased innovation $\Delta \log (A)$, lifetime inequality $(q)$ and relative output $(y)$ adjust slower in economies with a lower cost of skill investment for younger workers (higher $\psi$ ). Formally,

$$
\frac{\partial \operatorname{DCIR}(q)}{\partial \psi}>0, \quad \frac{\partial \operatorname{DCIR}(y)}{\partial \psi}>0
$$

Proof. The proof is analogous to the one for Theorem 2.1 but using Proposition A.2 in Appendix A.7 instead.

\subsection{Back to the LeChatelier principle}

To better understand the previous comparative statics, it is useful to return to the reduced-form supply elasticity $\varphi_{t}$ introduced in Section 4 . The different dynamic implications of changing $\eta$ or $\psi$ arise because the two parameters shape different horizons of this elasticity. Appendix A.5 formally shows these implications. Here, we illustrate them with Figure 5.

Both higher values of $\eta$ and $\psi$ increase the elasticity in the long-run, but the timing of the rise is different for the two. Specifically, increasing $\eta$ flattens the path of $\varphi_{t}$ but increasing $\psi$ steepens it. Intuitively, a higher $\eta$ front-loads more the response in the relative supply of $H$ by making it easier for skill types to reallocate across technologies in response to the shock. That is, it strengthens the within-generation adjustment margin. 
Figure 5: Effect of $\eta$ and $\psi$ on the elasticity of relative output supply $\left(\varphi_{t}\right)$

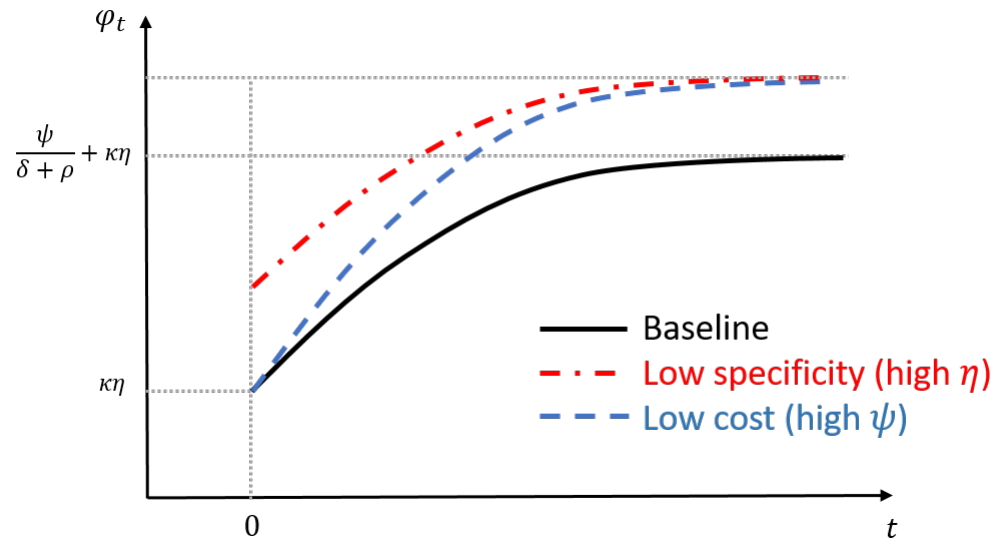

This in turn reduces the relative wage change in the short-run and, as a result, attenuates changes in the skill distribution and $\varphi_{t}$ over time. That is, it weakens the cross-generation adjustment margin. In contrast, a higher $\psi$ implies that it is easier for new generations to invest in skills. This increases the importance of the cross-generation margin compared to the within-generation margin, amplifying changes in the skill distribution and $\varphi_{t}$ across horizons.

This discussion indicates when researchers should be more cautious about extrapolating from observed changes at short horizons: economies where technology-skill specificity is higher and/or the cost of skill investment for young generations is lower. In such economies, the adjustment is slower and more back-loaded, implying larger changes in all outcomes across generations.

\subsection{Extensions: additional determinants of skill distribution dynamics}

The theory so far has ignored several determinants of the dynamics of the skill distribution along the transition. In Online Appendix 1.2, we present three extensions that relax some of the assumptions of our baseline model. For all extensions, our comparative static results above with respect to $\eta$ and $\psi$ remain valid.

Learning-from-others. Our first extension considers a "learning-from-others" externality. Specifically, we relax the assumption that the reference distribution $\bar{s}_{\tau}(i)$ in the skill investment problem is exogenous and fixed over time. Instead, we assume that certain skills may be easier to acquire than others because workers can "learn from others" when such skills are already abundant in the economy. This extension introduces a backward-looking element into the skill investment problem and complementarities 
in skill investment decisions across generations. ${ }^{24}$ It yields dynamic responses that are qualitatively similar to those of our baseline economy when $\psi$ is higher and $\delta$ is lower, thus making the adjustment slower.

Skill investment by old workers. Our second extension relaxes the assumptions that workers can only invest in new skills upon birth. We allow an exogenous fraction of workers that were present before the skill-biased innovation to re-optimize their skill investment "as if" they were a young generation entering at time $t=0$. One interpretation of this is that old workers can now re-train after the innovation arrives. This extension yields responses that are qualitatively similar to our baseline when $\eta$ is higher, making the adjustment faster.

Population growth. Our third extension allows for population growth by making birth and death rates different. This increases the rate of convergence $\lambda$, making the adjustment faster.

\section{Observable Implications at Short Horizons}

We now use the results above to address the following question: What do we learn about the dynamic effects of new technologies over many generations from reduced-form evidence that spans short periods of time? Our answer relies on the observable predictions directly associated with the parameters controlling the two adjustment margins in the theory: technology-skill specificity $(\eta)$ and cost of skill investment $(\psi)$. As discussed above, these parameters are central determinants of the full adjustment dynamics following technological innovations.

In deriving such observable predictions, we take into account two considerations. First, there are practical challenges when analyzing transitions over long periods. Either because the technological innovations are recent and thus the adjustment is still ongoing or because the effects of new technologies are typically harder to separate from other confounding shocks over longer horizons. We thus relate the structural objects in our theory to responses that can be measured over short horizons.

Second, we acknowledge that measuring several of our outcomes requires strong assumptions that would reduce the credibility of any empirical investigation based on our theory. For example, "selection forces" imply that the relative wage in efficiency units, $\omega_{t}$, is not the relative average labor income. Furthermore, $q_{t}$ is a forward-looking variable, so measuring it requires observing $\omega_{t}$ along the full transition. Finally, the measurement of the skill distribution $s_{t}(i)$ and the technology-skill assignment $l_{t}$ require

\footnotetext{
${ }^{24}$ This is similar to the cross-generation complementarities that arise in the environment considered by Chari and Hopenhayn (1991).
} 
taking an explicit stance on observable attributes determining a worker's skill vector (e.g., college graduation), leading to misspecification if the chosen attributes do not fully determine technology-specific skills.

Given these considerations, we map technologies in our theory to sectors/occupations that are differentially affected by technological innovations. We then study the short-run impact of technological innovations on payroll and employment across different sectors and/or occupations. Our novel insight is that changes in these outcomes for different generations are connected to technology-skill specificity $(\eta)$ and cost of skill investment $(\psi)$. As a result, even if we only observe these changes at short horizons, they are informative about how economies adjust at longer horizons.

In Sections 4 and 5, we have already characterized the short-run response of relative payroll. We now focus on the short-run responses of two additional outcomes: (i) the relative employment of the "old" generations born before $t=0$ (i.e., within-generation change) and (ii) the difference between the relative employment of the "young" generation born at $t=0$ and the "old" generations born before $t=0$ (i.e., cross-generation change). These are the same type of outcomes that we presented for many countries in Figure 1. We formally define the elasticity of these outcomes to the technological innovation as

$$
\varepsilon_{0}^{\text {within }} \equiv \frac{\log \left(\frac{\int_{l_{0}}^{1} s_{0}(i) d i / \int_{0}^{l_{0}} s_{0}(i) d i}{\int_{l_{0}-}^{1} s_{0}(i) d i / \int_{0}^{l_{0}-} s_{0}(i) d i}\right)}{\Delta \log (A)} \text { and } \quad \varepsilon_{0}^{\text {cross }} \equiv \frac{\log \left(\frac{\int_{l_{0}}^{1} \tilde{s}_{0}(i) d i / \int_{0}^{l_{0}} \tilde{s}_{0}(i) d i}{\int_{l_{0}}^{1} s_{0}(i) d i / \int_{0}^{l_{0}} s_{0}(i) d i}\right)}{\Delta \log (A)} \text {. }
$$

The following theorem shows how $\eta$ and $\psi$ affect these elasticities.

Theorem 3 (Observable implications in the short-run)

$$
\frac{\partial\left|\varepsilon_{0}^{\text {within }}\right|}{\partial \eta}>0, \quad \frac{\partial\left|\varepsilon_{0}^{\text {within }}\right|}{\partial \psi}=0, \quad \text { and } \quad \frac{\partial\left|\varepsilon_{0}^{\text {cross }}\right|}{\partial \eta}<0, \quad \frac{\partial\left|\varepsilon_{0}^{\text {cross }}\right|}{\partial \psi}>0
$$

Proof. See Appendix A.9.

In terms of relative employment in the short-run, economies with higher technologyskill specificity (i.e., lower $\eta$ ) experience weaker within-generation responses for older workers, but stronger cross-generation differences in relative employment of younger versus older workers. Intuitively, the lower $\eta$ weakens the within-generation adjustment margin in our theory. Given the size of the innovation, a lower $\eta$ yields a smaller reallocation of skill types across technologies. At impact, this attenuates the reallocation of older workers, amplifies the increase in relative wages, and, consequently, induces larger differences in the skill distribution across generations. 
The theorem also describes how short-run relative employment responses depend on the cost of skill investment for younger generations. A lower investment cost (i.e., higher $\psi$ ) does not affect the within-generation response because the skills of older workers are predetermined. The lower cost however leads to stronger changes in the skill investment decisions of young workers, giving rise to stronger cross-generation differences in relative employment.

Together, Theorems 2.1-2.2 and 3 indicate the type of observable short-run responses to new technologies that are consistent with the beginning of a particularly slow and unequal transition. Consider estimates that point to a small within-generation elasticity and a large cross-generation elasticity. This is consistent with high technology-skill specificity and/or small costs of skill investment for young workers. As a consequence, through the lens of our theory, the adjustment should be more unequal and unfold slowly over many generations. This is precisely the type of responses that Figure 1 illustrates for recent cognitive-biased innovations. Such patterns are thus features of slow, back-loaded transitions in which the response of inequality (economic activity) is much stronger (weaker) in the short-run than in the long-run.

Finally, we point out that the results in this section are intended to clearly illustrate the observable implications of two determinants of technological transitions. For this reason, we analyze how they affect the instantaneous relative employment elasticity to the one-time, permanent shock $\Delta \log (A)$. However, the use of these results to recover the structural parameters of the model face two further practical challenges: the shock is neither directly observed nor fully completed at a point in time. In Online Appendix 3 , we show that we can account for these challenges when we set parameters by matching theoretical and empirical impulse response functions. Intuitively, we can use the observed response of relative payroll in Proposition 1 to recover the size of the shock. We can also use the sum of theoretical impulse response functions to allow for a sequence of unanticipated shocks. ${ }^{25}$ In Section 8, we use these insights to parameterize our model using estimates of the impact of cognitive-biased innovations on employment and payroll across occupations and generations.

\section{Cognitive-biased Transitions: Evidence from Germany}

Our theoretical results established that technology-skill specificity and the cost of skill investment for entering generations are connected to within- and cross-generation changes in relative employment and payroll following technological innovations. Qualitatively, this links the two structural determinants of technological transitions to the type of

\footnotetext{
${ }^{25}$ Technically, our approach permits a sequence of uncorrelated shocks. When shocks are persistent, one needs to modify our procedure to account for responses of skill investment decisions to expected future shocks.
} 
patterns across occupations and generations we documented in Figure 1. However, such patterns may not provide a fully adequate account of the dynamic adjustment to cognitive-biased innovations. For example, they are subject to concerns about confounding shocks driving cognitive-intensive employment growth. They also do not provide any direct evidence about the changes in skill investment decisions that drive the transitional dynamics in our theory. Moreover, by not relying on a specific innovation, they are not informative about how the impact of new technologies changes over time.

For these reasons, we now move beyond these aggregate patterns to provide additional evidence coming from Germany's dynamic adjustment to recent cognitive-biased innovations. We first investigate generation-specific changes in employment, payroll, and numbers of trainees across narrowly defined occupations with different degrees of cognitive-intensity. We then exploit quasi-random cross-regional variation in adoption timing of broadband internet in the early 2000s to estimate the dynamic impact of this particular technology on the growth of employment and payroll in cognitive-intensive occupations for different worker generations.

Overall, the evidence shows strong employment responses for younger generations in cognitive-intensive occupations compared to the muted reallocation of older generations. In fact, we document that young workers increase their investment on cognitive skills through vocational training in cognitive intensive occupations. Moreover, the relative employment and payroll responses become stronger over time as predicted by our theory's version of the LeChatelier's principle. The adjustment patterns are thus consistent with high technology-skill specificity and slow changes in the skill distribution across generations.

\subsection{Data}

We base our analysis on the labor market data in the LIAB Longitudinal Model between 1995 and 2014. We follow Card et al. (2013) to construct a sample of employed males aged 15-64. We first construct a dataset with yearly outcomes for 120 occupations in West Germany. We then construct a second dataset with annual outcomes for each occupation in 323 districts in West Germany. Appendix B describes the data construction. Online Appendix 2 presents summary statistics and additional details.

We define cognitive-intensive occupations as being those disproportionately augmented by recent innovations, like the computer and the internet. We thus map this set of occupations to the $H$ technology in the theory. This approach follows an extensive literature documenting that recent innovations had a stronger positive impact on cognitive-intensive jobs whose daily activities require problem-solving, creativity, or complex interpersonal interactions - e.g. Autor et al. (2003), Spitz-Oener (2006), Autor and Dorn (2013), Akerman et al. (2015). We use the BERUFNET data to measure each 
occupation's cognitive intensity using the share of time spent on analytical non-routine and interactive tasks. Figure 6 graphically depicts how the use of recent innovations varies with the cognitive-intensity of the occupation. It shows that usage of both internet and computers are strongly correlated with time spent on cognitive tasks across occupations.

We construct outcomes for two worker generations. The "Young" generation comprises workers born after 1960, and the "Old" generation includes all other workers. The young generation was at most 35 years old in 1995 when it represented $58 \%$ of the German labor force. Its overall employment share then increased to $89 \%$ in 2014 when workers were at most 54 years old. We also define a trainee sub-sample with workers whose employment status was a trainee, student trainee, or intern. In this sub-sample, $98 \%$ of all workers are below 30 years old and the mean age is 21 . Notice that, in line with our theory, Figure 6 documents that there are no systematic differences in internet and computer usage across workers of different ages employed in the same occupation. ${ }^{26}$

Figure 6: Internet and Computer Usage by Occupation: Within- and Cross-Generation
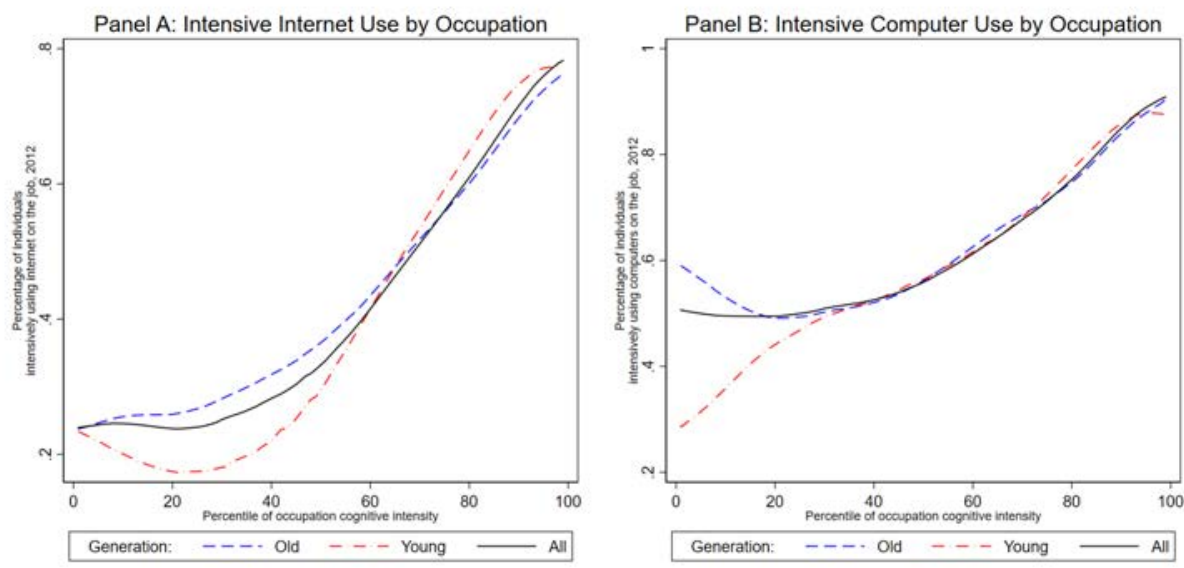

Note. Sample of 85 occupations in the 2012 Working Condition Survey. For each occupation, we compute the share of individuals reporting intensive internet and computer usage on their job. Young generations defined as workers aged below 40 years and Old generations defined as all workers aged above 40 years. The occupation cognitive-skill intensity is the share of time spent on cognitive-intensive tasks in the BERUFNET dataset (2011-2013). Figure reports the lowess smooth fit.

\subsection{Cognitive intensity and labor market outcomes across occupations}

Our first piece of evidence investigates whether the type of generation-specific trends in Figure 1 also holds for narrowly defined occupations over different horizons in Germany. We therefore move from the sharp predictions of our two-technology theory to look at employment trends across multiple occupations. This yields more variation to

\footnotetext{
${ }^{26}$ These results complement the finding in Spitz-Oener (2006) that there were small cross-cohort differences in the change of the task content of German occupations in the 1990s. In results available upon request, we attest that these patterns are similar if we define young generations to include workers who are less than 30, 35 or 45 years old.
} 
empirically investigate the main mechanisms in our theory.

For each worker generation $g$ and year $t$, we estimate the following linear regression:

$$
\log Y_{o, t}^{g}-\log Y_{o, 1995}^{g}=\alpha_{t}^{g}+\beta_{t}^{g} \bar{C}_{o}+\epsilon_{o, t}^{g}
$$

where $Y_{o, t}^{g}$ is an outcome in occupation $o$ at year $t$ for workers of generation $g$, and $\bar{C}_{o}$ is the cognitive intensity of occupation $o$.

Table 1 reports the estimation of equation (22) in the periods of 1995-2000 (Panel A) and 1995-2014 (Panel B). We report the estimated impact of the occupation's cognitive intensity on the log-change of employment in columns (1)-(3), payroll in columns (4)-(6), and number of trainees in column (7).

Table 1: Cognitive intensity and labor market outcomes across occupations in Germany

\begin{tabular}{|c|c|c|c|c|c|c|c|}
\hline \multirow[t]{3}{*}{ Dependent variable: } & \multicolumn{3}{|c|}{ Employment Growth } & \multicolumn{3}{|c|}{ Real Payroll Growth } & \multirow{3}{*}{$\begin{array}{c}\text { Trainee } \\
\text { Growth } \\
(7) \\
\end{array}$} \\
\hline & All & Young & Old & All & Young & Old & \\
\hline & (1) & (2) & (3) & (4) & (5) & (6) & \\
\hline \multicolumn{8}{|c|}{ Panel A: Change in 1995-2000 } \\
\hline Cognitive intensity & $\begin{array}{c}0.388^{* * *} \\
(0.076)\end{array}$ & $\begin{array}{c}0.650^{* * *} \\
(0.098)\end{array}$ & $\begin{array}{c}0.113^{* * *} \\
(0.043)\end{array}$ & $\begin{array}{c}0.340^{* * * *} \\
(0.048)\end{array}$ & $\begin{array}{c}0.616^{* * *} \\
(0.070)\end{array}$ & $\begin{array}{c}0.157^{* * * *} \\
(0.037)\end{array}$ & $\begin{array}{l}0.379^{*} \\
(0.209)\end{array}$ \\
\hline \multicolumn{8}{|c|}{ Panel B: Change in 1995-2014 } \\
\hline Cognitive intensity & $\begin{array}{c}1.488^{* * * *} \\
(0.225)\end{array}$ & $\begin{array}{c}1.894^{* * *} \\
(0.234)\end{array}$ & $\begin{array}{c}0.871^{* * *} \\
(0.229)\end{array}$ & $\begin{array}{c}1.535^{* * * *} \\
(0.227)\end{array}$ & $\begin{array}{c}2.029^{* * * *} \\
(0.238)\end{array}$ & $\begin{array}{c}1.044^{* * *} \\
(0.223)\end{array}$ & $\begin{array}{c}2.121^{* * * *} \\
(0.385)\end{array}$ \\
\hline
\end{tabular}

Note. Sample of 120 occupations. Each panel reports the estimate for the dependent variable over the indicated time period. Young cohort defined as all workers born after 1960 and Old cohort as all workers born before 1960. Robust standard errors in parentheses. ${ }^{*} p<0.1,{ }^{* *} p<0.05,{ }^{* * *} p<0.01$

Column (1) indicates that occupations with higher cognitive intensity experienced stronger employment growth. This differential employment response is larger over longer horizons. Compared to the least cognitive-intensive occupation, the employment growth in the most cognitive-intensive occupation was 143\% higher in 1995-2014. Importantly, columns (2)-(3) indicate that cognitive-intensive employment growth was weaker for older generations than for younger generations. In fact, estimated coefficients for the old generation are at most one-half those of the young generations. These results show that the German trends in Figure 1 also hold across more disaggregated occupations with different levels of cognitive intensity. Moreover, these responses become stronger over the period of analysis.

Columns (4)-(6) show that the relative payroll responses are slightly stronger than the relative employment responses in 1995-2014. This suggests that there were only small relative changes in the average earnings of those employed in cognitive-intensive occupations. As discussed before, in our theory, these relative payroll responses combine 
changes in both the relative marginal value of labor and the worker "selection" in more cognitive intensive occupations. So, the difference between columns (4) and (1) do not correspond to the response of the relative wage per efficiency units of more cognitiveintensive occupations. In fact, the small responses in relative average earnings for both young and old are consistent with strong selection forces created by entry of marginal workers with lower occupation-specific productivity than infra-marginal workers. ${ }^{27}$

Column (7) shows that occupations with a higher cognitive intensity experienced stronger growth in the number of trainees. Trainee programs are an important part of the formal training of young individuals in Germany - especially for non-degree occupations (Eckardt, 2019). As such, changes in the occupation allocation among trainees are a proxy for the changes in the skill investment decision of incoming generations in our theory. So, the estimated coefficient suggests that new generations tilted their investments towards cognitive skills in 1995-2014.

Taken together, this evidence again speaks qualitatively to the main mechanisms in our model. The small responses in employment for old workers suggest that the skills required in more cognitive intensive occupations are rather different from those used in other occupations. The large differences in employment responses across generations suggest that the cost of skill investment is smaller for younger workers than for older workers. In fact, young workers increase their investment on cognitive skills by becoming trainees in occupations with a higher cognitive intensity. The larger overall responses at longer horizons are consistent with our theory's version of the LeChatelier's principle.

One concern with this interpretation is that our estimates are not tied to a single technological innovation. Instead, they may be driven by different innovations introduced sequentially in the period - e.g. computers, industrial robots, or the internet. Thus, while our interpretation remains qualitatively valid, it is hard to quantitatively connect the estimates above to the mechanism in our theory because the empirical estimates are not impulse response functions to one-time permanent shocks. That is, the estimated dynamics may potentially confound both the endogenous skill distribution dynamics and the exogenous sequence of innovations. We address this concern in the next section.

Robustness. Online Appendix 2.3.1 investigates the robustness of our findings. Table 2.2 shows that results are qualitatively similar over different horizons. Table 2.3 shows that the positive relative employment growth in cognitive occupations is driven by the top third of occupations in terms of cognitive intensity. Table 2.4 shows that results are similar when we either change the definition of the young generation, restrict the sample to native-born Germans, or control for exposure to trade and immigration shocks.

\footnotetext{
${ }^{27}$ An extreme version of this pattern arises in assignment models with a Frechet distribution of technology-specific skills where average earnings are identical in all occupations (Hsieh et al., 2013; Burstein et al., 2016).
} 


\subsection{Dynamic adjustment to broadband internet adoption}

In this section, we analyze the dynamic response to one cognitive-biased innovation: the introduction of broadband internet in the early 2000s. ${ }^{28}$ There are two main reasons to focus on this particular innovation in Germany. First, it resembles the one-time permanent shock studied in Section 4 since its adoption was fast: the share of households with broadband access increased from $0 \%$ in 2000 to over $90 \%$ in 2009 . Second, it is possible to explore cross-regional variation in adoption timing to estimate impulse response functions of labor market outcomes for different worker generations. We do so by following Falck et al. (2014) to isolate exogenous spatial variation in adoption timing implied by the suitability of pre-existing local telephone networks for broadband internet transmission.

Empirical Strategy. Our goal is to estimate the dynamic impact of broadband internet adoption on labor market outcomes across districts in Germany. For each year between 1996 and 2014, we estimate the following linear specification

$$
Y_{i 0, t}^{g}-Y_{i o, 1999}^{g}=\sum_{c \in\{\text { young, old }\}}\left(\alpha_{t}^{c}+\beta_{t}^{c} \bar{C}_{0}\right) 1_{[g=c]} D S L_{i}+\delta_{o, t}+\zeta_{g, t}+X_{i o, t}^{g} \gamma_{t}^{g}+\epsilon_{i o, t^{\prime}}^{g}
$$

where $o$ is an occupation, $i$ is a district, and $g$ is a generation. In this specification, $Y_{i o, t}^{g}$ is an outcome, $D S L_{i}$ is the broadband internet penetration in district $i$ in 2005 (normalized to have standard deviation of one), and $\bar{C}_{o}$ is the time-invariant measure of the cognitive intensity of occupation $o$. The specification includes generation-year fixed effects that capture nationwide trends for different cohorts, as well as occupation-year fixed effects that absorb confounding shocks affecting an occupation equally in all regions. We also include a control vector $X_{i o, t}^{g}$ to absorb confouding shocks associated with the pretrend growth in 1995-1999 and the initial demographics of the district. ${ }^{29}$

We are mainly interested on the impact of broadband internet adoption on the relative outcomes of more cognitive intensive occupations for each generation: $\beta_{t}^{g}$ in equation (23). To understand the interpretation of this coefficient, consider region A whose broadband internet penetration in 2005 was one standard deviation higher than that of region $\mathrm{B}$. At year $t, \beta_{t}^{g}$ is the difference between regions $A$ and $B$ in the relative outcome of more cognitive intensive occupation among workers of generation $g$.

\footnotetext{
${ }^{28}$ As shown by Akerman et al. (2015), broadband internet expanded the relative demand for more educated workers in non-routine jobs inside firms. In Figure 6, we showed that internet usage is higher in more cognitive-intensive occupations and does not differ across worker cohorts conditional on their occupation.

${ }^{29}$ We follow Dix-Carneiro and Kovak (2017) and Freyaldenhoven et al. (2018) by explicitly controlling for pretrends. As argued by the latter paper, pretrends caused by unobserved confounding effects might exist even when they are not actually observed in the data due to estimation error, implying they should be controlled for in estimation. The demographic controls are the college graduate population share, the manufacturing employment share, the immigrant employment share, and the age composition of the labor force. In the Online Appendix we report estimates based on alternative control sets.
} 
The unbiased estimation of $\beta_{t}^{g}$ requires an exogenous source of variation on the adoption of broadband internet across districts. However, internet penetration is unlikely to be random since adoption should be faster in regions with workers more suitable to use that technology. For instance, this would be the case if broadband internet providers decide to first enter regions with a growing number of young individuals specialized in cognitive-intensive occupations.

To circumvent this issue, we follow Falck et al. (2014) by exploiting variation in the location of pre-existing main distribution frames (MDFs) of the telephone network. The initial roll-out of DSL internet in Germany used the pre-existing telephone network. The transmission technology could not supply high-speed internet to areas more than $4200 \mathrm{~m}$ away from an existing MDF. Thus, regions located close to MDFs were more likely to adopt broadband internet early. The use of MDF location as an instrument then requires that, conditional on controls, the determinants of MDF construction in the 1960s were orthogonal to the determinants of changes in labor market outcomes in the 2000s, except through their effect on broadband internet penetration in 2005. As argued by Falck et al. (2014), the location of MDFs in the 1960s did not take into account how attractive the nearby region was for broadband internet suppliers in the 2000s. This is reasonable because one of the main determinants of the MDF location was the availability of large empty building sites. In addition, MDFs could be used to provide telephone connections over much larger distances than they could be used to provide broadband internet.

We construct two instrumental variables that measure the district's population share located in areas where the existing telephone network could not be used to supply highspeed internet. These variables are aggregates of the municipality-level variables in Falck et al. (2014). The first variable is a count of the number of municipalities in the district that did not have a MDF within the municipality, and whose population-weighted centroid was further than the cut-off threshold of $4200 \mathrm{~m}$ to the municipality's MDF. The second variable counts the number of municipalities that satisfied the conditions in the first variable, but were further hampered by the lack of MDFs in neighboring municipalities that were closer than $4200 \mathrm{~m} .{ }^{30}$ We then estimate (23) using the exogenous variation induced by these two measures. Specifically, since the observation unit in equation (23) is an occupation-generation-district triple, our instrument vector includes the two measures interacted with generation dummies and the cognitive intensity of each occupation $o, \bar{C}_{0}$.

Appendix B investigates how broadband internet penetration in 2005 responded to our two measures of the cost of expanding broadband access across districts. Appendix Table B.1 shows that regions with higher values of these cost measures had a lower share of households with broadband access in 2005. To test for weak instruments in our

\footnotetext{
${ }^{30}$ Appendix Figure B.1 presents the pattern of cross-district variation in the cost measures.
} 
specification with multiple endogenous variables, Appendix Table B.2 shows that we obtain high values for the Sanderson-Windmeijer F-statistics for all variables (Sanderson and Windmeijer, 2016).

Results. Panel A of Figure 7 reports the estimates of $\beta_{t}^{\text {old }}$ and $\beta_{t}^{\text {young }}$ implied by equation (23) for each year between 1996 and 2014. Prior to 2003, regions with early DSL expansion did not experience differential growth in the relative outcomes of more cognitive intensive occupations for old and young workers. After 2005, there is a significant impact on the relative employment of young cohorts in more cognitive intensive occupations. In 2014, the point estimate suggests that a region with a one-standard deviation higher broadband internet penetration in 2005 had 0.5 log-points more young workers employed in the most cognitive-intensive occupation than in the least cognitive-intensive occupation. However, we do not find such an effect for old cohorts - if anything, the effect is negative. Online Appendix Figure 2.3 shows that the cross-generation difference is statistically different from zero for every year after 2006.

In our theory, the small relative employment response of old generations suggests that technology-skill specificity is high (i.e., $\eta \approx 0$ ). In this case, most workers from old generations do not switch occupations as their skills would have a lower value in the more cognitive-intensive occupations. The positive cross-generation difference in the relative employment response indicates that incoming generations tilt their investments towards skills more suitable for cognitive-intensive occupations (i.e., $\psi>0$ ). ${ }^{31}$ This creates changes in the skill distribution across generations.

In Panel B of Figure 7, we investigate how early broadband expansion affected the relative payroll of more cognitive intensive occupations for all worker generations. Specifically, we estimate equation (23) with a single generation $c$ containing workers of all ages in the district. This is the empirical analog of the impulse response function for relative output $y_{t}$ presented in Section 4. Again, we find no evidence of responses in the pre-shock period of 1996-2005. Starting in 2006, there is a slow and steady increase in the relative payroll of more cognitive-intensive occupations. In our theory, this is consistent with broadband internet augmenting the relative productivity of cognitive intensive occupations when cognitive and non-cognitive intensive occupations are substitutes in production (i.e., $\theta>1$ ).

Additional results and robustness. In Online Appendix 2.3.2, we analyze the robustness of our estimates. Table 2.5 shows that results are qualitatively similar when we drop the pretrend control, but estimated coefficients are less precise and slightly smaller in

\footnotetext{
${ }^{31}$ In line with this mechanism, Online Appendix Table 2.7 shows that early adopting regions experienced stronger growth in the number of trainees in more cognitive intensive occupations.
} 
Figure 7: Impact of early DSL adoption on more cognitive-intensive occupations

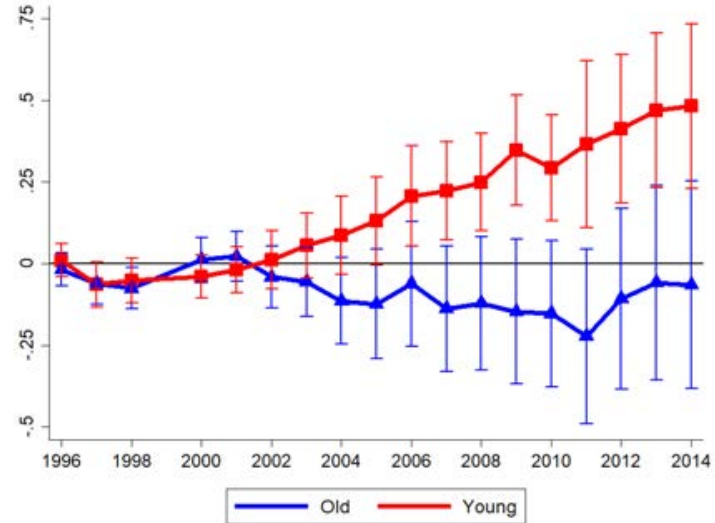

(a) Relative employment response by generation

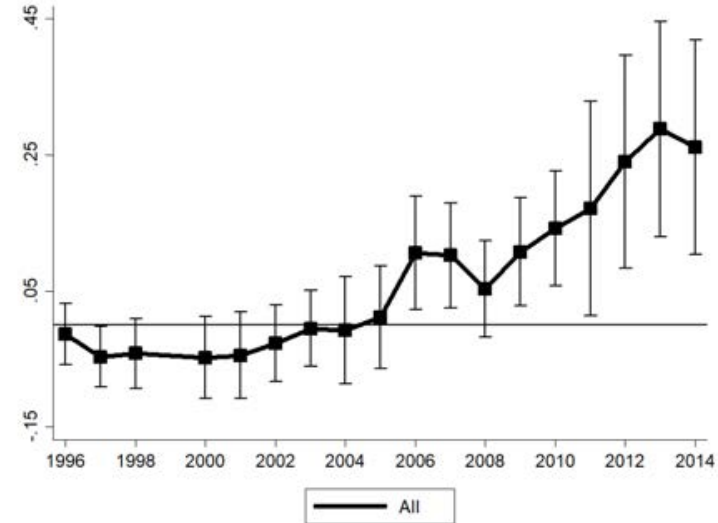

(b) Relative payroll response for all generations

Note. Left panel: estimation of equation (23) for log-employment as dependent variable in the sample of 2 generations, 120 occupations and 323 districts. Right panel: estimation of equation (23) for log-payroll as dependent variable in the sample of 120 occupations, 323 districts, and a single generation with all working-age employed individuals. For each year, the dot is the point estimate of $\beta_{t}^{g}$. Young cohort defined as all workers born after 1960 and Old cohort as all workers born before 1960. All regressions are weighted by the district population size in 1999 and include occupation-time and generation-time fixed-effects. Baseline controls include the following district variables in 1999: college graduate population share, manufacturing employment share, immigrant employment share, district age composition, and the dependent variable pre-shock growth in 1995-1999. Bars are the $90 \%$ confidence interval implied by the standard error clustered at the district level.

magnitude. Results are also similar when controlling for district-generation-year fixedeffects, so that identification comes purely from the differential effect of the shock on occupations with a higher cognitive intensity. Table 2.6 further shows that our estimates are similar when we use alternative definitions of the young generation. Finally, Table 2.6 reports estimates using a sample excluding workers employed in large establishments that might have received broadband internet access early through private networks. Consistent with this intuition, this sample yields quantitatively stronger estimates.

\section{How Different are Cognitive-biased Transitions?}

Our empirical results establish that recent cognitive-biased innovations, like the arrival of broadband internet in the 2000s, gave rise to weak reallocation of older generations and large cross-generation differences in occupation composition changes. The theoretical results in Sections 5 and 6 indicate that these response patterns are consistent with this type of innovations being biased towards occupations intensive in skills which were markedly different from those used in the rest of the economy, i.e., an economy featuring relatively high technology-skill specificity.

In this section, we ask: if technological innovations had not been cognitive-biased and had instead been biased towards economic activities intensive in skills which were 
more similar to those used in other activities, how different would the economy's adjustment have been? To answer this counterfactual question, we first use the evidence for Germany to discipline the structural parameters in our theory. Second, we solve for the full non-linear equilibrium dynamics-instead of approximating them-following a skill-biased innovation that reallocates 30 percent of employment across the two technologies in the long-run. We then compare the adjustment dynamics under our benchmark parameterization to those that result from a counterfactual parameterization associated with a lower technology-skill specificity. ${ }^{32}$ We conclude by providing suggestive evidence that the U.S. and German economies in the mid-century might have featured lower technology-skill specificity than in recent decades.

\subsection{Counterfactual Exercise: the role of technology-skill specificity}

Parameterization. We begin by parameterizing the model to match the empirical impulse responses shown in Section 7.3. As above, we map the $H$ technology to cognitiveintensive occupations. We then select the model's parameters in two steps.

We first externally calibrate the parameters $(\rho, \theta, r)$. We set the discount rate $\rho$ to match an annual interest rate of $2 \%$. We follow Hsieh et al. (2013) by setting the elasticity of substitution across occupations $\theta$ equal to $3 .{ }^{33}$ Finally, we set the discount rate of social welfare to $r=\rho+\delta$, so that the social discounting of future generations is identical to the discounting of worker's future utility.

We then select the parameters governing production technologies $(\alpha(i), \sigma(i))$ and the skill distribution dynamics $(\delta, \psi, \eta)$ to match the estimates in Figure 7 under the assumption of a one-time, permanent shock in 2004. ${ }^{34}$ The decline in the share of the old workers in total employment from 1997 to 2014 implies $\delta=0.057$, i.e, an expected working life-span of about 18 years after age 35 . The small response in the cognitive-intensive employment of old generations yields an $\eta$ close to zero, and the large young-old gap in the relative employment response implies $\psi=0.35$. Online Appendix 3 presents the matching procedure, along with the model's goodness of fit.

Results. We use the parameterized model to study the consequences of a cognitivebiased innovation that increases the employment share in the cognitive-intensive technology from $20 \%$ to $50 \%$. These values approximately correspond to the cognitive-intensive

\footnotetext{
${ }^{32}$ This exercise thus gives a sense of the magnitudes involved in our comparative static results in Section 5 and also shows that they are not driven by the first-order approximations.

${ }^{33}$ We do not try to estimate the demand elasticity of substitution across technologies since it requires observing an exogenous shock to the skill distribution, as in Katz and Murphy (1992).

${ }^{34}$ This is the last year for which the relative employment response of young workers is not statistically significant at $10 \%$. In parameterizing the model, we maintain our baseline assumption of a single shock. However, as discussed in the Online Appendix, we can adapt the procedure to a sequence of unanticipated shocks.
} 
employment share in 1997 of the countries with the lowest and the highest cognitiveintensive employment share among those listed in Figure 1 (Portugal and Netherlands, respectively). Thus, our results can be seen as analyzing the transitional dynamics of a shock that generates convergence in cognitive-intensive employment shares across such countries.

We focus here on how slow the adjustment is, as measured by $D C I R(q)$, as well as the impact on average welfare $(\Delta \bar{U})$ and lifetime welfare inequality $(\Delta \bar{\Omega})$, as defined in Section 4.2. For completeness, we show the full dynamic responses in Online Appendix 3. Table 2 shows that the increase in the average consumption-equivalent welfare is $46 \%$ and the increase in lifetime welfare inequality is $39 \%$. These large effects follow from the substantial shock size necessary to induce the reallocation of almost one-third of the economy's labor force.

Our theory indicates that the impact of the shock is remarkably different over different horizons. We quantify this by reporting the 'Short-run' changes in average welfare and inequality at the moment of the shock, and the 'Long-run' changes in the same outcomes across stationary equilibria. ${ }^{35}$ Inequality increases by $70 \%$ in the short-run, but it falls to $30 \%$ in the long-run. The inequality decline unfolds slowly over generations: the $\operatorname{DCIR}(q)$ of 0.9 implies that workers born right before the shock experience (in expectation) an increase in inequality during their lifetime that is $90 \%$ larger than the corresponding change in the long-run. Similarly, the average consumption-equivalent welfare gain is $31 \%$ right after the shock, but this increases to $55 \%$ in the long-run. Moreover, this calculations quantify the large biases induced by naively extrapolating from changes observed over short or long horizons that do not account for slow transitional dynamics.

The remaining rows of Table 2 report the welfare consequences of the same shock in a counterfactual economy with lower technology-skill specificity (i.e., higher $\eta$ ). ${ }^{36}$ The second panel of Table 2 shows that the higher $\eta$ implies a faster transition in which $\operatorname{DCIR}(q)$ is 0.4 (relative to 0.9 in the baseline economy). This follows from the smaller cross-generation differences in the skill distribution that arise because of the weaker inequality increase in the short-run (i.e., $45 \%$ in the counterfactual economy compared to $76 \%$ in the baseline economy). The lower inequality increase is a consequence of the stronger within-generation reallocation of old workers at impact. This also leads to a stronger decline in the price index, which translates into a higher average welfare gain

\footnotetext{
${ }^{35}$ Formally, the 'Short-run' calculation assumes that changes observed at impact are permanent, while the 'Longrun' calculation assumes that the changes observed in the long-run were permanent and happened at impact.

${ }^{36}$ We use an estimate of $\eta=0.75$ that is consistent with technology-skill specificity associated with a broader set of occupations beyond cognitive-intensive ones. Estimates in the literature are typically not reported in terms of $\eta$. Instead, they report the elasticity of relative occupation-level employment with respect to a change in relative occupation-level wages: $\frac{\Delta \log (e)}{\Delta \log (\omega)}$. Estimates for this elasticity are between 1 and 2 - e.g., see Hsieh et al. (2013). Given that the equilibrium employment share is 0.5 in the long-run of our economy, a reported relative employment elasticity of 1.5 (the mid-point between 1 and 2) implies $\eta=0.75$.
} 
in the short-run ( $40 \%$ in the counterfactual economy compared to $31 \%$ in the baseline economy). Moreover, these calculations confirm that the biases from not accounting for transitional dynamics are much smaller when the adjustment is faster.

Table 2: Changes in Average Welfare and Lifetime Welfare Inequality

\begin{tabular}{|c|c|c|c|c|}
\hline & \multicolumn{2}{|c|}{ 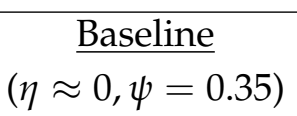 } & \multicolumn{2}{|c|}{$\frac{\text { Low specificity }}{(\eta=0.75, \psi=0.35)}$} \\
\hline & $\Delta \bar{U}$ & $\Delta \bar{\Omega}$ & $\Delta \bar{U}$ & $\Delta \bar{\Omega}$ \\
\hline True & $46 \%$ & $39 \%$ & $44 \%$ & $29 \%$ \\
\hline Short-run & $31 \%$ & $76 \%$ & $40 \%$ & $45 \%$ \\
\hline Long-run & $55 \%$ & $30 \%$ & $47 \%$ & $24 \%$ \\
\hline $\operatorname{DCIR}(q)$ & & & & \\
\hline
\end{tabular}

Note. The table reports the the changes in average welfare $\Delta \bar{U}$ and lifetime welfare inequality $\Delta \bar{\Omega}$ implied by a shock calibrated to increase the employment share in cognitive-intensive occupations from $20 \%$ to $50 \%$ between stationary equilibria. 'True' corresponds to the measures that fully account for the economy's transitional dynamics. 'Short-run' assumes that changes at impact are permanent. 'Long-run' assumes that long-run changes happened at impact.

\subsection{Historical trends across generations and occupations}

The counterfactual exercise above speaks to the possibility that the economy's adjustment to cognitive-biased innovations may be quite different than to other types of innovations. That is, cognitive-biased innovations lead to a particularly unequal and slow adjustment because they are biased towards economic activities intensive in skills which are markedly different from those used in the rest of the economy. We now provide suggestive evidence that the high technology-skill specificity observed in the U.S. and German economies after 1990 might not have been a feature of these economies before 1990. That is, prior to 1990, the main innovations (technological or otherwise) driving changes in employment composition might have been biased towards occupations intensive in skills which were similar to those used in other economic activities. If this was the case, compared to the adjustment in recent decades, our theory's key prediction is that we should have observed similar changes in occupation composition for all generations before 1990.

We thus next investigate whether the observed cross-generation differences in occupational composition changes pre and post 1990 are consistent with this narrative. To obtain a measure of the expanding occupations that is consistent over time, we no longer rely on the set of cognitive intensive occupations since past innovations may have impacted a different set of economic activities. Instead, for each country and period, we define a set of impacted occupations as the top tercile of occupations in terms of employment expansion among young workers. Through the lens of our theory, since 
young workers differentially invest in new skills to work on occupations that became more attractive, their employment decisions provide a revealed-preference way of recovering the occupations experiencing positive demand shocks under the assumption of no shocks to the cost of investing on different skills. ${ }^{37}$

Table 3 reports the employment growth trends in the three occupations with the highest growth among young workers. Columns (1) and (3) report substantial growth in these occupations for both periods and countries. Interestingly, columns (2) and (4) show that the two periods differ in the relative magnitude of the cross- and within-generation components of employment changes. As in Figure 1, there is a large cross-generation difference in recent years when most expanding occupations were cognitive intensive. However, such cross-generation differences were much smaller before 1990 when changes in the occupation composition were more similar for young and old generations. In this earlier period, the set of expanding occupations was less cognitive intensive, with services and retail occupations at the top of the list in both countries. In fact, Germany did not have any cognitive intensive occupation among the fastest growing occupations in 1970-1987.38

Table 3: Cross-generation differences in occupational composition changes pre and post 1990

\begin{tabular}{|c|c|c|c|c|}
\hline & \multicolumn{2}{|c|}{ Early period (pre 1990) } & \multicolumn{2}{|c|}{ Recent period (post 1990) } \\
\hline & $\frac{1}{T} \Delta \log e_{t}^{\text {all }}$ & $\frac{\Delta \log \left(e_{t}^{\text {yon }} / e_{t}^{\text {old }}\right)}{\left.\Delta \log e_{t}^{\text {old }}\right)}$ & $\frac{1}{T} \Delta \log e_{t}^{\text {all }}$ & 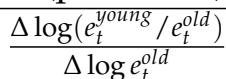 \\
\hline & (1) & $(2)$ & (3) & (4) \\
\hline Germany & $1.94 \%$ & 0.173 & $1.59 \%$ & 0.456 \\
\hline United States & $0.91 \%$ & 0.206 & $1.45 \%$ & 0.476 \\
\hline
\end{tabular}

Note. Columns (1) and (3) report the annualized growth rate in the three 2-digit ISCO occupations with the highest change in log employment share in the period among young workers in the country (where $T$ is the number of years in the period). For the top 3 occupations by log-employment growth for young workers, columns (2) and (4) report the ratio between the log-change in the cross-generation difference in employment shares and the log-change in employment share for old workers. Early period: 1970-1987 for West Germany and 1960-1990 for the United States. Recent period: 1997-2017 for Germany and 2000-2015 for the United States. Sample of males in two age groups: "Young" workers aged 15-39yrs and "Old" workers aged 40-64yrs.

This evidence indicates that it is not always the case that young and old workers have very different trends in occupation employment growth. Prior to 1990, changes in occupation composition did not exhibit the large cross-generation differences observed in recent years. Such patterns are consistent with an economy featuring lower technologyskill specificity, potentially due to different types of innovations driving employment

\footnotetext{
${ }^{37}$ We use again the nine aggregate occupations in the 2-digit ISCO classification that we used to construct Figure 1. Our primary data source for the early period is the individual-level Census data downloaded from IPUMS international. We compute changes in occupation employment shares for males in 1970-1987 for Germany and 1960-1990 for the United States. For the later period, we use the same data used to construct the trends in Figure 1.

${ }^{38}$ In Online Appendix 2.4, we attest that cross-generation differences in occupation employment growth become stronger in every 20-year period since 1960 for the United States.
} 
changes in the decades before $1990 .^{39}$

\section{Conclusions}

We develop a theory where overlapping generations of workers are heterogeneous over a continuum of technology-specific skills. Technological transitions are driven both by the reallocation of workers within a generation and changes in the skill distribution across generations. We characterize the equilibrium dynamics of this economy, showing that they resemble those of a $q$-theory of skill investment. This allow us to sharply characterize the determinants of transitional dynamics and welfare following a skillbiased innovation, as well as derive observable predictions for changes in labor market outcomes within and across generations. We then use these insights to study the adjustment of developed economies to recent cognitive-biased technological innovations. Several pieces of evidence show strong responses of cognitive-intensive employment for young but not old generations.

Taken together, we derive two broad takeaways from this piece. First, the evidence suggests that transitions following cognitive-biased innovations may be particularly unequal and slow to play out because this type of innovations are biased towards economic activities intensive in skills which are markedly different from those used in other activities. This results in an economy featuring high technology-skill specificity where the adjustment is mostly driven by slow changes in the skill distribution across generations as opposed to the fast reallocation of workers within a generation. These features are not universal though. If other episodes of adjustment, past or future, involved different types of innovations and skills, then they would also vary in how slow and unequal they are. Second, caution should be exercised when interpreting technological transitions based on evidence over short time horizons. This may lead to overly pessimistic views of the consequences of new technologies for inequality and average welfare. Yet, observed changes for different generations, even at short horizons, are useful when combined with a theory of technological transitions. Looking at the decisions of younger workers allows us to "see the future" and thus appropriately derive the full implications of technological innovations.

We conclude by commenting on how some ideas developed in this paper may be useful to tackle other questions in future research. It is relatively straightforward to extend the theory to multiple sectors in order to study how economies adjust to more nuanced labor demand shocks (e.g., trade liberalizations, routine-biased innovations), to

\footnotetext{
${ }^{39}$ This is of course just one of many possible interpretations of this evidence, so we do not claim that it establishes a causal impact of past innovations. For example, the generation-specific shocks in college graduation rates documented in Card and Lemieux (2001) may help explain why young and old generations have similar changes in employment composition in the 1970s and 1980s.
} 
include different worker groups (e.g, gender, race) in order to analyze changes in discrimination, or to reinterpret sectors as regions in order to study migration. Moreover, future work can address normative questions related to the optimal speed of adjustment to technological (and trade) shocks or the role of workers with more transferable skills in providing aggregate insurance against these shocks. Finally, the notion that withinand cross-generation changes at short horizons are informative about structural parameters governing elasticities at longer horizons can be used both to improve on empirical projections about future labor market conditions as well as to discipline other dynamic models with, for instance, incumbents and entrant firms.

\section{References}

Abramitzky, R., Lavy, V., and Segev, M. (2019). The effect of changes in the skill premium on college degree attainment and the choice of major. Technical report, National Bureau of Economic Research.

Acemoglu, D. and Autor, D. (2011). Skills, tasks and technologies: Implications for employment and earnings. In Handbook of labor economics, volume 4, pages 1043-1171. Elsevier.

Acemoglu, D. and Restrepo, P. (2017). Robots and jobs: Evidence from us labor markets. Working Paper 23285, National Bureau of Economic Research.

Acemoglu, D. and Restrepo, P. (2018). The race between man and machine: Implications of technology for growth, factor shares, and employment. American Economic Review, 108(6):1488-1542.

Adão, R. (2016). Worker heterogeneity, wage inequality, and international trade: Theory and evidence from brazil. Unpublished paper, MIT.

Akerman, A., Gaarder, I., and Mogstad, M. (2015). The Skill Complementarity of Broadband Internet. The Quarterly Journal of Economics, 130(4):1781-1824.

Atkeson, A., Burstein, A., and Chatzikonstantinou, M. (2018). Transitional dynamics in aggregate models of innovative investment. Technical report, National Bureau of Economic Research.

Atkeson, A. and Kehoe, P. J. (2007). Modeling the Transition to a New Economy: Lessons from Two Technological Revolutions. American Economic Review, 97(1):64-88.

Atkin, D. (2016). Endogenous skill acquisition and export manufacturing in mexico. American Economic Review, 106(8):2046-85.

Autor, D. and Dorn, D. (2009). This job is "getting old": Measuring changes in job opportunities using occupational age structure. American Economic Review, 99(2):4551.

Autor, D. H. and Dorn, D. (2013). The growth of low-skill service jobs and the polarization of the us labor market. American Economic Review, 103(5):1553-97.

Autor, D. H., Levy, F., and Murnane, R. J. (2003). The Skill Content of Recent Technological Change: An Empirical Exploration. The Quarterly Journal of Economics, 118(4):12791333. 
Ben-Porath, Y. (1967). The production of human capital and the life cycle of earnings. Journal of political economy, 75(4, Part 1):352-365.

Blanchard, O. J. (1985). Debt, deficits, and finite horizons. Journal of political economy, 93(2):223-247.

Buera, F. J. and Kaboski, J. P. (2012). The rise of the service economy. American Economic Review, 102(6):2540-69.

Buera, F. J., Kaboski, J. P., and Shin, Y. (2011). Finance and development: A tale of two sectors. American economic review, 101(5):1964-2002.

Burstein, A., Morales, E., and Vogel, J. (2016). Changes in between-group inequality: computers, occupations, and international trade. Technical report, mimeo.

Calvo, G. A. and Obstfeld, M. (1988). Optimal time-consistent fiscal policy with finite lifetimes. Econometrica: Journal of the Econometric Society, pages 411-432.

Card, D., Heining, J., and Kline, P. (2013). Workplace Heterogeneity and the Rise of West German Wage Inequality. The Quarterly Journal of Economics, 128(3):967-1015.

Card, D. and Lemieux, T. (2001). Can falling supply explain the rising return to college for younger men? a cohort-based analysis. The Quarterly Journal of Economics, 116(2):705-746.

Carneiro, P., Heckman, J. J., and Vytlacil, E. J. (2011). Estimating marginal returns to education. American Economic Review, 101(6):2754-81.

Caselli, F. (1999). Technological revolutions. American economic review, 89(1):78-102.

Chari, V. V. and Hopenhayn, H. (1991). Vintage human capital, growth, and the diffusion of new technology. Journal of political Economy, 99(6):1142-1165.

Charles, K. K., Hurst, E., and Notowidigdo, M. J. (2018). Housing booms and busts, labor market opportunities, and college attendance. American Economic Review, 108(10):294794.

Costinot, A. and Vogel, J. (2010). Matching and inequality in the world economy. Journal of Political Economy, 118(4):747-786.

Dix-Carneiro, R. and Kovak, B. K. (2017). Trade liberalization and regional dynamics. American Economic Review, 107(10):2908-46.

Dvorkin, M. and Monge-Naranjo, A. (2019). Occupation mobility, human capital and the aggregate consequences of task-biased innovations. Technical report.

Eckardt, D. (2019). Are chemists good bankers? returns to the match between training and occupation. Technical report, LSE.

Falck, O., Gold, R., and Heblich, S. (2014). E-lections: Voting behavior and the internet. American Economic Review, 104(7):2238-65.

Freyaldenhoven, S., Hansen, C., and Shapiro, J. M. (2018). Pre-event trends in the panel event-study design. Working Paper 24565, National Bureau of Economic Research.

Fudenberg, D., Iijima, R., and Strzalecki, T. (2015). Stochastic choice and revealed perturbed utility. Econometrica, 83(6):2371-2409. 
Galor, O. and Moav, O. (2002). Natural Selection and the Origin of Economic Growth. The Quarterly Journal of Economics, 117(4):1133-1191.

Ghose, D. (2019). Trade, internal migration, and human capital: Who gains from india's it boom?

Goldin, C. D. and Katz, L. F. (2009). The Future of Inequality: The Other Reason Education Matters So Much. Scholarly articles, Harvard University Department of Economics.

Hansen, L. P. and Sargent, T. J. (2008). Robustness. Princeton university press.

Heckman, J. J. and Honore, B. E. (1990). The empirical content of the roy model. Econometrica, 58(5):1121-1149.

Heckman, J. J., Lochner, L., and Taber, C. (1998). Explaining rising wage inequality: Explorations with a dynamic general equilibrium model of labor earnings with heterogeneous agents. Review of economic dynamics, 1(1):1-58.

Herrendorf, B., Rogerson, R., and Valentinyi, Á. (2014). Growth and structural transformation. In Handbook of economic growth, volume 2, pages 855-941. Elsevier.

Hobijn, B., Schoellman, T., and Vindas, A. (2019). Wages during structural transformation: The importance of cohort labor supply decisions.

Hsieh, C.-T., Hurst, E., Jones, C. I., and Klenow, P. J. (2013). The allocation of talent and us economic growth. Technical report, National Bureau of Economic Research.

Katz, L. F. and Murphy, K. M. (1992). Changes in relative wages, 1963-1987: supply and demand factors. The quarterly journal of economics, 107(1):35-78.

Kim, D.-I. and Topel, R. H. (1995). Labor markets and economic growth: lessons from korea's industrialization, 1970-1990. In Differences and changes in wage structures, pages 227-264. University of Chicago Press.

Krusell, P. and Smith, Jr, A. A. (1998). Income and wealth heterogeneity in the macroeconomy. Journal of political Economy, 106(5):867-896.

Lagakos, D. and Waugh, M. E. (2013). Selection, agriculture, and cross-country productivity differences. American Economic Review, 103(2):948-80.

Lee, D. and Wolpin, K. I. (2006). Intersectoral labor mobility and the growth of the service sector. Econometrica, 74(1):1-46.

Lucas, R. E. and Moll, B. (2014). Knowledge growth and the allocation of time. Journal of Political Economy, 122(1):1-51.

Matějka, F. and McKay, A. (2015). Rational inattention to discrete choices: A new foundation for the multinomial logit model. American Economic Review, 105(1):272-98.

Matsuyama, K. (1992). A simple model of sectoral adjustment. The Review of Economic Studies, 59(2):375-387.

McFadden, D. (1973). Conditional logit analysis of qualitative choice behavior.

Moll, B., Rachel, L., and Restrepo, P. (2019). Uneven growth: Automation's impact on income and wealth inequality. 
Murphy, K. M. and Topel, R. H. (1987). The evolution of unemployment in the united states: 1968-1985. NBER macroeconomics annual, 2:11-58.

Ngai, L. R. and Pissarides, C. A. (2007). Structural change in a multisector model of growth. American economic review, 97(1):429-443.

Perla, J. and Tonetti, C. (2014). Equilibrium imitation and growth. Journal of Political Economy, 122(1):52-76.

Porzio, T. and Santangelo, G. (2019). Does schooling cause structural transformation?

Rogerson, R. (2008). Structural transformation and the deterioration of european labor market outcomes. Journal of political Economy, 116(2):235-259.

Roy, A. D. (1951). Some thoughts on the distribution of earnings. Oxford economic papers, 3(2):135-146.

Sanderson, E. and Windmeijer, F. (2016). A weak instrument f-test in linear iv models with multiple endogenous variables. Journal of Econometrics, 190(2):212-221.

Sims, C. A. (2003). Implications of rational inattention. Journal of monetary Economics, 50(3):665-690.

Spitz-Oener, A. (2006). Technical change, job tasks, and rising educational demands: Looking outside the wage structure. Journal of labor economics, 24(2):235-270.

Yaari, M. E. (1965). Uncertain lifetime, life insurance, and the theory of the consumer. The Review of Economic Studies, 32(2):137-150. 


\section{Appendix}

\section{Appendix A Proofs}

\section{A.1 Proof of Lemma 2}

We obtain (14) by applying this expression into the relative supply expression in (13) and the relative demand expression in (2). We can re-write it as

$$
A_{t}^{\theta-1}=\frac{\int_{l_{t}}^{1} \alpha(i) \sigma(i) s_{t}(i) d i}{\sigma\left(l_{t}\right)^{\theta} \int_{0}^{l_{t}} \alpha(i) s_{t}(i) d i}
$$

The right-hand side is strictly decreasing in $l_{t}$, converges to zero as $l_{t} \rightarrow 1$, and converges to infinity as $l_{t} \rightarrow 0$. Then, existence and uniqueness of a solution follows from applying Bolzano's theorem.

\section{A.2 Proof of Lemma 3}

The FOC of workers' skill-accumulation problem are:

$$
\begin{aligned}
V_{t}(i)-\frac{1}{\psi}\left(1+\log \left(\frac{\tilde{s}_{t}(i)}{\bar{s}_{t}(i)}\right)\right)-\lambda_{t} & =0 \\
\lambda_{t}\left(\int_{0}^{1} \tilde{s}_{t}(x) d x-1\right) & =0
\end{aligned}
$$

Integrating over $i \in[0,1]$, we obtain an equation characterizing $\lambda_{t}$ :

$$
\log \left(\int_{0}^{1} \bar{s}_{t}(i) e^{\psi V_{t}(i)} d i\right)=\psi \lambda_{t}+1
$$

Therefore,

$$
\tilde{s}_{t}(i)=\frac{\bar{s}_{t}(i) e^{\psi V_{t}(i)}}{\int_{0}^{1} \bar{s}_{t}(j) e^{\psi V_{t}(j)} d j} .
$$

Using the wage expressions and assignment function in Lemma 1, we can write the value function of a worker $i$ at time $t$ as

$$
\begin{aligned}
V_{t}(i) & =\int_{t}^{\infty} e^{-(\rho+\delta)(s-t)} \log \left(w_{s}(i)\right) d s-\int_{t}^{\infty} e^{-(\rho+\delta)(s-t)} \log \left(P_{s}\right) d s \\
& =\int_{t}^{\infty} e^{-(\rho+\delta)(s-t)}\left(\log \left(\omega_{s} \sigma(i) \alpha(i)\right) \mathbb{I}_{i \geq l_{s}}+\log (\alpha(i))\left(1-\mathbb{I}_{i<l_{s}}\right)\right) d s-\int_{t}^{\infty} e^{-(\rho+\delta)(s-t)} \log \left(P_{s}\right) d s \\
& =\frac{\log (\alpha(i))}{\rho+\delta}+\int_{t}^{\infty} e^{-(\rho+\delta)(s-t)} \log \left(\omega_{s} \sigma(i)\right) \mathbb{I}_{i \geq l_{s}} d s-\int_{t}^{\infty} e^{-(\rho+\delta)(s-t)} \log \left(P_{s}\right) d s
\end{aligned}
$$


By defining $Q_{t}(i) \equiv e^{\int_{t}^{\infty} e^{-(\rho+\delta)(s-t)} \log \left(\omega_{s} \sigma(i)\right) \mathbb{I}_{i \geq l_{s}} d s}$, we obtain

$$
\tilde{s}_{t}(i)=\frac{\bar{s}_{t}(i) \alpha(i)^{\frac{\psi}{\rho+\delta}} Q_{t}(i)^{\psi}}{\int_{0}^{1} \bar{s}_{t}(j) \alpha(j)^{\frac{\psi}{\rho+\delta}} Q_{t}(j)^{\psi} d j}
$$

\section{A.3 Proof of Theorem 1}

Part 1. We begin by solving for the stationary skill distribution $s(i)$ implied by (10) and (12)

$$
s(i)=\tilde{s}(i)=\frac{\bar{s}(i)\left(\alpha(i) \max \left\{\frac{\sigma(i)}{\sigma(l)}, 1\right\}\right)^{\frac{\psi}{\rho+\delta}}}{\int_{0}^{1} \bar{s}(j)\left(\alpha(j) \max \left\{\frac{\sigma(i)}{\sigma(l)}, 1\right\}\right)^{\frac{\psi}{\rho+\delta}} d j}
$$

We then take a first order approximation around the stationary equilibrium of equations (10), (12) and (14). We obtain

$$
\begin{aligned}
\frac{\partial \hat{s}_{t}(i)}{\partial t} & =-\delta \hat{s}_{t}(i)+\delta \hat{\tilde{s}}_{t}(i) \\
\hat{l}_{t} & =\frac{\eta}{\theta-1} \hat{y}_{t} \\
\hat{l}_{t} & =\frac{\eta}{\kappa \eta+\theta}\left(\int_{l}^{1} \hat{s}_{t}(i) \frac{\alpha(i) \sigma(i) s(i)}{\int_{l}^{1} \alpha(i) \sigma(i) s(i) d i} d i-\int_{0}^{l} \hat{s}_{t}(i) \frac{\alpha(i) s(i)}{\int_{0}^{l} \alpha(i) s(i) d i} d i\right)
\end{aligned}
$$

where

$$
\kappa \equiv \frac{\alpha(l) s(l) l}{\int_{0}^{l} \alpha(i) s(i) d i}+\frac{\alpha(l) \sigma(l) s(l) l}{\int_{l}^{1} \alpha(i) \sigma(i) s(i) d i} .
$$

Differentiating (A.4) with respect to time, we get that

$$
\frac{\partial \hat{l}_{t}}{\partial t}=\frac{\eta}{\kappa \eta+\theta}\left(\int_{l}^{1} \frac{\partial \hat{s}_{t}(i)}{\partial t} \frac{\alpha(i) \sigma(i) s(i)}{\int_{l}^{1} \alpha(i) \sigma(i) s(i) d i} d i-\int_{0}^{l} \frac{\partial \hat{s}_{t}(i)}{\partial t} \frac{\alpha(i) s(i)}{\int_{0}^{l} \alpha(i) s(i) d i} d i\right)
$$

Applying (A.2) to this expression, we obtain

$$
\frac{\partial \hat{l}_{t}}{\partial t}=-\delta \hat{l}_{t}+\frac{\eta}{\kappa \eta+\theta} \delta\left(\int_{l}^{1} \hat{\tilde{s}}_{t}(i) \frac{\alpha(i) \sigma(i) s(i)}{\int_{l}^{1} \alpha(i) \sigma(i) s(i) d i} d i-\int_{0}^{l} \hat{\tilde{s}}_{t}(i) \frac{\alpha(i) s(i)}{\int_{0}^{l} \alpha(i) s(i) d i} d i\right) .
$$

We now guess and verify that $l_{t}$ converges monotonically along the equilibrium path. We establish this starting from $\hat{l}_{0}<0$. We omit the analogous proof for $\hat{l}_{0}>0$. Whenever $\hat{l}_{0}<0$ and increases monotonically along the equilibrium path, we have that for all $s>t$, types $i<l_{t}$ are employed in technology $L$ and types $i>l$ are employed in technology $H$. Also, for workers with $i \in\left(l_{t}, l\right)$, there exist a $\tau(i)$ such that they work in $H$ for all 
$t<s<t+\tau(i)$ and in $L$ for all $s>t+\tau(i)$. Thus, given the definition of $Q_{t}(i)$, we get

$$
Q_{t}(i)= \begin{cases}1 & i \leq l_{t} \\ e^{\int_{t}^{t+\tau(i)} e^{-(\rho+\delta)(s-t)} \log \left(\omega_{s} \sigma(i)\right) d s} & i \in\left(l_{t}, l\right) \\ \sigma(i)^{\frac{1}{\rho+\delta}} q_{t} & i \geq l\end{cases}
$$

This implies the following expression for the optimal lottery:

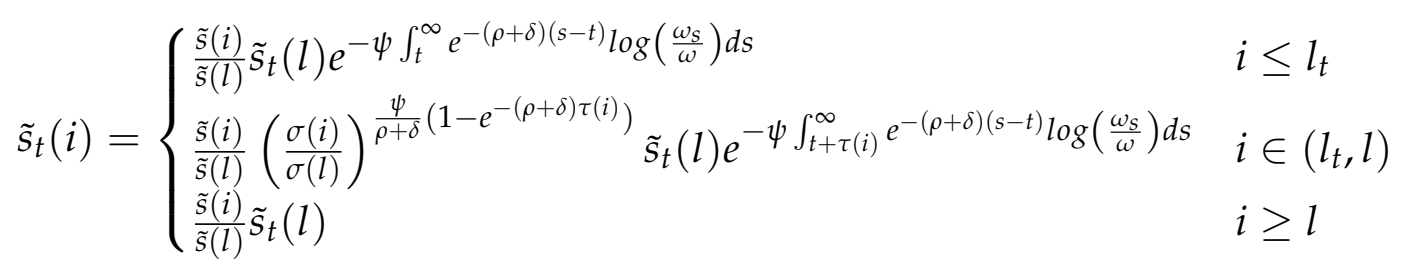

The log-linearization of (A.7) implies

$$
\hat{\tilde{s}}_{t}(i)=\hat{\tilde{s}}_{t}(l)-\psi \hat{q}_{t} \mathbb{I}_{i \leq l_{t}}-\psi \hat{q}_{t+\tau(i)} \mathbb{I}_{i \in\left(l_{t}, l\right)} .
$$

By replacing (A.8) into the expression inside the parenthesis in (A.5), we obtain

$$
\begin{array}{r}
\left(\int_{l}^{1} \hat{\tilde{s}}_{t}(i) \frac{\alpha(i) \sigma(i) s(i)}{\int_{l}^{1} \alpha(i) \sigma(i) s(i) d i} d i-\int_{0}^{l} \hat{\tilde{s}}_{t}(i) \frac{\alpha(i) s(i)}{\int_{0}^{l} \alpha(i) s(i) d i} d i\right)= \\
\int_{0}^{l} \psi\left(\hat{q}_{t} \mathbb{I}_{i \leq l_{t}}+\hat{q}_{t+\tau(i)} \mathbb{I}_{i \geq l_{t}}\right) \frac{\alpha(i) s(i)}{\int_{0}^{l} \alpha(x) s(x) d x} d i= \\
\psi \hat{q}_{t}-\psi \int_{l_{t}}^{l}\left(\hat{q}_{t}-\hat{q}_{t+\tau(i)}\right) \frac{\alpha(i) s(i)}{\int_{0}^{l} \alpha(x) s(x) d x} d i
\end{array}
$$

where the last line uses our guess that $l_{t} \leq l$ for all $t$.

Then, given our guess that $l_{t}$ increases monotonically along the equilibrium path, from (12) we see that $\omega_{t}$ decreases monotonically along the equilibrium path. This implies that $\hat{q}_{t}>\hat{q}_{t+\tau(i)}>0$ for all $i$ and all $t$. So, we can show that the term inside the integral is of second order:

$$
0 \leq \int_{l_{t}}^{l}\left(\hat{q}_{t}-\hat{q}_{t+\tau(i)}\right) \frac{\alpha(i) s(i)}{\int_{0}^{l} \alpha(x) s(x) d x} d i \leq \int_{l_{t}}^{l} \hat{q}_{t} \frac{\alpha(i) s(i)}{\int_{0}^{l} \alpha(x) s(x) d x} d i \leq \frac{\max _{i \in\left(l_{t}, l\right)} \alpha(i) s(i) l}{\int_{0}^{l} \alpha(x) s(x) d x} \hat{l}_{t} \hat{q}_{t} \approx 0 .
$$

We then obtain (16) by replacing this expression back in (A.5).

To show (17), we differentiate the definition of $\log \left(q_{t}\right)$ with respect to time:

$$
\frac{\partial \log \left(q_{t}\right)}{\partial t}=-\log \left(\omega_{t}\right)+(\rho+\delta) \log \left(q_{t}\right)
$$

Notice that indifference condition (A.5) immediately implies that $\hat{\omega}_{t}=-(1 / \eta) \hat{l}_{t}$. 
Then, by log-linearizing the expression above and replacing, we obtain (17)

$$
\frac{\partial \hat{q}_{t}}{\partial t}=\frac{1}{\eta} \hat{l}_{t}+(\rho+\delta) \hat{q}_{t}
$$

Part 2. We now derive the policy functions, show that the equilibrium is saddle-path stable, and verify that $l_{t}$ increases monotonically along the equilibrium path.

We start by guessing that the policy functions are given by $\frac{\partial \hat{l}_{t}}{\partial t}=-\lambda \hat{l}_{t}$ and $\hat{q}_{t}=\zeta \hat{l}_{t}$. By replacing this guess into (16)-(17), we obtain the following system:

$$
\begin{aligned}
-\lambda & =-\delta+\frac{\eta}{\kappa \eta+\theta} \delta \psi \zeta \\
-\zeta \lambda & =\frac{1}{\eta}+(\rho+\delta) \zeta .
\end{aligned}
$$

The second equation immediately yields the expression for $\zeta$. To get the expression for $\lambda$, notice that substituting the expression for $\zeta$ into the first equation implies that

$$
(\delta-\lambda)(\rho+\delta+\lambda)+\frac{\psi \delta}{\kappa \eta+\theta}=0,
$$

which yields the following solutions

$$
\lambda=-\frac{\rho}{2} \pm \sqrt{\left(\frac{\rho}{2}\right)^{2}+\delta\left((\rho+\delta)+\frac{\psi}{\kappa \eta+\theta}\right)} .
$$

Because the term inside the square root is always positive, two solutions always exist with one being positive and the other negative. This implies that the equilibrium is saddle-path stable. The positive solution is the speed of convergence of $l_{t}$.

Finally, the equilibrium threshold is $\hat{l}_{t}=\hat{l}_{0} e^{-\lambda t}$. Then, if $\hat{l}_{0}<0$, this implies that $l_{t}$ increases monotonically along the equilibrium path, which verifies our initial guess and completes the proof of the theorem.

Part 3. Notice that $\int s(i) \hat{\tilde{s}}_{t}(i) d i=\int\left(\tilde{s}_{t}(i)-s(i)\right) d i=0$. Using (A.8), we have that

$$
\begin{aligned}
0 & =\int_{0}^{1} s(i) \hat{\tilde{s}}_{t}(i) d i \\
& =\hat{\tilde{s}}_{t}(l)-\psi \int_{0}^{l}\left(\hat{q}_{t} \mathbb{I}_{i<l_{t}}+\hat{q}_{t+\tau(i)} \mathbb{I}_{i \in\left(l_{t}, l\right)}\right) s(i) d i \\
& =\hat{\tilde{s}}_{t}(l)-\left(\int_{0}^{l} s(i) d i\right) \psi \hat{q}_{t}+\psi \int_{l_{t}}^{l}\left(\hat{q}_{t}-\hat{q}_{t+\tau(i)}\right) s(i) d i
\end{aligned}
$$

We can use use the same arguments as in Appendix A.3 to show that the last term is of second order. Thus,

$$
\hat{\tilde{s}}_{t}(l)=\left(\int_{0}^{l} s(i) d i\right) \psi \hat{q}_{t}
$$


and, therefore,

$$
\hat{\tilde{s}}_{t}(i)=\left(\int_{0}^{l} s(i) d i\right) \psi \hat{q}_{t}-\psi \hat{q}_{t} \mathbb{I}_{i<l}+\psi\left(\hat{q}_{t}-\hat{q}_{t+\tau(i)}\right) \mathbb{I}_{i \in\left(l_{t}, l\right)} .
$$

To prove the result, we use the fact that $\hat{q}_{t+\tau(i)}=\hat{q}_{t} e^{-\lambda \tau(i)}$. So,

$$
\begin{aligned}
\hat{\tilde{s}}_{t}(i) & =\left(\int_{0}^{l} s(i) d i\right) \psi \hat{q}_{t}-\psi \hat{q}_{t} \mathbb{I}_{i<l}+\psi\left(\hat{q}_{t}-\hat{q}_{t+\tau(i)}\right) \mathbb{I}_{i \in\left(l_{t}, l\right)} \\
& =\mathbb{I}_{i>l} \psi \hat{q}_{t}-\left(1-\int_{0}^{l} s(i) d i\right) \psi \hat{q}_{t}+\psi \hat{q}_{t}\left(1-e^{-\lambda \tau(i)}\right) \mathbb{I}_{i \in\left(l_{t}, l\right)} \\
& =\left(\mathbb{I}_{i>l}-\int_{l}^{1} s(i) d i\right) \psi \hat{q}_{t}+o_{t}(i)
\end{aligned}
$$

where $o_{t}(i) \equiv \psi \hat{q}_{t}\left(1-e^{-\lambda \tau(i)}\right) \mathbb{I}_{i \in\left(l_{t}, l\right)}$ and has $\int s(i) o_{t}(i) d i=0$.

Finally, the dynamics of the skill distribution and the relative value of output follow from equations A.2 and A.3:

$$
\begin{aligned}
\hat{s}_{t}(i) & =\hat{s}_{0}(i) e^{-\delta t}+\int_{0}^{t} e^{\delta(\tau-t)} \hat{\tilde{s}}_{\tau}(i) d \tau, \\
\hat{y}_{t} & =(\theta-1) \frac{1}{\eta} \hat{l}_{t}
\end{aligned}
$$

\section{A.4 Proof of Proposition 1}

Using the definitions $y_{t}$ and $q_{t}$ together with Theorem 1, we have

$$
\begin{aligned}
\Delta \log \left(y_{t}\right) & =(\theta-1)\left(\Delta \log (A)-\Delta \log (\omega)-\hat{\omega}_{t}\right) \\
& =(\theta-1)\left(\Delta \log (A)-\left(\Delta \log (\omega)+\hat{\omega}_{0} e^{-\lambda t}\right)\right) \\
\Delta \log \left(q_{t}\right) & =\Delta \log (q)+\hat{q}_{t} \\
& =\frac{1}{\rho+\delta} \Delta \log (\omega)+\frac{1}{\rho+\delta+\lambda} \hat{\omega}_{0} e^{-\lambda t}
\end{aligned}
$$

Furthermore,

$$
\Delta \log \left(l_{t}\right)=-\eta \Delta \log \left(\omega_{t}\right)=-\eta\left(\Delta \log (\omega)+\hat{\omega}_{0} e^{-\lambda t}\right)
$$

We next derive the long-run change $\Delta \log (\omega)$ and the short-to-long-run change $\hat{\omega}_{0}$

Long-run. In this case the skill distribution is given by (A.1), so that the equilibrium 
threshold solves

$$
A^{\theta-1} \sigma(l)^{\theta} \int_{0}^{l} \bar{s}(i) \alpha(i)(\alpha(i))^{\frac{\psi}{\rho+\delta}} d i=\int_{l}^{1} \bar{s}(i) \alpha(i) \sigma(i)\left(\alpha(i) \frac{\sigma(i)}{\sigma(l)}\right)^{\frac{\psi}{\rho+\delta}} d i
$$

Consider a log-linear approximation around the final stationary equilibrium:

$$
(\theta-1) \Delta \log (A)+\left(\left(\theta+\frac{\psi}{\rho+\delta}\right) \frac{1}{\eta}+\kappa\right) \Delta \log (l)=0
$$

Thus,

$$
\Delta \log (l)=-\frac{\eta}{\left(\theta+\frac{\psi}{\rho+\delta}\right)+\eta \kappa}(\theta-1) \Delta \log (A)
$$

From equation (12), $\Delta \log (\omega)=-\frac{1}{\eta} \Delta \log (l)$ and, therefore,

$$
\Delta \log (\omega)=\frac{1}{\left(\theta+\frac{\psi}{\rho+\delta}\right)+\eta \kappa}(\theta-1) \Delta \log (A)
$$

Short-to-Long We start by deriving the change in the skill distribution using (A.1): $\hat{s}_{0}(i)=\hat{s}_{0}(l)$ if $i<l$ and $\hat{s}_{0}(i)=\hat{s}_{0}(l)-\frac{\psi}{\rho+\delta} \Delta \log (\omega)$ if $i>l$. Along the transition, the change in the assignment threshold is determined by (14) given the change in the skill distribution:

$$
\left(\frac{\theta}{\eta}+\kappa\right) \hat{l}_{0}=-\frac{\psi}{\rho+\delta} \Delta \log (\omega)
$$

Then,

$$
\hat{\omega}_{0}=\frac{1}{\theta+\kappa \eta} \frac{\psi}{\rho+\delta} \Delta \log (\omega)
$$

Dynamic responses We now use the derivations above to show that

$$
\begin{aligned}
& \Delta \log \left(l_{t}\right)=-\frac{\eta}{\theta+\kappa \eta}\left(1+\frac{1}{\theta+\kappa \eta+\frac{\psi}{\rho+\delta}} \frac{\psi}{\rho+\delta}\left(e^{-\lambda t}-1\right)\right)(\theta-1) \Delta \log (A) \\
& \Delta \log \left(y_{t}\right)=\frac{1}{\theta+\kappa \eta}\left((1+\kappa \eta)+\frac{(\theta-1)}{\theta+\kappa \eta+\frac{\psi}{\rho+\delta}} \frac{\psi}{\rho+\delta}\left(1-e^{-\lambda t}\right)\right)(\theta-1) \Delta \log (A) \\
& \Delta \log \left(q_{t}\right)=\frac{1}{\theta+\kappa \eta+\frac{\psi}{\rho+\delta}} \frac{1}{\rho+\delta}\left(1+\frac{\lambda-\delta}{\delta} e^{-\lambda t}\right)(\theta-1) \Delta \log (A)
\end{aligned}
$$

where the last line uses the solution to $\lambda$ from Theorem 1 . 


\section{A.5 Proof of Demand-Supply representation in (20)-(21)}

The demand equation in (2) immediately implies that

$$
\Delta \log x_{t}=(\theta-1) \Delta \log (A)-\theta \Delta \log \omega_{t} .
$$

We guess and verify the responses in Proposition 1 can be derived from a relative supply equation with the following form:

$$
\Delta \log x_{t}=\varphi_{t} \log \omega_{t}
$$
by

By combining the supply and demand equations, the change in relative wage is given

$$
\Delta \log \omega_{t}=\frac{1}{\varphi_{t}+\theta}(\theta-1) \Delta \log (A)
$$

We now derive the expression for $\Delta \log \omega_{t}$ implied by Proposition 1 . The demand equations in (2) implies that

$$
\Delta \log \omega_{t}=\Delta \log (A)+\frac{1}{1-\theta} \Delta \log y_{t}
$$

which combined with Proposition 1 yields

$$
\Delta \log \omega_{t}=\left[\left(\frac{1}{\theta+\kappa \eta}\right)-\frac{\psi}{\chi}\left(1-e^{-\lambda t}\right) \frac{1}{\theta+\kappa \eta}\right](\theta-1) \Delta \log (A) .
$$

Equalizing the two expressions above for $\Delta \log \omega_{t}$, we obtain

$$
\varphi_{t}+\theta=\frac{\theta+\kappa \eta}{1-\frac{\psi}{\chi}\left(1-e^{-\lambda t}\right)},
$$

which implies that

$$
\varphi_{t}=\frac{\kappa \eta \chi+\theta \psi\left(1-e^{-\lambda t}\right)}{(\theta+\kappa \eta)(\delta+\rho)+\psi e^{-\lambda t}} .
$$

This establishes the representation in (20)-(21) that yields the same path for $\Delta \log \omega_{t}$ and $\Delta \log y_{t}$ implied by Proposition 1 . Since $e^{-\lambda t} \leq 1$ for all $t \geq 0$, this expression implies that $\varphi_{t}>0$ for all $t$. In addition, we can verify that $\varphi_{t}$ is increasing over time because

$$
\frac{\partial \varphi_{t}}{\partial t}=\frac{\theta(\theta+\kappa \eta)(\delta+\rho)+\kappa \eta \chi+\theta \psi}{\left((\theta+\kappa \eta)(\delta+\rho)+\psi e^{-\lambda t}\right)^{2}} \psi \lambda e^{-\lambda t}>0 .
$$

\section{A.6 Proof of Proposition 2}

The following proposition first characterizes the induced changes in average welfare $\Delta \bar{U} \equiv \bar{U}_{0}-U_{0^{-}}$and lifetime inequality $\Delta \bar{\Omega} \equiv \bar{\Omega}_{0}-\log \left(q_{0^{-}}\right)$. It is easy to then see that Proposition 2 follows from the expressions for $\Delta \bar{U}$ and $\Delta \Omega$ because, when $r=\delta$, $\frac{r \lambda}{r+\lambda} \int_{0}^{\infty} \frac{\hat{q}_{\tau}}{\Delta \log (A)} d \tau=\operatorname{DCIR}(q)$. 
Proposition 4 (Average welfare and lifetime welfare inequality) The changes in average welfare $\Delta \bar{U}$ and lifetime inequality $\Delta \bar{\Omega}$ are approximately:

$$
\begin{aligned}
& \Delta \bar{U}=\frac{y_{\infty}}{1+y_{\infty}} \Delta \log (A)-\left(\frac{y_{\infty}}{1+y_{\infty}}-\frac{e_{\infty}}{1+e_{\infty}}\right) \Delta \bar{\Omega} \\
& \Delta \bar{\Omega}=(\rho+\delta)\left(\Delta \log \left(q_{\infty}\right)+\frac{\lambda r}{r+\lambda} \int_{0}^{\infty} \hat{q}_{\tau} d \tau\right)
\end{aligned}
$$

where $e_{\infty} \equiv\left(\int_{l_{\infty}}^{1} s(i) d i\right) /\left(\int_{0}^{l_{\infty}} s(i) d i\right)$ is the relative high-tech employment in the long-run.

\section{Proof.}

We have that, because of the envelope theorem, for any $\tau \geq 0^{-}$

$$
\begin{aligned}
U_{\tau} & =\int \tilde{s}_{\tau}(i) V_{\tau}(i) d i-\frac{1}{\psi} \int \tilde{s}_{\tau}(i) \log \left(\frac{\tilde{s}_{\tau}(i)}{\bar{s}(i)}\right) d i \\
& \approx \int s(i)\left(V_{\tau}(i)-V(i)\right) d i+U_{\infty}
\end{aligned}
$$

Then, for $\tau \geq 0$

$$
\begin{aligned}
U_{\tau}-U_{\infty} & =\int_{\tau}^{\infty} e^{-(\rho+\delta)(t-\tau)} \int s(i) \log \left(\frac{\alpha(i) \max \left(\omega_{t} \sigma(i), 1\right)}{P_{t}}\right) d i d t \\
& -\int_{0}^{\infty} e^{-(\rho+\delta) t} \int s(i) \log \left(\frac{\alpha(i) \max (\omega \sigma(i), 1)}{P}\right) d i d t \\
& \approx \int_{l}^{1} s(i) d i\left(\int_{\tau}^{\infty} e^{-(\rho+\delta+\lambda)(t-\tau)} \hat{\omega}_{\tau} d t\right)-\left(\int_{\tau}^{\infty} e^{-(\rho+\delta+\lambda)(t-\tau)} \hat{P}_{\tau} d t\right) \\
& =-\left(\frac{y_{\infty}}{1+y_{\infty}} \frac{1}{1-\theta} \hat{y}_{0}-\int_{l}^{1} s(i) d i \hat{\omega}_{0}\right) \frac{1}{\rho+\delta+\lambda} e^{-\lambda \tau} \\
& =-\left(\frac{y_{\infty}}{1+y_{\infty}}-\int_{l}^{1} s(i) d i\right) \hat{q}_{\tau}
\end{aligned}
$$

Also, for $\tau=0^{-}$

$$
\begin{aligned}
U_{\infty}-U_{0^{-}} & \approx\left(\int_{l}^{1} s(i) d i\right) \frac{1}{\rho+\delta} \Delta \log \left(\omega_{\infty}\right)+\frac{y_{\infty}}{1+y_{\infty}} \frac{1}{\theta-1} \frac{1}{\rho+\delta} \Delta \log \left(y_{\infty}\right) \\
& =\left(\int_{l}^{1} s(i) d i\right) \frac{1}{\rho+\delta} \Delta \log \left(\omega_{\infty}\right)+\frac{y_{\infty}}{1+y_{\infty}} \frac{1}{\rho+\delta}\left(\Delta \log (A)-\Delta \log \left(\omega_{\infty}\right)\right) \\
& =\frac{y_{\infty}}{1+y_{\infty}} \frac{1}{\rho+\delta} \Delta \log (A)-\left(\frac{y_{\infty}}{1+y_{\infty}}-\int_{l}^{1} s(i) d i\right) \Delta \log \left(q_{\infty}\right)
\end{aligned}
$$


Then,

$$
\begin{aligned}
\Delta \bar{U} & =(\rho+\delta)\left(U_{\infty}-U_{0^{-}}\right)+(\rho+\delta) r \int_{0}^{\infty} e^{-r \tau}\left(U_{\tau}-U_{\infty}\right) d \tau \\
& \approx(\rho+\delta)\left(U_{\infty}-U_{0^{-}}\right)-\left(\frac{y_{\infty}}{1+y_{\infty}}-\int_{l}^{1} s(i) d i\right)(\rho+\delta) r \int_{0}^{\infty} e^{-r \tau} \hat{q}_{\tau} d \tau \\
& =\frac{y_{\infty}}{1+y_{\infty}} \Delta \log (A)-\left(\frac{y_{\infty}}{1+y_{\infty}}-\int_{l}^{1} s(i) d i\right) \Delta \bar{\Omega}
\end{aligned}
$$

Finally, using Proposition 1,

$$
\begin{aligned}
\Delta \bar{\Omega} & =(\rho+\delta) r \int_{0}^{\infty} e^{-r \tau} \Delta \log \left(q_{\tau}\right) d \tau \\
& =(\rho+\delta) \Delta \log \left(q_{\infty}\right)+(\rho+\delta) r \int_{0}^{\infty} e^{-r \tau} \hat{q}_{\tau} d \tau \\
& \approx(\rho+\delta) \Delta \log \left(q_{\infty}\right)+(\rho+\delta) \frac{r}{r+\lambda} \hat{q}_{0} \\
& \approx(\rho+\delta) \Delta \log \left(q_{\infty}\right)+(\rho+\delta) \frac{r \lambda}{r+\lambda} \int_{0}^{\infty} \hat{q}_{\tau} d \tau
\end{aligned}
$$

\section{A.7 Comparative Statics with respect to $\eta$ and $\psi$}

Proposition A.1 (Comparative statics with respect to $\eta$ ) Assume that $\theta>1$. Then,

1. Short-run adjustment

$$
\frac{\partial \Delta \log \left(y_{0}\right)}{\partial \eta}>0, \quad \frac{\partial\left|\Delta \log \left(l_{0}\right)\right|}{\partial \eta}>0, \quad \frac{\partial \Delta \log \left(q_{0}\right)}{\partial \eta}<0 ;
$$

2. Long-run adjustment

$$
\frac{\partial \Delta \log \left(y_{\infty}\right)}{\partial \eta}>0, \quad \frac{\partial\left|\Delta \log \left(l_{\infty}\right)\right|}{\partial \eta}>0, \quad \frac{\partial \Delta \log \left(q_{\infty}\right)}{\partial \eta}<0 ;
$$

3. Rate of convergence

$$
\frac{\partial \lambda}{\partial \eta}<0
$$

4. Cumulative impulse response

$$
\frac{\partial\left(\int_{0}^{\infty}\left|\hat{y}_{t}\right| d t\right)}{\partial \eta}<0, \quad \frac{\partial\left(\int_{0}^{\infty}\left|\hat{l}_{t}\right| d t\right)}{\partial \eta} \stackrel{?}{\risingdotseq} 0, \quad \frac{\partial\left(\int_{0}^{\infty} \hat{q}_{t} d t\right)}{\partial \eta}<0 ;
$$


Proposition A.2 (Comparative statics with respect to $\psi$ ) Assume that $\theta>1$. Then,

1. Short-run adjustment

$$
\frac{\partial \Delta \log \left(y_{0}\right)}{\partial \psi}=0, \quad \frac{\partial\left|\Delta \log \left(l_{0}\right)\right|}{\partial \psi}=0, \quad \frac{\partial \Delta \log \left(q_{0}\right)}{\partial \psi}<0
$$

2. Long-run adjustment

$$
\frac{\partial \Delta \log \left(y_{\infty}\right)}{\partial \psi}>0, \quad \frac{\partial\left|\Delta \log \left(l_{\infty}\right)\right|}{\partial \psi}<0, \quad \frac{\partial \Delta \log \left(q_{\infty}\right)}{\partial \psi}<0
$$

3. Rate of convergence

$$
\frac{\partial \lambda}{\partial \psi}>0
$$

4. Cumulative impulse response

$$
\left.\frac{\partial\left(\int_{0}^{\infty}\left|\hat{y}_{t}\right| d t\right)}{\partial \psi}\right|_{\psi=0}>0,\left.\quad \frac{\partial\left(\int_{0}^{\infty}\left|\hat{l}_{t}\right| d t\right)}{\partial \psi}\right|_{\psi=0}>0,\left.\quad \frac{\partial\left(\int_{0}^{\infty} \hat{q}_{t} d t\right)}{\partial \psi}\right|_{\psi=0}>0
$$

Next, we prove each of the items of the two propositions above.

1. Short-run adjustment

$$
\begin{aligned}
\Delta \log \left(y_{0}\right) & =\left(1-\frac{\theta-1}{\theta+\kappa \eta}\right)(\theta-1) \Delta \log (A) \\
\Delta \log \left(q_{0}\right) & =\frac{1}{\theta+\kappa \eta+\frac{\psi}{\rho+\delta}} \frac{\lambda}{\delta} \frac{1}{\rho+\delta}(\theta-1) \Delta \log (A) \\
& =\frac{1}{\theta+\kappa \eta} \frac{1}{\rho+\lambda}(\theta-1) \Delta \log (A) \\
\left|\Delta \log \left(l_{0}\right)\right| & =\frac{\eta}{\theta+\kappa \eta}(\theta-1) \Delta \log (A)
\end{aligned}
$$

The first and last lines show that $\Delta \log \left(y_{0}\right),\left|\Delta \log \left(l_{0}\right)\right|$ are increasing in $\eta$ and independent of $\psi$. Since $\lambda$ is decreasing in $\eta$, the second line shows that $\Delta \log \left(q_{0}\right)$ is decreasing in $\eta$. Since $\lambda$ is increasing in $\psi$, the third line shows that $\Delta \log \left(q_{0}\right)$ is decreasing in $\psi$. 
2. Long-run adjustment

$$
\begin{aligned}
\Delta \log \left(y_{\infty}\right) & =\left(1-\frac{\theta-1}{\theta+\kappa \eta+\frac{\psi}{\rho+\delta}}\right)(\theta-1) \Delta \log (A) \\
\Delta \log \left(q_{\infty}\right) & =\frac{1}{\theta+\kappa \eta+\frac{\psi}{\rho+\delta}} \frac{1}{\rho+\delta}(\theta-1) \Delta \log (A) \\
\Delta \log \left(l_{\infty}\right) & =-\frac{\eta}{\theta+\kappa \eta+\frac{\psi}{\rho+\delta}}(\theta-1) \Delta \log (A)
\end{aligned}
$$

Then, it is straightforward to see that $\Delta \log \left(y_{\infty}\right)$ is increasing in both $\eta$ and $\psi$, while the opposite holds for $\Delta \log \left(q_{\infty}\right)$. Moreover,,$\left|\Delta \log \left(l_{\infty}\right)\right|$ is increasing in $\eta$ but decreasing in $\psi$.

3. Rate of convergence

From the expression for $\lambda$ in Theorem 1 it is straightforward to see that is decreasing in $\eta$ and increasing in $\psi$.

4. Cumulative impulse response

$$
\begin{aligned}
\int_{0}^{\infty}\left|\hat{y}_{t}\right| d t & =-\frac{1}{\lambda} \hat{y}_{0}=\frac{1}{\lambda} \frac{\frac{\psi}{\rho+\delta}}{\theta+\kappa \eta+\frac{\psi}{\rho+\delta}} \frac{\theta-1}{\theta+\kappa \eta}(\theta-1) \Delta \log (A) \\
\int_{0}^{\infty} \hat{q}_{t} d t & =\frac{1}{\lambda} \hat{q}_{0}=\frac{1}{\theta+\eta \kappa+\frac{\psi}{\rho+\delta}} \frac{\lambda-\delta}{\lambda} \frac{1}{\delta} \frac{1}{\rho+\delta}(\theta-1) \Delta \log (A) \\
\int_{0}^{\infty}\left|\hat{l}_{t}\right| d t & =\frac{\eta}{\theta-1} \int_{0}^{\infty}\left|\hat{y}_{t}\right| d t
\end{aligned}
$$

The second line shows that $\int_{0}^{\infty} \hat{q}_{t} d t$ is decreasing in $\eta$, since $\lambda$ is decreasing in $\eta$. Furthermore, $\int_{0}^{\infty} \hat{q}_{t} d t$ is increasing in $\psi$ around $\psi=0$. This is because $\lambda$ is increasing in $\psi, \lambda=\delta$ when $\psi=0$, and $\frac{\partial\left(\frac{1}{\lambda} \frac{1}{\theta+\kappa \eta+\frac{\psi}{\rho+\delta}}\right)}{\partial \psi}$ is bounded.

The first line shows that $\int_{0}^{\infty}\left|\hat{y}_{t}\right| d t$ is increasing in $\psi$ around $\psi=0$ since $\frac{\partial\left(\frac{1}{\lambda} \frac{\frac{1}{\rho+\delta}}{\theta+\kappa \eta+\frac{\psi}{\rho+\delta}}\right)}{\partial \psi}$ is bounded. To show that it is decreasing in $\eta$, we show that: 


$$
\begin{aligned}
\frac{\partial \log \left(\frac{1}{\lambda} \frac{\frac{\psi}{\rho+\delta}}{\theta+\kappa \eta+\frac{\psi}{\rho+\delta}} \frac{\theta-1}{\theta+\kappa \eta}\right)}{\partial \eta} & =\frac{1}{\lambda} \frac{1}{\rho+2 \lambda} \frac{\psi \delta \kappa}{(\theta+\kappa \eta)^{2}}-\frac{\kappa}{\theta+\kappa \eta+\frac{\psi}{\rho+\delta}}-\frac{\kappa}{\theta+\kappa \eta} \\
& =-\left(\left(1-\frac{\lambda-\delta \rho+\delta+\lambda}{\frac{\lambda}{\lambda} \frac{\rho}{\rho+2 \lambda}}\right) \frac{1}{(\theta+\kappa \eta)}+\frac{1}{\theta+\kappa \eta+\frac{\psi}{\rho+\delta}}\right) \kappa<0
\end{aligned}
$$

Finally, $\int_{0}^{\infty}\left|\hat{l}_{t}\right| d t$ is increasing in $\psi$ around $\psi=0$, since it is proportional to $\int_{0}^{\infty}\left|\hat{y}_{t}\right| d t$. However, the derivative with respect to $\eta$ is ambiguous. This is because the constant of proportionality $\eta /(\theta-1)$ is increasing in $\eta$ while $\int_{0}^{\infty}\left|\hat{y}_{t}\right| d t$ is decreasing in $\eta$

\section{A.8 Proof of Proposition 3}

From the proof of Proposition A.1 in Appendix A.7, we have that

$\operatorname{DCIR}(q)=\frac{\delta \lambda}{\lambda+\delta} \frac{\int_{0}^{\infty}\left|\hat{q}_{t}\right| d t}{\Delta \log (A)}=\left(\frac{1}{\theta+\eta \kappa+\frac{\psi}{\rho+\delta}} \frac{\delta}{\lambda+\delta}\right)(\lambda-\delta) \frac{|\theta-1|}{\delta(\rho+\delta)}$

$\operatorname{DCIR}(y)=\frac{\delta \lambda}{\lambda+\delta} \frac{\int_{0}^{\infty}\left|\hat{y}_{t}\right| d t}{\Delta \log (A)}=\frac{\delta}{\lambda+\delta} \frac{\frac{\psi}{\rho+\delta}}{\theta+\kappa \eta+\frac{\psi}{\rho+\delta}} \frac{(\theta-1)^{2}}{\theta+\kappa \eta}=\frac{\delta}{\lambda+\delta} \frac{(\rho+\delta+\lambda)}{\lambda(\rho+\lambda)}(\lambda-\delta) \frac{(\theta-1)^{2}}{(\theta+\kappa \eta)^{2}}$.

The definition of $\lambda$ in Theorem 1 implies that $\left.\lambda\right|_{\psi \rightarrow 0}=\left.\lambda\right|_{\theta \rightarrow \infty}=\delta$ and $\left.\frac{\partial \lambda}{\partial \eta}\right|_{\psi \rightarrow 0}=$ $\left.\frac{\partial \lambda}{\partial \eta}\right|_{\theta \rightarrow \infty}=0$. Taken together, they immediately imply that $\left.\frac{\partial D C I R(q)}{\partial \eta}\right|_{\psi \rightarrow 0}=\left.\frac{\partial D C I R(q)}{\partial \eta}\right|_{\theta \rightarrow \infty}=$ 0 and $\left.\frac{\partial D C I R(y)}{\partial \eta}\right|_{\psi \rightarrow 0}=\left.\frac{\partial D C I R(y)}{\partial \eta}\right|_{\theta \rightarrow \infty}=0$

\section{A.9 Proof of Theorem 3}

We start by deriving the elasticity of relative employment of old generations with respect to $\Delta \log (A)$. We first use a first-order approximation to write the log-change in relative high-tech employment in terms of changes in the high-tech employment share:

$$
\varepsilon_{0}^{\text {within }} \approx \frac{1}{\Delta \log (A)} \frac{1}{e_{\infty}\left(1-e_{\infty}\right)}\left(\int_{l_{0}}^{1} s_{0}(i) d i-\int_{l_{0^{-}}}^{1} s_{0}(i) d i\right)
$$

Taking a first-order approximation around $l$, 


$$
\begin{aligned}
\int_{l_{0}}^{1} s_{0}(i) d i-\int_{l_{0^{-}}}^{1} s_{0}(i) d i & \approx-s_{0}(l) l\left(\hat{l}_{t}+\Delta \log \left(l_{\infty}\right)\right) \\
& \approx s_{0}(l) \ln \Delta \log \left(\omega_{t}\right) \\
& \approx \frac{s_{0}(l) l}{e_{\infty}\left(1-e_{\infty}\right)} \eta\left(-\frac{1}{\theta-1} \Delta \log y_{0}+\Delta \log A\right) .
\end{aligned}
$$

where the last line uses the demand expression in (2).

Then, using Proposition 1,

$$
\varepsilon_{0}^{\text {within }} \approx \frac{s_{0}(l) l}{e_{\infty}\left(1-e_{\infty}\right)} \frac{\eta}{\theta+\kappa \eta}(\theta-1)
$$

Thus,

$$
\frac{\partial\left|\varepsilon_{0}^{\text {within }}\right|}{\partial \eta}=\frac{s_{0}(l) l}{e_{\infty}\left(1-e_{\infty}\right)} \frac{\theta}{(\theta+\kappa \eta)^{2}}|\theta-1|>0 \quad \text { and } \quad \frac{\partial\left|\varepsilon_{0}^{\text {within }}\right|}{\partial \psi}=0 .
$$

We first use a first-order approximation to write the relative high-tech employment in terms of changes in the high-tech employment share:

$$
\begin{aligned}
\varepsilon_{0}^{\text {cross }} & \approx \frac{1}{e_{\infty}\left(1-e_{\infty}\right)} \frac{1}{\Delta \log A}\left(\int_{l_{0}}^{1}\left(\tilde{s}_{0}(i)-s_{0}(i)\right) d i\right) \\
& \approx \frac{1}{e_{\infty}\left(1-e_{\infty}\right)} \frac{1}{\Delta \log A}\left(\int_{l}^{1} s(i)\left(\hat{\tilde{s}}_{0}(i)-\hat{s}_{0}(i)\right) d i\right)
\end{aligned}
$$

To write this expression in term of fundamentals, we derive the changes in the skill distribution between stationary equilibria. Using the expression for the stationary skill distribution in (A.1),

$$
\begin{aligned}
& s_{0}(i)=\frac{\bar{s}(i) \alpha(i)^{\frac{\psi}{\rho+\delta}}\left(\omega_{0}-\sigma(i)\right)^{\frac{\psi}{\rho+\delta}} \mathbb{I}_{i>l_{0}}}{\int_{0}^{l_{0^{-}}} \bar{s}(j) \alpha(j)^{\frac{\psi}{\rho+\delta}} d j+\int_{l_{0^{-}}}^{1} \bar{s}(j) \alpha(j)^{\frac{\psi}{\rho+\delta}}\left(\omega_{0^{-}} \sigma(j)\right)^{\frac{\psi}{\rho+\delta}} d j} \\
& \Longrightarrow \\
& \hat{s}_{0}(i) \approx-\left(\mathbb{I}_{i>l}-\int_{l}^{1} s(j) d j\right) \frac{\psi}{\rho+\delta} \Delta \log (\omega)
\end{aligned}
$$

Recall also that the third part of Theorem 1 yields

$$
\hat{\tilde{s}}_{0}(i)=\left(\mathbb{I}_{i>l}-\int_{l}^{1} s(i) d i\right) \psi \hat{q}_{0}+o_{0}(i) .
$$

Combining the expressions above, 


$$
\begin{aligned}
\varepsilon_{0}^{\text {cross }} & \approx \frac{1}{\Delta \log A}\left(\psi \hat{q}_{0}+\frac{\psi}{\rho+\delta} \Delta \log (\omega)\right) \\
& \approx \frac{1}{\Delta \log A} \psi\left(\hat{q}_{0}+\Delta \log \left(q_{\infty}\right)\right) \\
& \approx \frac{1}{\Delta \log A} \psi \Delta \log \left(q_{0}\right)
\end{aligned}
$$

Using the expression for $\Delta \log \left(q_{0}\right)$ in Proposition 1,

$$
\varepsilon_{0}^{\text {cross }} \approx \frac{\psi}{(\rho+\lambda)(\theta+\kappa \eta)}(\theta-1) .
$$

Using the expressions derived in Appendix A.8 and defining $\varrho \equiv\left(\frac{\rho}{2}\right)^{2}+\delta\left((\rho+\delta)+\frac{\psi}{\theta+\kappa \eta}\right)$, we obtain

$$
\begin{aligned}
\frac{\partial\left|\varepsilon_{0}^{\text {cross }}\right|}{\partial \psi} & =\frac{1-e_{\infty}}{(\theta+\kappa \eta)(\rho+\lambda)^{2}}\left(\rho+\lambda-\psi \frac{\partial \lambda}{\partial \psi}\right)|\theta-1| \\
& =\frac{1}{(\theta+\kappa \eta)(\rho+\lambda)^{2}}\left(\frac{\rho}{2}+\varrho^{1 / 2}-\frac{1}{2} \varrho^{-1 / 2} \frac{\delta \psi}{\theta+\kappa \eta}\right)|\theta-1| \\
& =\frac{1}{(\theta+\kappa \eta)(\rho+\lambda)^{2}} \varrho^{-1 / 2}\left(\frac{\rho}{2} \varrho^{-1 / 2}+\varrho-\frac{1}{2} \frac{\delta \psi}{\theta+\kappa \eta}\right)|\theta-1| \\
& =\frac{1}{(\theta+\kappa \eta)(\rho+\lambda)^{2}} \varrho^{-1 / 2}\left(\frac{\rho}{2} \varrho^{-1 / 2}+\left(\frac{\rho}{2}\right)^{2}+\delta(\rho+\delta)+\frac{1}{2} \frac{\delta \psi}{\theta+\kappa \eta}\right)|\theta-1|,
\end{aligned}
$$

which implies that $\frac{\partial\left|\varepsilon_{0}^{\text {cross }}\right|}{\partial \psi}>0$.

Using the expressions derived in Appendix A.8,

$$
\begin{aligned}
\frac{\partial\left|\varepsilon_{0}^{\text {cross }}\right|}{\partial \eta} & =-\left(1-e_{\infty}\right) \frac{\psi}{[(\rho+\lambda)(\theta+\kappa \eta)]^{2}}\left(\kappa(\rho+\lambda)+(\theta+\kappa \eta) \frac{\partial \lambda}{\partial \eta}\right)|\theta-1| \\
& =-\frac{\psi}{[(\rho+\lambda)(\theta+\kappa \eta)]^{2}} \kappa \varrho^{-1 / 2}\left(\frac{\rho}{2} \varrho^{-1 / 2}+\varrho-\frac{1}{2} \frac{\delta \psi}{(\theta+\kappa \eta)}\right)|\theta-1| \\
& =-\frac{\psi}{[(\rho+\lambda)(\theta+\kappa \eta)]^{2}} \kappa \varrho^{-1 / 2}\left(\frac{\rho}{2} \varrho^{-1 / 2}+\left(\frac{\rho}{2}\right)^{2}+\delta(\rho+\delta)+\frac{1}{2} \frac{\delta \psi}{(\theta+\kappa \eta)}\right)|\theta-1|,
\end{aligned}
$$

which implies that $\frac{\partial\left|\varepsilon_{0}^{\text {cross }}\right|}{\partial \eta}<0$. 


\section{Appendix B Dynamic adjustment to broadband internet adoption across regions and occupations}

Data construction. The raw data in the LIAB comes in the form of entire job histories of workers in the sample. Individual entries therefore contain worker information, as well as information on the start and end date of a job spell for that individual, the location (establishment), and characteristics of the job spell. We transform this data into an annual panel dataset following the steps in Card et al. (2013), with minor modifications. Specifically, we sequentially restrict our sample by selecting (i) males in West Germany, (ii) those aged 15-64 years at the time of the job spell, and (iii) the job-spell within a calendar year with maximum earnings. We then adjust wages by (i) deflating earnings using German CPI information from FRED (Series id: DEUCPIALLMINMEI) and (ii) replacing daily wages with Upper Earnings Limits in Card et al. (2013) for daily wages above censor limit. Finally, we impute each individual's district of employment using the district of the establishment of the individual's main job in each year. Since this information only exists after 1999, we assign the establishment's district in 1999 to 19951998.

While the years represented in our data and our underlying data sample differ from those of Card et al. (2013), our panel well represents the data used in that paper. In results available upon request, we attest that the mean wage changes of job movers, classified by the mean log wages of coworkers in their old and new establishments, is similar in our data to the main findings in Card et al. (2013) (their Figure Vb).

Instrumental Variables. We link our LIAB-based worker panel to the DSL access data from Falck et al. (2014) using the district identifiers in both datasets. We then construct the instrumental variables discussed in Section 7.3. Figure B.1 illustrates the spatial variation of the instruments used to estimate our baseline results.

We start by examining the first-stage regression that relates the initial telephone network to DSL access. Although the unit of observation in equation (23) is a districtoccupation-generation triple, the exogenous variation in the instrument vector comes only from cross-district variation. Therefore, to provide a clear picture of the exogenous variation underlying the first-stage regression, we first examine the impact of the instrument vector $Z_{i}$ on the district's share of population with broadband internet access in 2005, $D S L_{i}$. That is, we begin by estimating the following linear regression:

$$
D S I_{i}=Z_{i} \rho+X_{i} \gamma+\epsilon_{i}
$$

where $Z_{i}$ is the vector of instruments described in 7 and $X_{i}$ is the vector of district-level controls used in the estimation of (23). We refer to the first instrument as "MDF Density Measure" (number of municipalities in the district without a MDF in a 4200m radius) and to the second instrument as "Alternative MDF Availability" (number of municipalities in the district without a MDF in a $4200 \mathrm{~m}$ radius and without access to an alternative MDF in a neighboring district in a $4200 \mathrm{~m}$ radius).

Table B.1 shows that districts with adverse initial conditions for internet adoption had a lower share of households with high-speed internet in 2005. Columns (1) reports the first-stage estimates controlling for the baseline set of district-level controls. We can see 
that the F statistic of excluded variables remains high in the presence of these controls.

As discussed in Section 7, equation (23) has multiple endogenous variables since they include DSL access interacted with occupation cognitive intensity and worker generation dummies. Table B.2 tests for weak instruments. We obtain uniformly high firststage Sanderson-Windmeijer F-statistics (Sanderson and Windmeijer, 2016) in all specifications, indicating that there are sufficiently many strong instruments to instrument the multiple endogenous variables.

Figure B.1: Spatial Variation in the Instrumental Variables
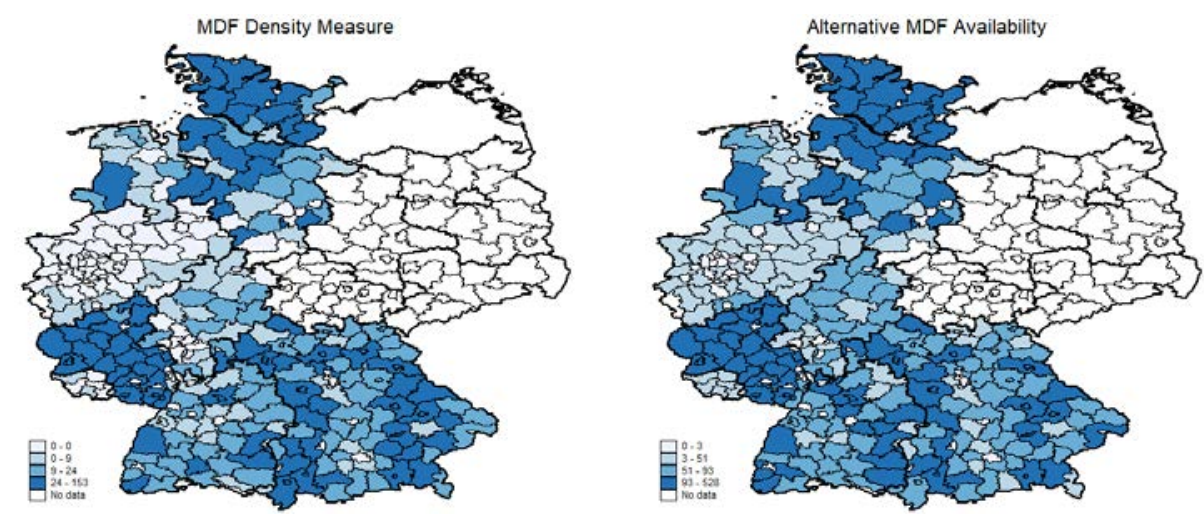

Note. Panel A illustrates the number of municipalities across districts in Germany that did not have access to an MDF within the $4200 \mathrm{~m}$ radius ("MDF Density Measure"), as described in Section 6.2. Panel B illustrates the number of municipalities across districts that did not have their own MDF and did not have access to an alternative MDF in a neighboring district "Alternative MDF Availability".

Table B.1: First-stage regressions - Share of households with DSL access in 2005

\begin{tabular}{lcc}
\hline & $(1)$ & $(2)$ \\
\hline \hline MDF density measure & $-0.020^{* * *}$ & $-0.018^{* * *}$ \\
& $(0.005)$ & $(0.005)$ \\
Alternative MDF availability & 0.002 & -0.001 \\
& $(0.001)$ & $(0.002)$ \\
\hline Baseline controls & Yes & No \\
F statistic & 26.49 & 43.06 \\
\hline
\end{tabular}

Note. Sample of 323 districts in West Germany. All regressions are weighted by the district population size in 1999. Baseline controls include the following district variables in 1999: college graduate population share, manufacturing employment share, immigrant employment share and workforce age composition. Robust standard errors in parentheses. ${ }^{*} p<0.1,{ }^{* *} p<0.05,{ }^{* * *} p<0.01$

Table B.2: First-stage SW F-statistics for estimation of equation (23) in Panel A of Figure 7

\begin{tabular}{llll}
\hline Instrumented Variable & 1997 & 2007 & 2014 \\
\hline \hline Young Generation*DSL Access & 18.74 & 18.78 & 19.04 \\
Old Generation* DSL Access & 19.04 & 17.57 & 20.45 \\
Young Generation*DSL Access*Cognitive Intensity & 21.95 & 20.48 & 19.77 \\
Old Generation*DSL Access*Cognitive Intensity & 21.31 & 18.57 & 22.32 \\
\hline
\end{tabular}

Note. Sample of 2 cohorts, 120 occupations and 323 districts. Table reports the Sanderson-Windmeijer F-statistic for each endogenous regressor when estimating equation (23). 


\section{Online Appendix (not for publication)}

\section{Appendix 1 Theoretical Analysis}

\subsection{Microfoundation of the Production Functions in equations (4)-(5) of the paper}

Consider two firms: high-tech $(k=H)$ and low-tech $(k=L)$. Assume that the output of firm $k$ at time $t$ aggregates per-worker output $x_{k t}(i)$,

$$
X_{k t}=\int_{0}^{1} x_{k t}(i) s_{k t}(i) d i
$$

where $s_{k t}(i)$ is the quantity demanded of workers of type $i$ at time $t$ by firm $k$.

The output of workers of type $i$ depends on their skills to perform cognitive and noncognitive tasks, $\left\{a_{C}(i), a_{N C}(i)\right\}$, as well as how intensely each task is used in the firm's production process:

$$
x_{k t}(i)=a_{C}(i)^{\beta_{k}} a_{N C}(i)^{1-\beta_{k}},
$$

where $\beta_{k}$ denotes the production intensity of firm $k$ on cognitive tasks.

In our model, technology-skill specificity arises whenever firms are heterogeneous in terms of task intensity and workers are heterogeneous in terms of their skills bundle. To see this, suppose that firm $H^{\prime}$ 's technology uses cognitive tasks more intensely than firm $L$ 's technology, $\beta_{H}>\beta_{L}$, and that a worker of type $i$ is able to produce a higher cognitive-noncognitive task ratio than a worker of type $j, a_{C}(i) / a_{N C}(i)>a_{C}(j) / a_{N C}(j)$. In this case, $i$ has a higher relative output with the cognitive-intensive technology $H$ than $j, x_{H t}(i) / x_{L t}(i)>x_{H t}(j) / x_{L t}(j)$, and, therefore, type $i$ is more complementary to the cognitive-intensive technology $H$ than type $j$.

To map this setting to the production functions in equations (4)-(5) of the paper, we assume that high-tech production is more intensive in cognitive tasks than low-tech production, $\beta_{H}>\beta_{L}$. We also assume that types differ in terms of their skill bundle and, without loss of generality, impose that high- $i$ types are relatively better in performing cognitive-intensive tasks.

1. High-tech technology $H$ uses cognitive tasks more intensely than Low-tech technology $L: \beta_{H}>\beta_{L}$.

2. Define $\sigma(i) \equiv\left(\frac{a_{C}(i)}{a_{N C}(i)}\right)^{\beta_{H}-\beta_{L}}$ and $\alpha(i) \equiv a_{C}(i)^{\beta_{L}} a_{N C}(i)^{1-\beta_{L}}$. Assume that high- $i$ types have higher cognitive-noncognitive task ratio: $\sigma(i)$ is increasing in $i$.

\subsection{Extensions}

This section discusses the extensions described in Section 5. 


\subsubsection{Learning-from-others}

We relax the assumption that the reference distribution $\bar{s}_{\tau}(i)$ in the skill investment problem is exogenous and fixed over time. Instead, we assume that certain skills may be easier to acquire than others because workers can "learn from others" when such skills are already abundant in the economy. Formally, we assume that the baseline distribution $\bar{s}_{\tau}(i)$ is a geometric average of a fixed distribution $\bar{\epsilon}(i)$ and the current skill distribution in the economy $s_{\tau}(i)$ at the time where generation $\tau$ is born,

$$
\bar{s}_{\tau}(i)=s_{\tau}(i)^{\gamma} \bar{\epsilon}(i)^{1-\gamma}, \quad \gamma \in[0,1) .
$$

Note that as $\gamma$ increases it becomes easier for workers to choose skill lotteries that put more weight in those skill types that are already abundant in the economy. As opposed to our benchmark case $(\gamma=0)$, this extension with $\gamma>0$ introduces a backward-looking element to the skill investment problem and complementarities in skill investment decisions across generations.

In what follows, we reproduce the key steps that change in the proofs in Appendix A.3. First, we log-linearize the extended version of (A.7). We begin by noting that the stationary distribution exist and is

$$
s(i)=\frac{s(i)^{\gamma} \epsilon(i)^{1-\gamma} w(i)^{\frac{\psi}{\rho+\delta}}}{\int_{0}^{1} s(j)^{\gamma} \epsilon(j)^{1-\gamma} w(j)^{\frac{\psi}{\rho+\delta}} d j} \Longrightarrow s(i)=\frac{\epsilon(i) w(i)^{\frac{1}{1-\gamma} \frac{\psi}{\rho+\delta}}}{\int_{0}^{1} \epsilon(i) w(i)^{\frac{1}{1-\gamma} \frac{\psi}{\rho+\delta}} d i} .
$$

Then, we obtain that

$$
\hat{\tilde{s}}_{t}(i)=\gamma\left(\hat{s}_{t}(i)-\hat{s}_{t}(l)\right)+\hat{\tilde{s}}_{t}(l)-\psi \hat{q}_{t} \mathbb{I}_{i<l_{t}}-\psi \hat{q}_{t+\tau(i)} \mathbb{I}_{i \in\left(l_{t}, l\right)} .
$$

Second, replacing the above in the expression inside the parenthesis in (A.5),

$$
\begin{array}{r}
\left(\int_{l}^{1} \hat{\tilde{s}}_{t}(i) \frac{\alpha(i) \sigma(i) s(i)}{\int_{l}^{1} \alpha(i) \sigma(i) s(i) d i} d i-\int_{0}^{l} \hat{\tilde{s}}_{t}(i) \frac{\alpha(i) s(i)}{\int_{0}^{l} \alpha(i) s(i) d i} d i\right)= \\
\gamma \int_{l}^{1} \hat{s}_{t}(i) \frac{\alpha(i) \sigma(i) s(i)}{\int_{l}^{1} \alpha(x) \sigma(x) s(x) d x} d i-\int_{0}^{l}\left(\gamma \hat{s}_{t}(i)-\psi \hat{q}_{t} \mathbb{I}_{i<l_{t}}-\psi \hat{q}_{t+\tau(i)} \mathbb{I}_{i>l_{t}}\right) \frac{\alpha(i) s(i)}{\int_{0}^{l} \alpha(x) s(x) d x} d i= \\
\gamma \frac{\kappa \eta+\theta}{\eta} \hat{l}_{t}+\psi \hat{q}_{t}-\psi \int_{l_{t}}^{l}\left(\hat{q}_{t}-\hat{q}_{t+\tau(i)}\right) \frac{\alpha(i) s(i)}{\int_{0}^{l} \alpha(x) s(x) d x} d i
\end{array}
$$

where the last line uses (A.4) annd (A.3).

Third, as in the proof in Appendix A.3, we can show that the last term inside the integral is of second order. Thus, replacing the above expression back in (A.5), we obtain the Kolmogorov-Forward equation for $\hat{l}_{t}$ in the economy with learning-from-others,

$$
\frac{\partial \hat{l}_{t}}{\partial t}=-\delta(1-\gamma) \hat{l}_{t}+\frac{\eta}{\kappa \eta+\theta} \delta \psi \hat{q}_{t}
$$


Fourth, since the law of motion for $\hat{q}_{t}$ is the same as in the benchmark model, this implies that the equilibrium is saddle-path stable where the new $\lambda$ in the economy with learning-from-others is the positive solution to

$$
(\delta(1-\gamma)-\lambda)(\rho+\delta+\lambda)+\frac{\psi \delta}{\kappa \eta+\theta}=0 .
$$

Finally, the optimal lottery in the economy with learning-from-others is

$$
\hat{\tilde{s}}_{t}(i)=\gamma \hat{s}_{t}(i)+\left(\mathbb{I}_{i>l}-\int_{l}^{1} s(i) d i\right) \psi \hat{q}_{t}+o_{t}(i) .
$$

Next, we reproduce the key steps that change in Appendices A.4 and A.7. First, from the expression for the stationary distribution above, note that the long-run skill supply elasticity in the learning-from-others economy is $\frac{1}{1-\gamma} \psi$ as opposed to simply $\psi$.

This implies that the dynamic responses are

$$
\begin{aligned}
& \Delta \log \left(l_{t}\right)=-\frac{\eta}{\theta+\kappa \eta}\left(1+\frac{1}{\theta+\kappa \eta+\frac{1}{1-\gamma} \frac{\psi}{\rho+\delta}} \frac{1}{1-\gamma} \frac{\psi}{\rho+\delta}\left(e^{-\lambda t}-1\right)\right)(\theta-1) \Delta \log (A) \\
& \Delta \log \left(y_{t}\right)=\frac{1}{\theta+\kappa \eta}\left((1+\kappa \eta)+\frac{(\theta-1)}{\theta+\kappa \eta+\frac{1}{1-\gamma} \frac{\psi}{\rho+\delta}} \frac{1}{1-\gamma} \frac{\psi}{\rho+\delta}\left(1-e^{-\lambda t}\right)\right)(\theta-1) \Delta \log (A) \\
& \Delta \log \left(q_{t}\right)=\frac{1}{\theta+\kappa \eta+\frac{1}{1-\gamma} \frac{\psi}{\rho+\delta}} \frac{1}{\rho+\delta}\left(1+\frac{\lambda-\delta(1-\gamma)}{\delta(1-\gamma)} e^{-\lambda t}\right)(\theta-1) \Delta \log (A)
\end{aligned}
$$

where the last line follows from the equation for the new $\lambda$.

Second, note that the short-run responses for $l_{t}$ and $y_{t}$ are identical than in the benchmark model. The long-run responses are larger (smaller) in magnitude for $y_{t}$ (for $l_{t}$ ) in the economy with learning-from-others since the long-run skill supply elasticity is larger and thus $\frac{1}{\theta+\kappa \eta+\frac{1}{1-\gamma} \frac{\psi}{\rho+\delta}} \frac{1}{1-\gamma} \frac{\psi}{\rho+\delta}$ is larger. As for the DCIR, note that $\lambda$ is smaller in the learning-from-others economy. Together with the fact that $\frac{1}{\theta+\kappa \eta+\frac{1}{1-\gamma} \frac{\psi}{\rho+\delta}} \frac{1}{1-\gamma} \frac{\psi}{\rho+\delta}$ is larger, they imply that the DCIR of both $y_{t}$ and $l_{t}$ is higher in the learning-from-others economy.

Third, for $q_{t}$ we have that

$$
\begin{aligned}
\Delta \log \left(q_{\infty}\right) & =\frac{1}{\theta+\kappa \eta+\frac{1}{1-\gamma} \frac{\psi}{\rho+\delta}} \frac{1}{\rho+\delta}(\theta-1) \Delta \log (A) \\
\Delta \log \left(q_{0}\right) & =\frac{1}{\theta+\kappa \eta} \frac{1}{\left(\rho+\delta+\frac{\psi \delta}{\theta+\kappa \eta} \frac{1}{\rho+\delta+\lambda}\right)}(\theta-1) \Delta \log (A) \\
\int_{0}^{\infty} \hat{q}_{t} d t & =\frac{\frac{1}{1-\gamma} \frac{\psi}{\rho+\delta}}{\theta+\kappa \eta+\frac{1}{1-\gamma} \frac{\psi}{\rho+\delta}} \frac{1}{\rho+\delta+\lambda} \frac{1}{\lambda} \frac{1}{\theta+\kappa \eta}(\theta-1) \Delta \log (A) .
\end{aligned}
$$


Then, since $\lambda$ is smaller, the short- and long-run responses are smaller in magnitude and the DCIR is larger in the economy with learning-from-others.

Finally, we note that the proofs for the comparative statics in Appendix A.7 with respect to $\eta$ and $\psi$ are unchanged. To see this, it suffices to show that the dynamics for $q_{t}, l_{t}, y_{t}$ in the economy with learning-from-others are equivalent to those from a re-parameterized benchmark economy where $\delta^{\prime}=\delta(1-\gamma), \psi^{\prime}=\frac{1}{1-\gamma} \psi$ and $\rho^{\prime}=\rho+\delta \gamma$.

\subsubsection{Old generations skill investment}

We now let a fraction of workers that were present before the shock re-optimize their skill investment "as if" they were a young generation entering at time $t=0$. Formally, the skill distribution on impact now becomes

$$
s_{0}(i)=(1-\beta) s_{0^{-}}(i)+\beta \tilde{s}_{0}(i),
$$

where $\beta$ is the fraction of workers in the generation present before the shock that can re-optimize.

The first thing to note is that this does not change any of the transitional dynamics given the new initial skill distribution on impact. As such Theorem 1 is unchanged. However, the initial conditions and the dynamic responses do change. Next, we reproduce the key steps that change in Appendix A.4.

The deviation from the skill distribution on impact from the new stationary distribution is now

$$
\begin{aligned}
\hat{s}_{0}(i) & =\hat{s}_{0^{-}}(i)+\beta\left(\hat{\hat{s}}_{0}(i)-\hat{s}_{0^{-}}(i)\right) \\
& =(1-\beta)\left(\hat{s}_{0}(l)-\mathbb{I}_{i>l} \frac{\psi}{\rho+\delta} \Delta \log (\omega)\right)+\beta\left(\mathbb{I}_{i>l}-\int_{l}^{1} s(i) d i\right) \psi \hat{q}_{0}+\beta o(i)
\end{aligned}
$$

where the long-run change $\Delta \log (\omega)$ is the same as in the benchmark model.

Following the same steps as in the benchmark proof, this then implies that

$$
\begin{aligned}
\left(\frac{\theta}{\eta}+\kappa\right) \hat{l}_{0} & =\int_{l}^{1} \frac{\sigma(i) \alpha(i) s(i)}{\int_{l}^{1} \sigma(i) \alpha(i) s(i)} \hat{s}_{0}(i) d i-\int_{0}^{l} \frac{\alpha(i) s(i)}{\int_{0}^{l} \alpha(i) s(i)} \hat{s}_{0}(i) d i \\
& =-(1-\beta) \frac{\psi}{\rho+\delta} \Delta \log (\omega)+\beta \psi \hat{q}_{0} .
\end{aligned}
$$


Thus,

$$
\begin{aligned}
\hat{\omega}_{0} & =-\frac{1}{\eta} \hat{l}_{0} \\
& =\frac{1}{\theta+\kappa \eta}\left(\frac{\psi}{\rho+\delta} \Delta \log (\omega)-\beta\left(\frac{\psi}{\rho+\delta} \Delta \log (\omega)+\psi \hat{q}_{0}\right)\right) \\
& =\frac{1}{\theta+\kappa \eta}\left(\frac{\psi}{\rho+\delta} \Delta \log (\omega)-\beta\left(\frac{\psi}{\rho+\delta} \Delta \log (\omega)+\frac{\psi}{\rho+\delta+\lambda} \hat{\omega}_{0}\right)\right) \\
& =\frac{1-\beta}{1+\beta \frac{\psi}{\rho+\delta+\lambda} \frac{1}{\theta+\kappa \eta}} \frac{1}{\theta+\kappa \eta} \frac{\psi}{\rho+\delta} \Delta \log (\omega) .
\end{aligned}
$$

Finally, using the above together with the expression for $\Delta \log (\omega)$ in equations (A.9)(A.11), we obtain:

$$
\begin{aligned}
& \Delta \log \left(y_{t}\right)=\frac{1}{\theta+\kappa \eta}\left(1+\kappa \eta+(\theta-1) \frac{\psi}{\chi}\left(1-\frac{1-\beta}{1+\beta \frac{\lambda-\delta}{\delta}} e^{-\lambda t}\right)\right)(\theta-1) \Delta \log (A) \\
& \Delta \log \left(q_{t}\right)=\frac{1}{\chi}\left(1+\frac{\lambda-\delta}{\delta} \frac{1-\beta}{1+\beta \frac{\lambda-\delta}{\delta}} e^{-\lambda t}\right)(\theta-1) \Delta \log (A) \\
& \Delta \log \left(l_{t}\right)=-\frac{\eta}{\theta+\kappa \eta}\left(1+\frac{\psi}{\chi}\left(\frac{1-\beta}{1+\beta \frac{\lambda-\delta}{\delta}} e^{-\lambda t}-1\right)\right)(\theta-1) \Delta \log (A)
\end{aligned}
$$

Then, mathematically, the dynamic responses in the economy where old generations can re-optimize their skills are similar to those in the benchmark economy except that the function $e^{-\lambda t}$ is now multiplied by $\frac{1-\beta}{1+\beta \frac{\lambda-\delta}{\delta}}<1$. This immediately implies that: the long-run responses are the same in both economies, the short-run responses of $y$ and $l$ (of $q$ ) are now larger (smaller) in magnitude, and the DCIR of all variables is now smaller. Hence, in many ways, this new economy behaves qualitatively similar to an economy with a lower degree of skill specificity (higher $\eta$ ), with the exception that longrun responses are unchanged.

\subsubsection{Population growth}

We now assume that the size of entering generations is $\mu$ as opposed to $\delta$. This implies that the population growth rate is $\mu-\delta$. The Kolmogorov-Forward equation describing the evolution of the skill distribution becomes

$$
\frac{\partial e^{(\mu-\delta) t_{s}}(i)}{\partial t}=-\delta e^{(\mu-\delta) t} s_{t}(i)+\mu e^{(\mu-\delta) t} \tilde{s}_{t}(i)
$$


Then, we have that

$$
\frac{\partial s_{t}(i)}{\partial t}=-\mu s_{t}(i)+\mu \tilde{s}_{t}(i) .
$$

The remaining elements in the model remain the same. Hence, the economy with population growth is identical to our benchmark economy except that the convergence rate $\lambda$ is higher iff $\mu>\delta$ since it is now the positive solution to:

$$
(\lambda-\mu)(\rho+\delta+\lambda)=\frac{\psi \mu}{\theta+\kappa \eta} .
$$

Then, if $\mu>\delta$, the short- and long-run dynamic responses for $y_{t}, l_{t}$ remain unchanged, the short-run response of $q$ is smaller in magnitude, and the DCIR of all variables is lower. The opposite holds when $\mu<\delta$.

\section{Appendix 2 Empirical Analysis}

\subsection{Cognitive intensity and use of new technologies across occupa- tions in Germany}

This section analyzes the types of tasks required by cognitive-intensive occupations. Figure 2.1 reports the correlation between the occupation's intensity in cognitive skills and the share of individuals in that occupation reporting they intensely perform each of the listed tasks. The top tasks performed in cognitive-intensive occupations are directly related to technological innovations recently introduced in the workplace: working with internet, in particular, and with computers, more generally. On the other extreme, individuals employed in the least cognitive-intensive occupations tend to perform routine tasks associated with manufacturing and repairing. The results in Figure 2.1 are consistent with the evidence establishing the heterogeneous impact of new technologies on different tasks performed by workers - e.g., Autor et al. (2003), Spitz-Oener (2006), Autor and Dorn (2013), and Akerman et al. (2015).

\subsection{Sample statistics}

This section reports the summary statistics of our baseline sample. We first focus on the increase in inequality, measured by the standard deviation of log wages, in our sample. Figure 2.2 compares the overall change in inequality together with the between district-generation-occupation component, which we measure using the residual logwage dispersion from a mincer regression including dummies for the district-generationoccupation estimated for each year. Between 1997-2012, overall inequality in our sample increased by about $8.5 \mathrm{log}$ points. Moreover, the between district-generation-occupation component explains about half of the increase in inequality during this period. In results available on request, we attest that each of these characteristics alone does not account 
for the inequality rise. ${ }^{40}$

Table 2.1 presents summary statistics underlying the FDZ microdata used in our empirical analysis. They illustrate the evolution of the number of employees, ages and log-wage of the baseline generations used in estimation.

Figure 2.1: Cross-occupation correlation between cognitive intensity and performance of different tasks

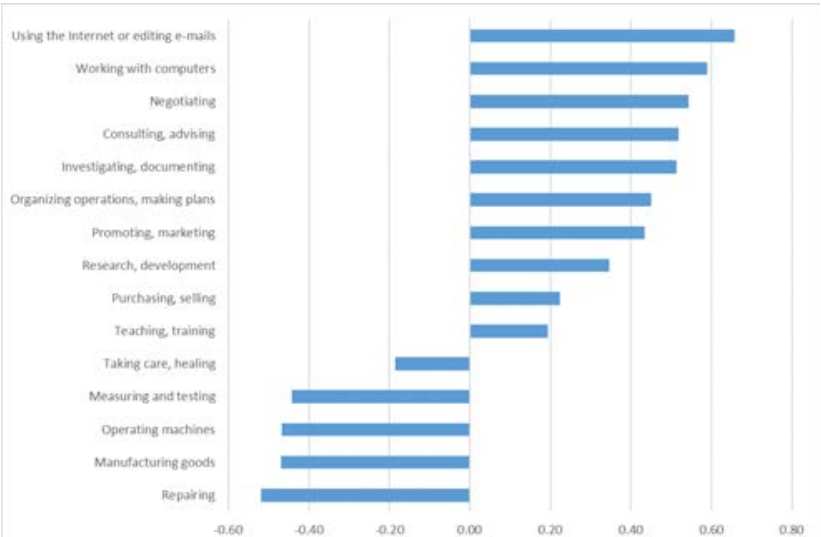

Note. Sample of 85 occupations. The occupation task intensity is the share of individuals in that occupation reporting to intensively perform the task in the 2012 Qualification and Working Conditions Survey. The occupation cognitive-skill intensity is the share of time spent on cognitive-intensive tasks in the BERUFNET dataset (2011-2013).

Figure 2.2: Aggregate Trends in Log Wage Variance

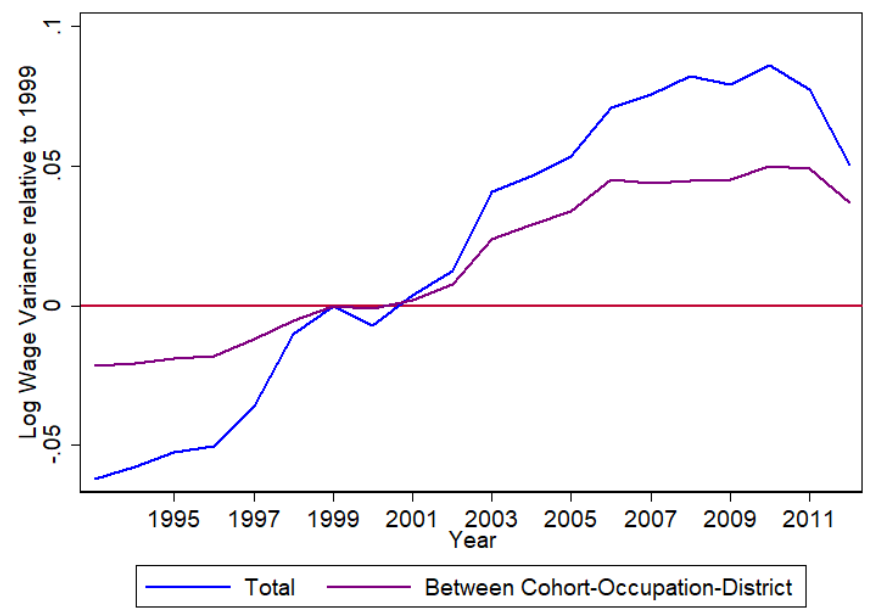

Note. Estimation of the aggregate standard deviation of log wages on the full LIAB sample and the residual dispersion in log wages from a mincer regression including districtoccupation-generation dummies. Estimates are changes in dispersion relative to 1999.

\footnotetext{
${ }^{40}$ We also attest that the explanatory power of the between district-generation-occupation component is similar to that of the between establishment component of log-wage variance, which Card et al. (2013) point as the main driver of the inequality increase in Germany during this period. Notice that this is not mechanical because there are nearly 50 times as many establishments as district-occupation-generation triples in our sample.
} 
Table 2.1: Summary Statistics: German Microdata

\begin{tabular}{ccc}
\hline & 1995 & 2014 \\
\hline Number of observations & & \\
Born before 1960 (“Old") & 185,751 & 96,045 \\
Born after 1960 ("Young") & 251,451 & 538,590 \\
& & \\
Mean log wage & & \\
Born before 1960 (“Old") & 4.54 & 4.42 \\
Born after 1960 ("Young") & 4.15 & 4.54 \\
& & \\
Mean age & & \\
Born before 1960 ("Old") & 44.86 & 60.53 \\
Born after 1960 ("Young") & 28.22 & 39.56
\end{tabular}

Note. Sample of male workers in LIAB data, living in West Germany, employed full-time with a positive wage in 120 occupations. Generations as defined in the table.

\subsection{Robustness and Additional Results}

\subsubsection{Cognitive intensity and labor market outcomes across occupations}

This section investigates complements the results presented in Section 7.2 of the paper.

We first report the impact of cognitive-intensity on occupation employment growth for different time horizons. The estimates in Table 2.2 show that results are qualitatively similar for 1995-2000 and 1995-2010. We can also see that the estimated coefficients increase continuously throughout the period of analysis.

We then investigate the impact of cognitive-intensity on occupation employment growth with a more flexible specification that allows for different coefficients for different levels of cognitive-intensity. As is clear from Table 2.3, the results in Table 1 of the paper are driven largely by an increase in employment for all generations in the most cognitive intensive occupations (above the 60th percentile of cognitive intensity). This increase is substantially stronger for the young generation. Some evidence of polarization is also evident for the young generation, as they also disproportionately enter the least cognitive intensive occupations.

Table 2.4 investigates the robustness of the estimates of equation (23) reported in Table 1 of the paper. Panel A of Table 2.4 reports similar results when we include occupation-level controls for import and export exposure and the growth in the fraction of migrants in the occupation. Panel B shows that results are also robust to restricting the sample to native-born German males only. Panel C presents results where the "Young" generation is defined alternatively as those born after 1965 or 1955. As expected, when the definition of the young generation is further restricted to include only more recent cohorts, the coefficient on "Young" is stronger. The opposite happens if we relax the young definition to include older cohorts. Panel $\mathrm{C}$ also shows that results are similar if the "Young" generation is defined as those aged below 40 in each year (as in Figure 6 of the paper). 
Table 2.2: Cognitive intensity and labor market outcomes across occupations in Germany

\begin{tabular}{|c|c|c|c|c|c|c|c|}
\hline \multirow[t]{3}{*}{ Dependent variable: } & \multicolumn{3}{|c|}{ Employment Growth } & \multicolumn{3}{|c|}{ Real Payroll Growth } & \multirow{3}{*}{$\begin{array}{c}\text { Trainee } \\
\text { Growth } \\
(7)\end{array}$} \\
\hline & All & Young & Old & All & Young & Old & \\
\hline & (1) & (2) & (3) & (4) & (5) & (6) & \\
\hline \multicolumn{8}{|c|}{ Panel A: Change in 1995-2000 } \\
\hline Cognitive intensity & $\begin{array}{c}0.388^{* * *} \\
(0.076)\end{array}$ & $\begin{array}{c}0.650^{* * *} \\
(0.098)\end{array}$ & $\begin{array}{c}0.113^{* * *} \\
(0.043)\end{array}$ & $\begin{array}{c}0.340^{* * *} \\
(0.048)\end{array}$ & $\begin{array}{c}0.616^{* * *} \\
(0.070)\end{array}$ & $\begin{array}{c}0.157^{* * *} \\
(0.037)\end{array}$ & $\begin{array}{l}0.379^{*} \\
(0.209)\end{array}$ \\
\hline \multicolumn{8}{|c|}{ Panel B: Change in 1995-2005 } \\
\hline Cognitive intensity & $\begin{array}{c}0.778^{* * *} \\
(0.111)\end{array}$ & $\begin{array}{c}1.150^{* * *} \\
(0.130)\end{array}$ & $\begin{array}{c}0.290^{* * *} \\
(0.079)\end{array}$ & $\begin{array}{c}0.741^{* * *} \\
(0.086)\end{array}$ & $\begin{array}{c}1.158^{* * *} \\
(0.114)\end{array}$ & $\begin{array}{c}0.404^{* * *} \\
(0.063)\end{array}$ & $\begin{array}{c}0.545 \\
(0.427)\end{array}$ \\
\hline \multicolumn{8}{|c|}{ Panel C: Change in 1995-2010 } \\
\hline Cognitive intensity & $\begin{array}{c}1.110^{* * *} \\
(0.137)\end{array}$ & $\begin{array}{c}1.523^{* * *} \\
(0.149)\end{array}$ & $\begin{array}{c}0.454^{* * *} \\
(0.125)\end{array}$ & $\begin{array}{c}1.036^{* * *} \\
(0.111)\end{array}$ & $\begin{array}{c}1.525^{* * *} \\
(0.133)\end{array}$ & $\begin{array}{c}0.539 * * * \\
(0.091)\end{array}$ & $\begin{array}{l}0.768^{*} \\
(0.430)\end{array}$ \\
\hline \multicolumn{8}{|c|}{ Panel D: Change in 1995-2014 } \\
\hline Cognitive intensity & $\begin{array}{c}1.488^{* * *} \\
(0.225)\end{array}$ & $\begin{array}{c}1.894^{* * *} \\
(0.234)\end{array}$ & $\begin{array}{c}0.871^{* * *} \\
(0.229)\end{array}$ & $\begin{array}{c}1.535^{* * *} \\
(0.227)\end{array}$ & $\begin{array}{c}2.029^{* * *} \\
(0.238)\end{array}$ & $\begin{array}{c}1.044^{* * *} \\
(0.223)\end{array}$ & $\begin{array}{c}2.121^{* * *} \\
(0.385)\end{array}$ \\
\hline
\end{tabular}

Note. Sample of 120 occupations. Each panel reports the estimate for the dependent variable over the indicated time period. Young cohort defined as all workers born after 1960 and Old cohort as all workers born before 1960. Robust standard errors in parentheses. ${ }^{*} p<0.1,{ }^{* *} p<0.05,{ }^{* * *} p<0.01$

Table 2.3: Cognitive intensity and labor market outcomes across occupations in Germany: Percentiles specification

\begin{tabular}{|c|c|c|c|c|c|c|c|}
\hline \multirow[t]{3}{*}{ Dependent variable: } & \multicolumn{3}{|c|}{ Employment Growth } & \multicolumn{3}{|c|}{ Real Payroll Growth } & \multirow{2}{*}{$\begin{array}{l}\text { Trainee } \\
\text { Growth }\end{array}$} \\
\hline & All & Young & Old & All & Young & Old & \\
\hline & (1) & (2) & (3) & (4) & (5) & (6) & (7) \\
\hline \multirow[t]{2}{*}{ Low: below P30 } & -0.012 & $0.286^{* *}$ & $-0.946^{* * *}$ & $0.220^{*}$ & $0.590^{* * *}$ & $-0.875^{* * *}$ & $-0.790^{* * *}$ \\
\hline & $(0.128)$ & $(0.137)$ & $(0.129)$ & $(0.132)$ & $(0.140)$ & $(0.135)$ & $(0.178)$ \\
\hline \multirow[t]{2}{*}{ Medium: P30-P60 } & -0.054 & -0.046 & 0.031 & -0.086 & -0.036 & -0.014 & -0.112 \\
\hline & $(0.194)$ & $(0.205)$ & $(0.208)$ & $(0.195)$ & $(0.208)$ & $(0.202)$ & $(0.274)$ \\
\hline \multirow[t]{2}{*}{ High: above P60 } & $0.812^{* * *}$ & $1.038^{* * *}$ & $0.531^{* * *}$ & $0.816^{* * *}$ & $1.099 * * *$ & $0.592^{* * *}$ & $1.052^{* * *}$ \\
\hline & $(0.156)$ & $(0.166)$ & $(0.016)$ & $(0.158)$ & $(0.169)$ & $(0.157)$ & $(0.237)$ \\
\hline
\end{tabular}


Table 2.4: Cognitive intensity and labor market outcomes across occupations in Germany: Robustness

\begin{tabular}{|c|c|c|c|c|c|}
\hline \multirow[t]{3}{*}{ Dependent variable: } & \multicolumn{4}{|c|}{ Employment Growth } & \multirow{3}{*}{$\begin{array}{l}\text { Trainee } \\
\text { Growth } \\
(5)\end{array}$} \\
\hline & All & Young & Old & Difference & \\
\hline & $(1)$ & (2) & (3) & (4) & \\
\hline \multicolumn{6}{|l|}{ Panel A: Alternative control set, 1995-2014 } \\
\hline Controls for immigration and trade & $\begin{array}{c}1.426^{* * *} \\
(0.261)\end{array}$ & $\begin{array}{c}1.807^{* * *} \\
(0.279)\end{array}$ & $\begin{array}{c}0.841^{* * *} \\
(0.252)\end{array}$ & $\begin{array}{c}0.966^{* * *} \\
(0.376)\end{array}$ & $\begin{array}{r}2.029^{* * *} \\
(0.457)\end{array}$ \\
\hline \multicolumn{6}{|c|}{ Panel B: Alternative sample definition, 1995-2014 } \\
\hline \multirow[t]{2}{*}{ Native-born Males Only } & $1.396^{* * *}$ & $1.807^{* * *}$ & $0.778^{* * *}$ & $1.029 * * *$ & $2.194^{* * *}$ \\
\hline & $(0.226)$ & $(0.235)$ & $(0.231)$ & $(0.340)$ & $(0.385)$ \\
\hline \multicolumn{6}{|c|}{ Panel C: Alternative generation definition, 1995-2014 } \\
\hline Young: Born after 1965 & $\begin{array}{c}1.488^{* * *} \\
(0.225)\end{array}$ & $\begin{array}{c}2.137^{* * *} \\
(0.299)\end{array}$ & $\begin{array}{c}0.857^{* * *} \\
(0.246)\end{array}$ & $\begin{array}{c}1.280^{* * *} \\
(0.387)\end{array}$ & $\begin{array}{c}2.121^{* * *} \\
(0.385)\end{array}$ \\
\hline Young: Born after 1955 & $\begin{array}{c}1.488^{* * *} \\
(0.225)\end{array}$ & $\begin{array}{c}1.639^{* * *} \\
(0.268)\end{array}$ & $\begin{array}{c}0.967^{* * *} \\
(0.290)\end{array}$ & $\begin{array}{l}0.671^{*} \\
(0.395)\end{array}$ & $\begin{array}{c}2.121^{* * *} \\
(0.385)\end{array}$ \\
\hline Young: Aged Below 40 in each year & $\begin{array}{c}1.488^{* * *} \\
(0.225)\end{array}$ & $\begin{array}{c}1.748^{* * *} \\
(0.294)\end{array}$ & $\begin{array}{c}0.773^{* * *} \\
(0.246)\end{array}$ & $\begin{array}{l}0.975^{* *} \\
(0.383)\end{array}$ & $\begin{array}{c}2.121^{* * *} \\
(0.385)\end{array}$ \\
\hline
\end{tabular}

Note. Sample of 120 occupations, sample periods as defined in the table. Columns (1)-(3) report the estimated coefficient on the occupation's cognitive intensity in equation (23) of the paper. Column (4) reports the difference between the coefficients in columns (3) and (2). Each row defines a separate robustness exercise. The row "Controls for immigration and trade" includes a set of baseline controls: growth in occupational exposure to exports during the sample period, growth in occupational exposure to imports during the sample period, and growth in the fraction of immigrants in the occupation during the sample period. Robust standard errors in parentheses. ${ }^{*} p<0.1,{ }^{* *} p<0.05,{ }^{* * *} p<0.01$ 


\subsubsection{Dynamic adjustment to broadband internet adoption (Section 7.3)}

This section complements the results presented in Section 7.3 of the paper. We first turn to a more careful investigation of the robustness of the results in Figure 7 in the paper. Table 2.5 investigates how our baseline set of controls affects estimates. The three panels of Table 2.5 present estimates for the entire post-shock period of the sample (1999-2014, Panel A), the period during which DSL was rolled out across German regions (1999-2007, Panel B), and the period before the shock (1996-1999, Panel C). Each panel includes the results of our baseline specification, as well as alternative specifications in which (i) we drop the pre-trend control, and (ii) we augment baseline controls with district-generation-year fixed effects.

Consider first the impact of the pretrend control in the second row of each panel. Results indicate that this control increases the magnitude and the precision of the estimates coefficients in the period of 1999-2007 and 1999-2014. However, it has the opposite impact on the pre-shock period of 1996-1999. In this pre-shock period, there are marginally significant negative responses without the pretrend control.

Turning to the specification including district-generation-year fixed effects, we can see that results are remarkably similar to our baseline estimates. This is reassuring as this specification includes a restrictive set of controls that absorb all potential confounding shocks that affect each district-generation pair in a year. In this case, identification comes purely from the differential effect of early broadband expansion on occupations with a higher cognitive intensity. That is, this control set captures any pre-existing variation that might have resulted in a district receiving broadband access early, including differential immigration into a district that received DSL or differential aging or birth patterns in the district over time.

Table 2.6 investigates the robustness of the baseline estimates in Figure 7 of the paper to the sample specification. The two panels present estimates for the entire post-shock period of the sample (1999-2014, Panel A), and the period during which DSL was rolled out across German regions (1999-2007, Panel B). All specifications include the baseline set of controls.

The second row of each panel shows that results are similar if we restrict the sample to only include workers born in Germany. This suggests that the inclusion of immigrants in our sample does not drive our baseline results.

We consider next several alternative definitions of the young generation based on (i) cohorts groups born after 1955, 1965 or 1970, and (ii) age groups aged below 35, 40 or 45 in each year. For all definitions, the coefficient on the cognitive intensity of the occupation for young workers is positive and strongly significant, while that for the old generation is insignificant and close to zero. As before, the coefficient in column (2) is stronger when we restrict the young generation to cohorts born in more recent years. Similar patterns arise when we define the young generation based on a lower or higher age cutoff in each year. This is consistent with our theory since the entering cohorts are those adjusting their skills in response to the introduction of broadband internet in the regional labor market.

The last row of each panel reports estimates when we restrict the sample by excluding workers employed in establishments belonging to the top 25 percentile of establishment sizes. This exercise accounts for the likelihood that the largest establishments in Germany acquired DSL earlier through specialized private connections. In this case, we 
would expect adjustment in these establishments to have occurred earlier, biasing our results to zero. In line with this intuition, estimated coefficients are stronger than the baseline for all workers in column (1) and for the young-old gap in column (4). This indicates that our instrument seems to generate variation in the roll-out of broadband internet that mostly affected the occupation composition of small establishments across German districts.

Table 2.7 investigates the impact of early DSL adoption on investment in cognitive skills by young workers in the district. Specifically, it reports the estimation of $\beta_{t}$ in equation (23) when the outcome is the number of trainees of all ages in an occupationdistrict. Our estimates suggest that regions where DSL expansion happened faster also experienced stronger growth in the number of trainees in more cognitive intensive occupations. This evidence is consistent with our model's prediction that, after the arrival of a cognitive-intensive innovation, incoming cohorts increase their investment in the skills used in more cognitive intensive occupations.

Finally, Figures 2.3 to 2.5 complement and extend the impulse responses shown in the main text. 
Table 2.5: Impact of early DSL adoption on more cognitive-intensive occupations: Alternative control sets

\begin{tabular}{ccccc}
\hline Dependent variable: & \multicolumn{4}{c}{ Employment Growth } \\
\cline { 2 - 5 } Control Set & All & Young & Old & Difference \\
\hline Panel A: 1999-2014 & $(1)$ & $(2)$ & $(3)$ & $(4)$ \\
Baseline & $0.240^{* * *}$ & $0.482^{* * *}$ & -0.065 & $0.546^{* *}$ \\
& $(0.085)$ & $(0.154)$ & $(0.193)$ & $(0.287)$ \\
No Pretrend Control & $0.177^{* *}$ & $0.292^{* * *}$ & -0.026 & 0.319 \\
& $(0.087)$ & $(0.114)$ & $(0.189)$ & $(0.222)$ \\
District-Year Effects & $0.149^{* *}$ & $0.475^{* * *}$ & -0.035 & $0.510^{*}$ \\
& $(0.067)$ & $(0.160)$ & $(0.203)$ & $(0.302)$ \\
Panel B: 1999-2007 & & & & \\
Baseline & $0.077^{*}$ & $0.223^{* * *}$ & -0.138 & $0.361^{* *}$ \\
& $(0.043)$ & $(0.092)$ & $(0.116)$ & $(0.177)$ \\
No Pretrend Control & 0.015 & 0.137 & -0.200 & 0.337 \\
& $(0.061)$ & $(0.085)$ & $(0.127)$ & $(0.149)$ \\
District-Year Effects & 0.093 & $0.234^{* *}$ & -0.134 & $0.368^{*}$ \\
& $(0.060)$ & $(0.098)$ & $(0.125)$ & $(0.019)$ \\
Panel C: 1996-1999 & & & & \\
Baseline & -0.002 & 0.011 & -0.019 & 0.029 \\
& $(0.026)$ & $(0.030)$ & $(0.031)$ & $(0.049)$ \\
No Pretrend Control & $-0.109^{*}$ & $-0.141^{*}$ & -0.074 & -0.068 \\
& $(0.065)$ & $(0.077)$ & $(0.084)$ & $(0.061)$ \\
District-Year Effects & 0.012 & 0.011 & -0.022 & 0.034 \\
& $(0.032)$ & $(0.032)$ & $(0.032)$ & $(0.050)$ \\
\hline
\end{tabular}

Note. Sample of 2 cohorts, 120 occupations and 323 districts. Sample periods as defined in the table. Column (1) reports the estimated coefficient on interaction between the occupation cognitive intensity and district DSL access in equation (24) for a single generation of working-age employed individuals. Columns (2)-(3) report the estimated coefficients on interaction between the occupation cognitive intensity, generation dummies and district DSL access in equation (24) for the old and young generations. Column (4) reports the difference between the coefficients in columns (3) and (2). Generations are the baseline generations with young workers those born after 1960. All regressions are weighted by the district population size in 1999 and include a set of baseline district-level controls as well as occupation-year and generation-year fixed effects. Each row defines a separate robustness exercise. "District-Year Effects" are estimated as district-year fixed effects in column (1) and as district-year-generation fixed effects in columns (2)-(4). Standard errors clustered at the district-level in parentheses. ${ }^{*} p<0.1,{ }^{* *} p<0.05,{ }^{* * *} p<0.01$ 
Table 2.6: Impact of early DSL adoption on more cognitive-intensive occupations: Sample selection

\begin{tabular}{|c|c|c|c|c|}
\hline \multirow{2}{*}{$\begin{array}{l}\text { Dependent variable: } \\
\text { Sample Definition }\end{array}$} & \multicolumn{4}{|c|}{ Employment Growth } \\
\hline & $\begin{array}{l}\text { All } \\
(1)\end{array}$ & $\begin{array}{c}\text { Young } \\
\text { (2) }\end{array}$ & $\begin{array}{l}\text { Old } \\
\text { (3) }\end{array}$ & $\begin{array}{c}\text { Difference } \\
\text { (4) }\end{array}$ \\
\hline \multicolumn{5}{|l|}{ Panel A: 1999-2014 } \\
\hline Baseline & $\begin{array}{c}0.240^{* * *} \\
(0.085)\end{array}$ & $\begin{array}{c}0.482^{* * *} \\
(0.154)\end{array}$ & $\begin{array}{l}-0.065 \\
(0.193)\end{array}$ & $\begin{array}{l}0.546^{* *} \\
(0.287)\end{array}$ \\
\hline Native-born Males Only & $\begin{array}{c}0.223^{* * *} \\
(0.078)\end{array}$ & $\begin{array}{c}0.446^{* * *} \\
(0.143)\end{array}$ & $\begin{array}{c}0.074 \\
(0.144)\end{array}$ & $\begin{array}{l}0.372^{* *} \\
(0.208)\end{array}$ \\
\hline Young: born after 1970 & & $\begin{array}{c}0.714^{* * *} \\
(0.182)\end{array}$ & $\begin{array}{l}-0.048 \\
(0.242)\end{array}$ & $\begin{array}{l}0.789^{* *} \\
(0.371)\end{array}$ \\
\hline Young: born after 1965 & & $\begin{array}{c}0.612^{* * *} \\
(0.157)\end{array}$ & $\begin{array}{l}-0.171 \\
(0.201)\end{array}$ & $\begin{array}{c}0.783^{* * *} \\
(0.303)\end{array}$ \\
\hline Young: born after 1955 & & $\begin{array}{c}0.573^{* * *} \\
(0.196)\end{array}$ & $\begin{array}{l}-0.298 \\
(0.233)\end{array}$ & $\begin{array}{l}0.871^{* *} \\
(0.355)\end{array}$ \\
\hline Young: Aged $<35$ in each year & & $\begin{array}{c}0.612^{* * *} \\
(0.139)\end{array}$ & $\begin{array}{c}0.059 \\
(0.139)\end{array}$ & $\begin{array}{c}0.553^{* * *} \\
(0.203)\end{array}$ \\
\hline Young: Aged $<40$ in each year & & $\begin{array}{c}0.529^{* * *} \\
(0.164)\end{array}$ & $\begin{array}{c}0.076 \\
(0.163)\end{array}$ & $\begin{array}{l}0.453^{* *} \\
(0.237)\end{array}$ \\
\hline Young: Aged $<45$ in each year & & $\begin{array}{c}0.445^{* * *} \\
(0.170)\end{array}$ & $\begin{array}{c}0.159 \\
(0.198)\end{array}$ & $\begin{array}{c}0.286 \\
(0.266)\end{array}$ \\
\hline Small Establishments Only & $\begin{array}{c}0.309^{* * *} \\
(0.083)\end{array}$ & $\begin{array}{c}0.466^{* * *} \\
(0.140)\end{array}$ & $\begin{array}{l}-0.128 \\
(0.183)\end{array}$ & $\begin{array}{l}0.594^{* *} \\
(0.286)\end{array}$ \\
\hline \multicolumn{5}{|l|}{ Panel B: 1999-2007 } \\
\hline Baseline & $\begin{array}{c}0.077^{*} \\
(0.043)\end{array}$ & $\begin{array}{c}0.223^{* * *} \\
(0.092)\end{array}$ & $\begin{array}{l}-0.138 \\
(0.116)\end{array}$ & $\begin{array}{l}0.361^{* *} \\
(0.177)\end{array}$ \\
\hline Native-born Males Only & $\begin{array}{c}0.054 \\
(0.045)\end{array}$ & $\begin{array}{l}0.145^{*} \\
(0.092)\end{array}$ & $\begin{array}{c}0.037 \\
(0.105)\end{array}$ & $\begin{array}{c}0.108 \\
(0.171)\end{array}$ \\
\hline Young: born after 1970 & & $\begin{array}{c}0.449^{* * *} \\
(0.120)\end{array}$ & $\begin{array}{l}-0.070 \\
(0.191)\end{array}$ & $\begin{array}{l}0.518^{*} \\
(0.289)\end{array}$ \\
\hline Young: born after 1965 & & $\begin{array}{c}0.298^{* * *} \\
(0.092)\end{array}$ & $\begin{array}{l}-0.168 \\
(0.118)\end{array}$ & $\begin{array}{l}0.465^{* *} \\
(0.183)\end{array}$ \\
\hline Young: born after 1955 & & $\begin{array}{l}0.203^{* *} \\
(0.087)\end{array}$ & $\begin{array}{l}-0.155 \\
(0.115)\end{array}$ & $\begin{array}{c}0.358^{* * *} \\
(0.167)\end{array}$ \\
\hline Young: Aged $<35$ in each year & & $\begin{array}{l}0.118^{* *} \\
(0.066)\end{array}$ & $\begin{array}{c}0.095 \\
(0.095)\end{array}$ & $\begin{array}{c}0.022 \\
(0.130)\end{array}$ \\
\hline Young: Aged $<40$ in each year & & $\begin{array}{l}0.195^{* *} \\
(0.086)\end{array}$ & $\begin{array}{c}0.030 \\
(0.104)\end{array}$ & $\begin{array}{c}0.165 \\
(0.166)\end{array}$ \\
\hline Young: Aged $<45$ in each year & & $\begin{array}{c}0.206^{* * *} \\
(0.090)\end{array}$ & $\begin{array}{c}0.091 \\
(0.111)\end{array}$ & $\begin{array}{c}0.115 \\
(0.174)\end{array}$ \\
\hline Small Establishments Only & $\begin{array}{l}0.129^{*} \\
(0.070)\end{array}$ & $\begin{array}{l}0.263^{* *} \\
(0.103)\end{array}$ & $\begin{array}{l}-0.170 \\
(0.120)\end{array}$ & $\begin{array}{l}0.434^{* *} \\
(0.181)\end{array}$ \\
\hline
\end{tabular}

Note. Sample of 2 cohorts, 120 occupations and 323 districts. Sample periods as defined in the table. Column (1) reports the estimated coefficient on interaction between the occupation cognitive intensity and district DSL access in equation (24) for a single generation of working-age employed individuals. Columns (2)-(3) report the estimated coefficients on interaction between the occupation cognitive intensity, generation dummies and district DSL access in equation (24) for the old and young generations. Column (4) reports the difference between the coefficients in columns (3) and (2). All regressions are weighted by the district population size in 1999 and include a set of baseline district-level controls, pretrend controls, occupation-year and generation-year fixed effects. Each row defines a separate sample selection exercise: (i) baseline sample restricted to only Germans ("Native-born"), (ii) different definitions of young w68kers based on year of birth or age cutoff in each year, and (iii) baseline sample restricted to workers employed in establishments below the 75th percentile of all establishment sizes ("Small Establishments Only"). Standard errors clustered at the district-level in parentheses. ${ }^{*} p<0.1,{ }^{* *} p<0.05,{ }^{* * *} p<0.01$ 
Table 2.7: Impact of early DSL adoption on the number of trainees in more cognitive-intensive occupations

$$
\text { Dependent variable: } \quad \text { Training Growth }
$$

\begin{tabular}{|c|c|}
\hline \multicolumn{2}{|c|}{ Panel A: 1999-2014 } \\
\hline Baseline & $\begin{array}{c}0.415^{*} \\
(0.237)\end{array}$ \\
\hline \multicolumn{2}{|c|}{ Panel B: 1999-2007 } \\
\hline Baseline & $\begin{array}{c}0.305 \\
(0.247)\end{array}$ \\
\hline \multicolumn{2}{|c|}{ Panel C: 1996-1999 } \\
\hline Baseline & $\begin{array}{l}-0.093 \\
(0.044)\end{array}$ \\
\hline
\end{tabular}

Note. Sample of 120 occupations and 323 districts. Sample periods as defined in the table. Table reports the estimated coefficient on interaction between the occupation cognitive intensity and district DSL access in equation (24) for a single generation of working-age individuals whose employment status is a trainee or intern in each year. All regressions are weighted by the district population size in 1999 and include a set of baseline district-level controls as well as occupation-year fixed effects. Standard errors clustered at the district-level in parentheses. ${ }^{*} p<0.1,{ }^{* *} p<0.05,{ }^{* * *} p<0.01$ 
Figure 2.3: Impact of early DSL adoption on employment in more cognitive-intensive occupations: Old and Young generations

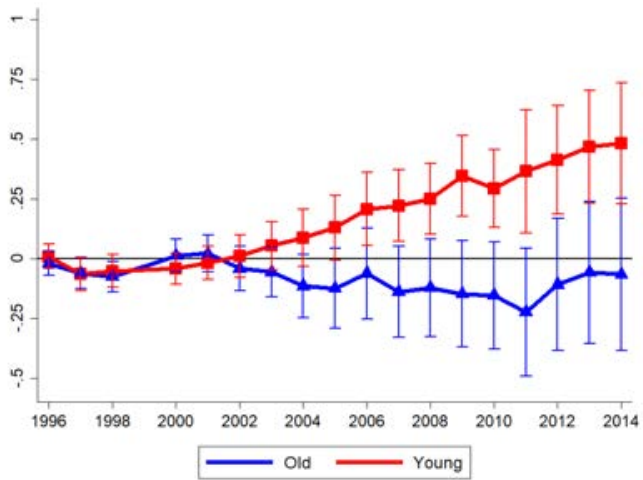

(a) Relative employment response for each generation

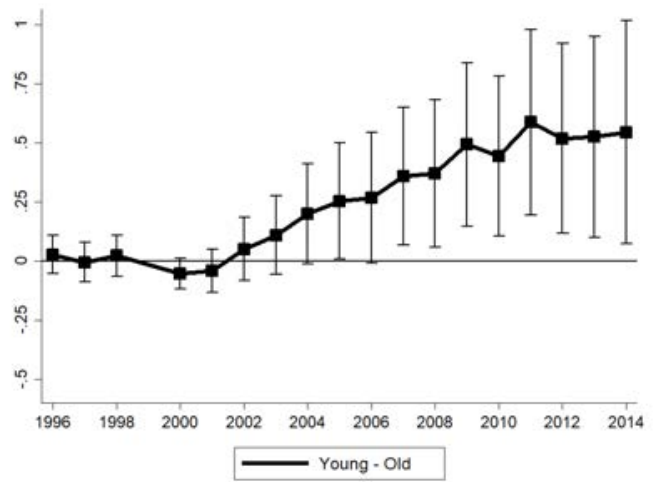

(b) Cross-generation difference in responses

Note. Estimation of equation (23) in the sample of 2 cohorts, 120 occupations and 323 districts. Dependent variable: log employment. The left panel reports $\beta_{t}^{g}$ for olf and young generations, and the right panel reports $\beta_{t}^{\text {young }}-\beta_{t}^{\text {old }}$. All regressions are weighted by the district population size in 1999 and include occupation-time and cohort-time fixed-effects. Baseline controls include the following district variables in 1999: college graduate population share, manufacturing employment share, immigrant employment share, district age composition, and the dependent variable pretrend growth in 1995-1999. Bars are the associated $90 \%$ confidence interval implied by the standard error clustered at the district level.

Figure 2.4: Impact of early DSL adoption on payroll in more cognitive-intensive occupations: Old and Young generations

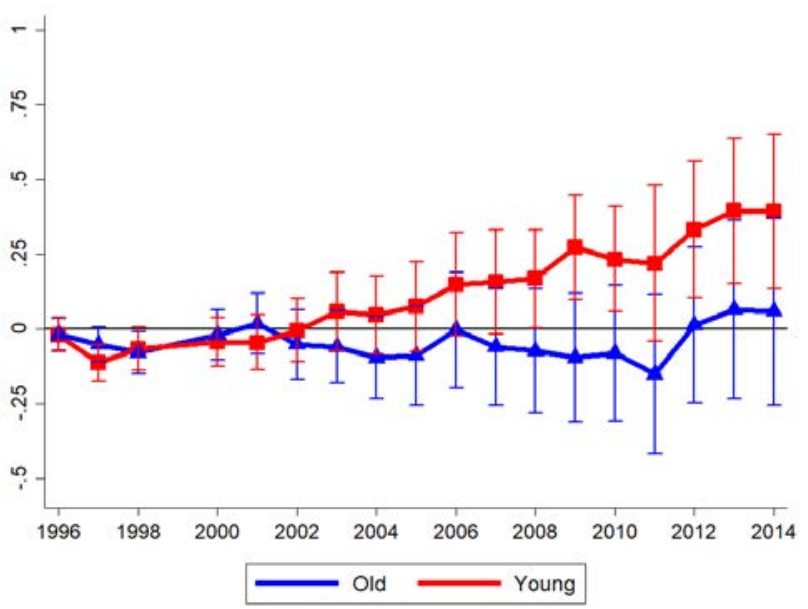

(a) Relative payroll response for each generation

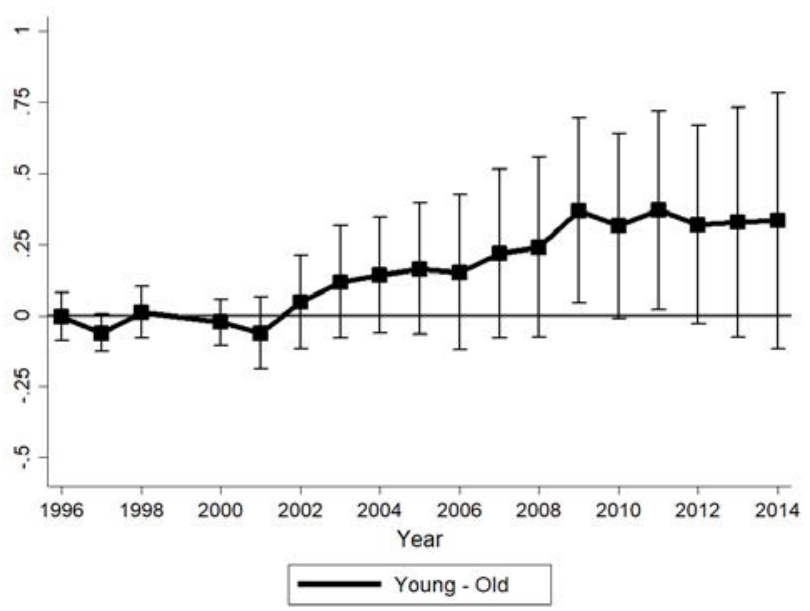

(b) Cross-generation difference in responses

Note. Estimation of equation (24) in the sample of 2 cohorts, 120 occupations and 323 districts. Dependent variable: log employment. The left panel reports $\beta_{t}^{g}$ for olf and young generations, and the right panel reports $\beta_{t}^{\text {young }}-\beta_{t}^{\text {old }}$. All regressions are weighted by the district population size in 1999 and include occupation-time and cohort-time fixed-effects. Baseline controls include the following district variables in 1999: college graduate population share, manufacturing employment share, immigrant employment share, district age composition, and the dependent variable pretrend growth in 1995-1999. Bars are the associated $90 \%$ confidence interval implied by the standard error clustered at the district level. 
Figure 2.5: Impact of early DSL adoption on more cognitive-intensive occupations: All generations

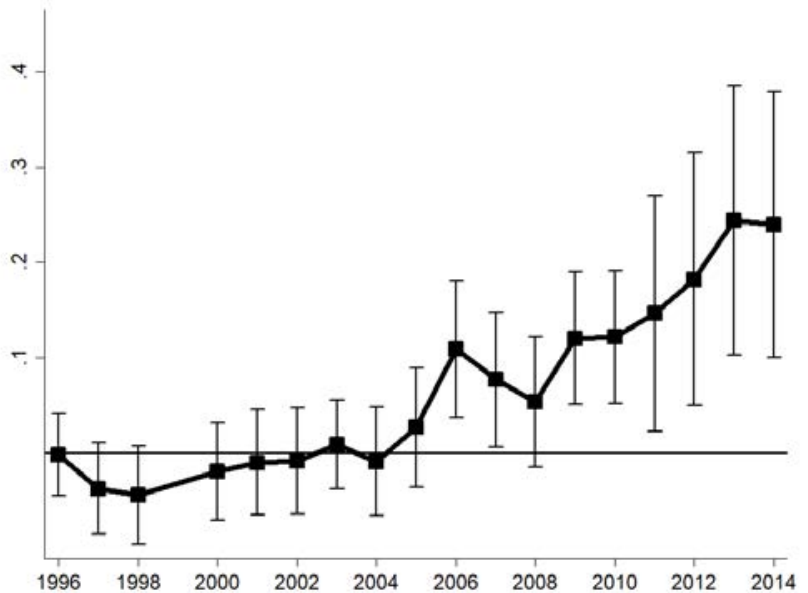

(a) Relative employment response for all generations

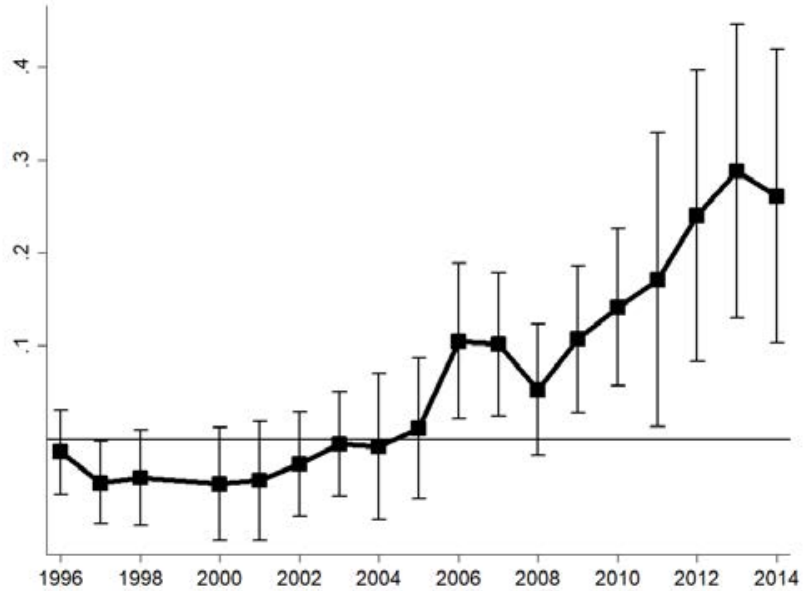

(b) Relative payroll response for all generations

Note. Estimation of equation (24) in the sample of 120 occupations and 323 districts for a single generation of working-age employed individuals. Dependent variable: log employment (left) and log payroll (right). All regressions are weighted by the district population size in 1999 and include occupation-time fixed-effects. Baseline controls include the following district variables in 1999: college graduate population share, manufacturing employment share, immigrant employment share, district age composition, and the dependent variable pre-shock growth in 1995-1999. For each year, the dot is the point estimate of $\beta_{t}^{\text {all }}$, and the bar is the associated $90 \%$ confidence interval implied by the standard error clustered at the district level. 


\subsection{Occupations composition changes for young and old workers in different periods}

This section investigate further the changes in cross-generation differences in occupation composition over time for the United States. We focus on the United States because it has individual-level data from the U.S. Census containing 2-digit ISCO occupation information for 1960, 1970, 1980, 1990, 2000, 2010, and 2015. We use this data to select a sample of males aged 16-64 years old in each year. For each occupation $o$, we use this sample to compute the change in the average age of its workers between years $t$ and $t_{0}\left(\Delta \bar{A}_{o, t} \equiv \bar{A}_{o, t}-\bar{A}_{o, t_{0}}\right)$ and the change in the employment share in the same period $\left(\Delta e_{0, t} \equiv e_{o, t}-e_{o, t_{0}}\right)$. We then compute the correlation between $\Delta \bar{A}_{o, t}$ and $\Delta e_{o, t}$ across the nine occupations weighted by their employment share in 1960.

Table 2.8 shows that, in line with Figure 1, the expanding occupations in recent periods attracted young individuals, leading to reductions in the average age of its workers. However, this was not the case in previous periods. Between 1960 and 1990, the correlation between changes in average age and employment share were much weaker. In fact, this correlation was positive in 1960-1980.

Table 2.8: Changes in mean age and employment share across occupations, United States

\begin{tabular}{cc}
\hline Period & $\operatorname{Corr}\left(\Delta \bar{A}_{o, t}, \Delta e_{o, t}\right)$ \\
\hline \hline $2000-2015$ & -0.53 \\
$1990-2010$ & -0.63 \\
$1980-2000$ & -0.60 \\
$1970-1990$ & -0.03 \\
$1960-1980$ & 0.35
\end{tabular}

Note. For each period, the table reports the correlation between $\Delta \bar{A}_{0, t}$ and $\Delta e_{0, t}$ across the nine 2-digit ISCO occupations (weighted by their employment share in 1960). For each occupation and period, $\Delta \bar{A}_{0, t}$ is the change in the mean age and $\Delta e_{0, t}$ is the change in employment share. Sample of males 16-64 years old in the United States.

\section{Appendix 3 Numerical Analysis}

This appendix discusses in detail the parameterization of the model. We first present the theoretical impulse response functions for the relative employment of different worker generations. Second, we describe the procedure to select the parameters that match the theoretical and empirical impulse response functions. Finally, we use the parameterized model to quantitatively evaluate the dynamic adjustment to cognitive-biased technological innovations.

\subsection{Impulse response functions of relative employment by generation}

As a first step to parameterize our theory using the empirical impulse response functions in Section 7.3 of the paper, we derive the theoretical responses of generation-specific 
relative employment. To this end, we consider the same one-time permanent change in $A$ at $t=0$. We define older generations as those born before period $t=-x$ and younger generations as those born at period $t=-x$. In period $t \geq 0$, the relative high-tech employment of these worker generations are given by

$$
e_{t}^{o l d}=\frac{\int_{l_{t}}^{1} s_{0}(i) d i}{\int_{0}^{l_{t}} s_{0}(i) d i} \quad \text { and } \quad e_{t}^{y o u n g}=\frac{\tilde{x}_{0} e^{-\delta t} \int_{l_{t}}^{1} s_{0}(i) d i+\delta \int_{0}^{t} e^{\delta(\tau-t)} \int_{l_{t}}^{1} \tilde{s}_{\tau}(i) d i d \tau}{\tilde{x}_{0} e^{-\delta t} \int_{0}^{l_{t}} s_{0}(i) d i+\delta \int_{0}^{t} e^{\delta(\tau-t)} \int_{0}^{l_{t}} \tilde{s}_{\tau}(i) d i d \tau},
$$

where $\tilde{x}_{0} \equiv 1-e^{-\delta x}$ is the population share of the young generation at $t=0$.

For both worker groups, the technology-skill assignment is identical and determined by the threshold $l_{t}$. Notice that all workers of the old generations have the pre-shock skill distribution, $s_{0}(i)$. However, the skill distribution of young generations combines the pre-shock distribution, $s_{0}(i)$, and the post-shock lotteries, $\tilde{s}_{\tau}(i)$. The overlapping generation structure of the model implies that the relative share of workers in the young generation with the pre-shock skill distribution decays at the constant rate $\delta$.

We allow the young group to include workers born before the shock (since $x \geq$ 0 ). This circumvents the challenge of identifying the cohorts that start adjusting their skills after the shock, which arises because, in practice, technologies may not be adopted instantaneously and young workers may still invest on skills after entering the labor force (in the form of vocational training or on-the-job learning). It is also possible to allow part of the workers born before the shock to adjust their skills at $t=0$. In this case, rather than $s_{0}(i)$, the initial skill distribution would be a mix of $s_{0}(i)$ and $\tilde{s}_{0}(i)$. This extension does not alter our main qualitative insights, but reduces the magnitude of the short-to-long adjustment in the economy.

Relative employment of old generation. We show below that the change in the relative employment of old generations is

$$
\Delta \log e_{t}^{\text {old }} \approx \frac{\eta}{\theta+\kappa \eta} \frac{1}{e_{H}}\left(1-\frac{\psi}{\chi}\left(1-e^{-\lambda t}\right)\right)(\theta-1) \Delta \log A
$$

where $e_{H}$ is the high-tech employment share at $t=0^{-}$.

Among old generations, the increase in the relative productivity of high-tech production induces the reallocation of workers towards high-tech production whenever $\theta>1$. The expression indicates that this positive effect on relative high-tech employment becomes weaker over time. This follows from the expansion of high- $i$ skills among younger generations, which displaces old workers with marginal skills from high-tech production - i.e., those with skills $i \in\left(l_{0}, l_{\infty}\right)$. Importantly, expression (3.1) shows that the magnitude of the increase in relative employment of older generations is decreasing in the degree of technology-skill specificity (i.e., increasing in $\eta$ ).

Relative employment of young generation. Turning to the employment response among young generations, we show below that

$$
\Delta \log e_{t}^{\text {young }} \approx \Delta \log e_{t}^{\text {old }}+\frac{\psi}{\chi} \frac{1-e^{-\lambda t}}{1-\left(1-\tilde{x}_{0}\right) e^{-\delta t}}(\theta-1) \Delta \log A .
$$


This expression indicates that the evolution of the allocation of young workers has two components. The first term captures the change in technology-skill assignment and, since it is the only determinant of the relative employment of old generations, it can be approximated by $\Delta \log e_{t}^{\text {old }}$. The second term captures the change in the skill investment decision of incoming cohorts. At each point in time, this term is positive as young workers distort skill investment towards high- $i$ skills that became more valuable in high-tech production. We can also show that the cross-generation difference grows shortly after the shock. Importantly, expression (3.1) indicates that the cross-generation difference in the response of relative employment is decreasing in the skill investment cost (i.e., it is increasing in $\psi$ ).

Relative payroll for all workers. For completeness, we also re-write the impulse response function for relative payroll in Proposition 1:

$$
\Delta \log y_{t}=\left(1+\kappa \eta+\frac{\psi}{\chi}(\theta-1)\left(1-e^{-\lambda t}\right)\right) \frac{\theta-1}{\theta+\kappa \eta} \Delta \log (A)
$$

where $\chi \equiv\left(\theta+\kappa \eta+\frac{\psi}{\rho+\delta}\right)(\rho+\delta)$.

Responses for multiple shocks. We now consider a sequence of unanticipated shocks, $\left\{\Delta \log A_{n}\right\}_{n=1}^{N}$, happening at periods $\left\{t_{n}\right\}_{n=1}^{N}$. We consider the approximate equilibrium dynamics around the final stationary equilibrium.

For simplicity, we consider the case in which the old group only includes individuals born before $t_{1}$. For any period $t>t_{N}$, we can sum the impulse response functions in (3.1) and (3.3) to obtain

$$
\begin{gathered}
\Delta \log e_{t}^{\text {old }} \approx \frac{\eta(\theta-1)}{\theta+\kappa \eta} \frac{1}{e_{H}}\left[\left(1-\frac{\psi}{\chi}\right) \Delta \log A+\frac{\psi}{\chi} e^{-\lambda t} \Delta \log \tilde{A}\right] \\
\Delta \log y_{t}=\frac{\theta-1}{\theta+\kappa \eta}\left[\left(1+\kappa \eta+\frac{\psi(\theta-1)}{\chi}\right) \Delta \log A-\frac{\psi(\theta-1)}{\chi} e^{-\lambda t} \Delta \log \tilde{A}\right]
\end{gathered}
$$

where $\Delta \log A \equiv \sum_{n=1}^{N} \Delta \log A_{n}$ and $\Delta \log \tilde{A} \equiv \sum_{n=1}^{N} e^{\lambda t_{n}} \Delta \log A_{n}$.

These expressions indicate that responses in all variables include a static component associated with response at impact to the combination of all shocks, $\sum_{n=1}^{N} \Delta \log A_{n}$, and a dynamic component associated with the weighted average of the shocks discounted by the time at which they happen, $\sum_{n=1}^{N} e^{\lambda t_{n}} \Delta \log A_{n}$.

To derive the cross-generation component, we consider the young generation born after $t_{N}$. Relative to the old generation born before the first shock, we have that

$$
\Delta \log \left(e_{t}^{\text {young }}\right)-\Delta \log \left(e_{t}^{\text {old }}\right) \approx \frac{\psi(\theta-1)}{\chi}\left(\left(e^{-\delta t}-e^{-\lambda t}\right) \Delta \log \tilde{A}+\left(1-e^{-\delta t}\right) \Delta \log A\right) .
$$

We again have two components. Since the young generation makes skill investment decisions after all shocks have happened, there is a static component associated with the combination of all shocks. However, in this case, the dynamics is driven by two 
eigenvalues: $\delta$ and $\lambda$. This arises because young generations are replaced at rate $\delta$ while prices change at rate $\lambda$.

\subsection{Proof of equations (3.1), (3.2), and (3.6)}

Proof of equation (3.1). We first use a first-order approximation to write the log-change in relative high-tech employment in terms of changes in the high-tech employment share:

$$
\Delta \log \left(e_{t}^{\text {old }}\right)=\log \left(\frac{e_{t}^{\text {old }}}{e_{0^{-}}^{\text {old }}}\right) \approx \frac{1}{\left(1-e_{H, \infty}\right) e_{H, \infty}}\left(e_{H, t}^{\text {old }}-e_{H, 0^{-}}^{\text {old }}\right)
$$

where $e_{H, t}^{o l d}=\int_{l_{t}}^{1} s_{0}(i) d i$. tion:

Since $\Delta\left(\frac{1}{\left(1-e_{H, \infty}\right) e_{H, \infty}}\right)\left(e_{H, t}^{o l d}-e_{H, 0^{-}}^{o l d}\right)$ is a second order term, we get the approxima-

$$
\Delta \log \left(e_{t}^{o l d}\right) \approx \frac{1}{\left(1-e_{H, 0^{-}}\right) e_{H, 0^{-}}}\left(e_{H, t}^{o l d}-e_{H, 0^{-}}^{\text {old }}\right)
$$

We have that

$$
e_{H, t}^{o l d}-e_{H, 0^{-}}^{o l d}=\int_{l_{t}}^{1} s_{0}(i) d i-\int_{l_{0^{-}}}^{1} s_{0}(i) d i
$$

By approximating these expressions around $l$,

$$
\begin{aligned}
e_{H, t}^{\text {old }}-e_{H, 0^{-}}^{\text {old }} & \approx-s_{0}(l) l\left(\Delta \log \left(l_{\infty}\right)+\hat{l}_{t}\right) \\
& \approx\left(s_{0}(l) l\right) \eta \Delta \log \left(\omega_{t}\right) \\
& \approx\left(s_{0}\left(l_{0^{-}}\right) l_{0^{-}}\right) \eta \Delta \log \left(\omega_{t}\right) \\
& \approx\left(1-e_{H, 0^{-}}\right) \eta \Delta \log \left(\omega_{t}\right)
\end{aligned}
$$

where the third equality follows from the fact that $\Delta\left(s_{0}(l) l\right) \Delta \log \left(\omega_{t}\right)$ is a second order term, and the last equality follows from normalizing the initial skill distribution to be uniform (which implies $s_{0}\left(l_{0^{-}}\right) l_{0^{-}}=1-e_{H, 0^{-}}$).

Combining the two expressions,

$$
\Delta \log \left(e_{t}^{o l d}\right) \approx \frac{1}{e_{H, 0^{-}}} \eta \Delta \log \left(\omega_{t}\right)
$$

Using the demand expression in equation (2) of the paper,

$$
\Delta \log \left(e_{t}^{\text {old }}\right) \approx \frac{1}{e_{H, 0^{-}}} \eta\left(-\frac{1}{\theta-1} \log y_{t}+\Delta \log A\right)
$$


Using the expression for the evolution of $y_{t}$ in Proposition 1 of the paper,

$$
\begin{gathered}
\Delta \log \left(e_{t}^{\text {old }}\right) \approx \frac{1}{e_{H, 0^{-}}} \frac{\eta}{\theta+\kappa \eta}\left(-1-\kappa \eta-\frac{\psi}{\chi}(\theta-1)\left(1-e^{-\lambda t}\right)+(\theta+\kappa \eta)\right) \Delta \log A \\
\Delta \log \left(e_{t}^{\text {old }}\right) \approx \frac{1}{e_{H, 0^{-}}} \frac{\eta}{\theta+\kappa \eta}\left(1-\frac{\psi}{\chi}\left(1-e^{-\lambda t}\right)\right)(\theta-1) \Delta \log A,
\end{gathered}
$$

which is identical to (3.1).

Proof of equation (3.2). We first use a first-order approximation to write the log-change in relative high-tech employment in terms of changes in the high-tech employment share:

$$
\begin{aligned}
\log \left(\frac{e_{t}^{\text {young }}}{e_{0^{-}}^{\text {young }}}\right)-\log \left(\frac{e_{t}^{\text {old }}}{e_{0^{-}}^{\text {old }}}\right) & \approx \frac{1}{1-e_{H, \infty}}\left(\frac{e_{H, t}^{\text {young }}-e_{H, 0^{-}}^{\text {young }}}{e_{H, \infty}}-\frac{e_{H, t}^{\text {old }}-e_{H, 0^{-}}^{\text {old }}}{e_{H, \infty}}\right) \\
& =\frac{1}{\left(1-e_{H, \infty}\right) e_{H, \infty}}\left(\left(e_{H, t}^{\text {young }}-e_{H, t}^{\text {old }}\right)-\left(e_{H, 0^{-}}^{\text {young }}-e_{H, 0^{-}}^{\text {old }}\right)\right) \\
& =\frac{1}{\left(1-e_{H, \infty}\right) e_{H, \infty}}\left(e_{H, t}^{\text {young }}-e_{H, t}^{\text {old }}\right)
\end{aligned}
$$

where the last equality follows from the fact that before the shock old and young make identical choices, $e_{H, 0^{-}}^{\text {young }}=e_{H, 0^{-}}^{o l}$.

Using the definition of employment shares for each generation,

$$
\begin{aligned}
e_{H, t}^{\text {young }}-e_{H, t}^{o l d} & \approx \frac{1}{1-\left(1-\tilde{x}_{0}\right) e^{-\delta t}}\left(\tilde{x}_{0} e^{-\delta t} \int_{l_{t}}^{1} s_{0}(i) d i+\delta \int_{0}^{t} e^{\delta(\tau-t)} \int_{l_{t}}^{1} \tilde{s}_{\tau}(i) d i d \tau\right)-\int_{l_{t}}^{1} s_{0}(i) d i \\
& \approx \frac{1}{1-\left(1-\tilde{x}_{0}\right) e^{-\delta t}}\left(\delta \int_{0}^{t} e^{\delta(\tau-t)} \int_{l_{t}}^{1}\left(\tilde{s}_{\tau}(i)-s_{0}(i)\right) d i d \tau\right)
\end{aligned}
$$

Thus,

$$
\log \left(\frac{e_{t}^{\text {young }}}{e_{0^{-}}^{\text {young }}}\right)-\log \left(\frac{e_{t}^{\text {old }}}{e_{0^{-}}^{\text {old }}}\right) \approx \frac{1}{\left(1-e_{H, \infty}\right) e_{H, \infty}} \frac{1}{1-\left(1-\tilde{x}_{0}\right) e^{-\delta t}}\left(\delta \int_{0}^{t} e^{\delta(\tau-t)} \int_{l_{t}}^{1}\left(\tilde{s}_{\tau}(i)-s_{0}(i)\right) \operatorname{did} \tau\right)
$$

We now consider the following approximation:

$$
\int_{l_{t}}^{1}\left(\tilde{s}_{\tau}(i)-s_{0}(i)\right) d i \approx \int_{l}^{1} s(i)\left(\hat{\tilde{s}}_{\tau}(i)-\hat{s}_{0}(i)\right) d i
$$


Then, we derive $\hat{s}_{0}(i)$ using the expression for the stationary skill distribution

$$
\begin{aligned}
& s_{0}(i)=\frac{\bar{s}(i) \alpha(i)^{\frac{\psi}{\rho+\delta}}\left(\omega_{0^{-}} \sigma(i)\right)^{\frac{\psi}{\rho+\delta} \mathbb{I}_{i>l_{0}}}}{\int_{0}^{l_{0^{-}}} \bar{s}(j) \alpha(j)^{\frac{\psi}{\rho+\delta}} d j+\int_{l_{0^{-}}}^{1} \bar{s}(j) \alpha(j)^{\frac{\psi}{\rho+\delta}}\left(\omega_{0^{-}} \sigma(j)\right)^{\frac{\psi}{\rho+\delta}} d j} \\
& \Longrightarrow \\
& \hat{s}_{0}(i) \approx-\left(\mathbb{I}_{i>l}-\int_{l}^{1} s(j) d j\right) \frac{\psi}{\rho+\delta} \Delta \log (\omega)
\end{aligned}
$$

Using the third part of Theorem 1 of the paper,

$$
\begin{aligned}
\int_{l_{t}}^{1}\left(\tilde{\mathcal{S}}_{\tau}(i)-s_{0}(i)\right) d i & \approx e_{H, \infty}\left(1-e_{H, \infty}\right)\left(\psi \hat{q}_{\tau}+\frac{\psi}{\rho+\delta} \Delta \log (\omega)\right) \\
& =e_{H, \infty}\left(1-e_{H, \infty}\right) \psi\left(\hat{q}_{\tau}+\Delta \log (q)\right)
\end{aligned}
$$

We now apply this expression into (3.7):

$$
\begin{aligned}
\log \left(\frac{e_{t}^{\text {young }}}{e_{0^{-}}^{\text {young }}}\right)-\log \left(\frac{e_{t}^{\text {old }}}{e_{0^{-}}^{\text {old }}}\right) & \approx \frac{\psi}{1-\left(1-\tilde{x}_{0}\right) e^{-\delta t}}\left(\delta \int_{0}^{t} e^{\delta(\tau-t)}\left(\hat{q}_{\tau}+\Delta \log (q)\right) d \tau\right) \\
& \approx \frac{\psi}{1-\left(1-\tilde{x}_{0}\right) e^{-\delta t}}\left(\delta \int_{0}^{t} e^{\delta(\tau-t)} \hat{q}_{0} e^{-\lambda \tau} d \tau+\left(1-e^{-\delta t}\right) \Delta \log (q)\right) \\
& \approx \frac{\psi}{1-\left(1-\tilde{x}_{0}\right) e^{-\delta t}}\left(\frac{\delta}{\lambda-\delta}\left(e^{-\delta t}-e^{-\lambda t}\right) \hat{q}_{0}+\left(1-e^{-\delta t}\right) \Delta \log (q)\right)
\end{aligned}
$$

Notice that Proposition 1 of the paper implies that

$$
\begin{gathered}
\Delta \log (q)=\frac{1}{\chi}(\theta-1) \Delta \log A \\
\Delta \log \left(q_{0}\right)=\frac{1}{\chi}\left(1+\frac{\lambda-\delta}{\delta}\right)(\theta-1) \Delta \log A \\
\hat{q}_{0}=\Delta \log \left(q_{0}\right)-\Delta \log (q)=\frac{1}{\chi} \frac{\lambda-\delta}{\delta}(\theta-1) \Delta \log A
\end{gathered}
$$

Thus,

$$
\begin{aligned}
\log \left(\frac{e_{t}^{\text {young }}}{e_{0^{-}}^{\text {young }}}\right)-\log \left(\frac{e_{t}^{\text {old }}}{e_{0^{-}}^{\text {old }}}\right) & \approx \frac{\psi}{\chi} \frac{1}{1-\left(1-\tilde{x}_{0}\right) e^{-\delta t}}\left(\left(e^{-\delta t}-e^{-\lambda t}\right)+\left(1-e^{-\delta t}\right)\right)(\theta-1) \log A \\
& \approx \frac{\psi}{\chi} \frac{1-e^{-\lambda t}}{1-\left(1-\tilde{x}_{0}\right) e^{-\delta t}}(\theta-1) \Delta \log A,
\end{aligned}
$$

which is equivalent to (3.2). 
Proof of equation (3.6). Equations (3.7)-(3.8) remain valid. For $\tilde{x}_{0}=1$,

$$
\Delta \log \left(e_{t}^{\text {young }}\right)-\Delta \log \left(e_{t}^{\text {old }}\right) \approx \psi\left(\delta \int_{0}^{t} e^{\delta\left(\tau-t_{N}\right)}\left(\hat{q}_{\tau}+\Delta \log (q)\right) d \tau\right)
$$

where

$$
\hat{q}_{\tau}=e^{-\lambda t} \sum_{n=1}^{N} \hat{q}_{t_{n}} e^{\lambda t_{n}}
$$

Thus,

$$
\Delta \log \left(e_{t}^{\text {young }}\right)-\Delta \log \left(e_{t}^{\text {old }}\right) \approx \psi\left(\frac{\delta}{\lambda-\delta}\left(e^{-\delta t}-e^{-\lambda t}\right) \sum_{n=1}^{N} \hat{q}_{t_{n}} e^{\lambda t_{n}}+\left(1-e^{-\delta t}\right) \Delta \log (q)\right)
$$

Notice that Proposition 1 of the paper implies that

$$
\begin{gathered}
\Delta \log (q)=\frac{1}{\chi}(\theta-1) \sum_{n=1}^{N} \Delta \log A_{n} \\
\hat{q}_{t_{n}}=\frac{1}{\chi} \frac{\lambda-\delta}{\delta}(\theta-1) \Delta \log A_{n}
\end{gathered}
$$

Using the definitions of $\Delta \log A \equiv \sum_{n=1}^{N} \Delta \log A_{n}$ and $\Delta \log \tilde{A} \equiv \sum_{n=1}^{N} e^{\lambda t_{n}} \Delta \log A_{n}$, the combination of the expressions above imply that

$$
\Delta \log \left(e_{t}^{\text {young }}\right)-\Delta \log \left(e_{t}^{\text {old }}\right) \approx \frac{\psi(\theta-1)}{\chi}\left(\left(e^{-\delta t}-e^{-\lambda t}\right) \Delta \log \tilde{A}+\left(1-e^{-\delta t}\right) \Delta \log A\right)
$$

\subsection{Parameterization by impulse response matching}

We now describe how to parameterize our theory to match the empirical impulse response functions in Section 7.3. To this end, we map the $H$ technology in our theory to the set of production activities performed by cognitive-intensive occupations. We calibrate our theory in two steps. In the first step, we exogenously specify a subset of parameters and functions in the theory. We set the discount rate to match an annual interest rate of $2 \%, \rho=0.02$. We calibrate the elasticity of substitution across cognitive and non-cognitive intensive occupations to $\theta=3$. Finally, for all welfare calculations, we specify welfare-weights $r e^{-r t}$ with $r=\rho+\delta$ so that the social discounting of future generations is identical to the discounting of worker's future utility.

We also specify functional forms for the productivity of skill types in the two technologies. We abstract from differences in non-cognitive productivity across skills by normalizing $\alpha(i) \equiv 1$. This implies that, for any given worker generation, employment and payroll responses are both driven by the degree of technology-skill specificity in the 
economy ${ }^{41}$ In addition, we assume that $\sigma(i)$ takes the form of a logistic function:

$$
\sigma(i)=\frac{e^{\sigma(i-l)}}{1+e^{\sigma(i-l)}}
$$

where $l$ is the assignment threshold in the initial stationary equilibrium. This specification is a tractable manner of capturing technology-skill specificity in the economy. It implies that the equilibrium exists for any $\sigma>0$ since the relative productivity is bounded. Also, by setting the midpoint of the function to $l$, the parameter $\sigma$ controls the elasticity of $\sigma(i)$ for the marginal skill types in the initial equilibrium (i.e., $i$ close to $l$ ). Thus, $\sigma$ specifies the magnitude of technology-skill specificity, $1 / \eta$.

In the second step, we use the estimated responses of Section 7.3 to calibrate $(\delta, \sigma, \psi)$. In doing so, we select the distribution of innate ability to normalize the initial skill distribution to be uniform: $s_{0}(i) \equiv 1{ }^{42}$ We formally present the parameterization procedure next, along with an analysis of the model fit. For all parameters, we assume that the shock starts with the roll-out of broadband internet in 2003. We then select parameters to match the estimates for the period of 2008 to 2014 in which we find statistically significant response in the relative payroll and relative employment of cognitive-intensive occupations.

Generation size: $\delta$ and $\tilde{x}_{0}$. We first set $\tilde{x}_{0}$ to match the $60 \%$ share of young workers in the national population in 1997. We then select $\delta$ to match the incline of 25 p.p. in the share of young workers in population between 1997 and 2014. Specifically, we select $x$ and $\delta$ such that

$$
\begin{gathered}
\hat{\delta}=\frac{1}{2014-1997} \log (0.40 / 0.15) \\
x=-\frac{1}{\delta} \log 0.4 .
\end{gathered}
$$

We obtain $\delta=0.0574$. This says that the expected work life of a worker after turning 40 years is 18 further years.

Rate of convergence: $\lambda$. Proposition 1 in the paper implies that it is possible to write the impulse response function of relative output as

$$
\Delta \log \left(y_{t}\right)=\alpha_{0}+\alpha_{1} e^{-\lambda t}
$$

where $\alpha_{0}>0, \alpha_{1}<0$, and $\lambda>0$.

We select the parameter $\lambda$ to match the growth in the estimates response of relative

\footnotetext{
${ }^{41}$ The function form of $\alpha(i)$ controls how labor earnings respond to changes in the employment composition across technologies - for a discussion, see Adão (2016). Alternative specifications of $\alpha(i)$ can thus be used to match responses in relative earnings for different worker generations.

${ }^{42}$ In this calibration, we select the distribution of innate ability distribution, $\bar{s}(i)$, to generate a uniform distribution of skills in the initial equilibrium: $s_{0}(i) \equiv 1$. In our theory, this normalization is innocuous since it does not affect changes in the skill distribution for a given change in $q$ conditional on setting $\eta$ to match the short-run employment change.
} 
payroll of more cognitive-intensive occupations:

$$
\hat{\lambda}=\arg \min _{\lambda} \sum_{t=2008}^{2014}\left[\left(\hat{\beta}_{t}^{y}-\hat{\beta}_{2007}^{y}\right)-\alpha_{1} e^{-\lambda(t-2007)}\right]^{2}
$$

where $\hat{\beta}_{t}^{y}$ are the estimated coefficient reported in Panel B of Figure 7 of the paper.

The minimization problem in (4) yields $\hat{\lambda}=0.135$. Figure 3.1 shows the fit of the calibrated model

Cost of skill investment: $\psi$. Theorem 1 of the paper implies that

$$
\kappa \eta=\psi \hat{\alpha}-\theta
$$

where

$$
\alpha=\delta\left[\left(\frac{\rho}{2}+\hat{\lambda}\right)^{2}-\left(\frac{\rho}{2}\right)^{2}-\delta(\rho+\delta)\right]^{-1} .
$$

Using expression (3.2), we have that

$$
\Delta \log e_{t}^{\text {young }}-\Delta \log e_{t}^{\text {old }}=\frac{\psi}{\chi} \frac{1-e^{-\lambda t}}{1-\left(1-\tilde{x}_{0}\right) e^{-\delta t}}(\theta-1) \Delta \log A .
$$

From Proposition 1 of the paper,

$$
(\theta-1) \Delta \log (A)=\Delta \log \left(y_{t}\right)\left(\frac{1+\kappa \eta}{\theta+\kappa \eta}+\frac{\psi}{\chi} \frac{\theta-1}{\theta+\kappa \eta}\left(1-e^{-\lambda t}\right)\right)^{-1}
$$

where $\chi=(\theta+\kappa \eta)(\rho+\delta)+\psi$.

Combining these two expressions, we get that

$$
\frac{\Delta \log e_{t}^{\text {young }}-\Delta \log e_{t}^{\text {old }}}{\Delta \log y_{t}}=\frac{1-e^{-\lambda t}}{1-\left(1-\tilde{x}_{0}\right) e^{-\delta t}}\left(\frac{1+\kappa \eta}{\theta+\kappa \eta} \frac{\chi}{\psi}+\frac{\theta-1}{\theta+\kappa \eta}\left(1-e^{-\lambda t}\right)\right)^{-1} .
$$

Using the expression for $\kappa \eta$ in (5),

$$
\frac{\Delta \log e_{t}^{\text {young }}-\Delta \log e_{t}^{\text {old }}}{\Delta \log y_{t}}=\frac{1-e^{-\lambda t}}{1-\left(1-\tilde{x}_{0}\right) e^{-\delta t}}\left((\rho+\delta) \frac{1+\psi \alpha-\theta}{\psi}+1-\frac{\theta-1}{\psi \alpha} e^{-\lambda t}\right)^{-1} .
$$

We then define the function:

$$
F^{\psi}(\psi, t) \equiv \frac{1-e^{-\hat{\lambda} t}}{1-\left(1-\tilde{x}_{0}\right) e^{-\hat{\delta} t}}\left((\rho+\hat{\delta}) \frac{1+\psi \hat{\alpha}-\theta}{\psi}+1-\frac{\theta-1}{\psi \hat{\alpha}} e^{-\hat{\lambda} t}\right)^{-1} .
$$

To calibrate $\psi$, we first our calibrated values of $(\lambda, \delta, \rho)$ to compute $\alpha$ using (6). Our baseline calibration implies that $\hat{\alpha}=3.484$. We then select the parameter $\psi$ to match the 
ratio of the cross-generation employment response and the payroll response:

$$
\hat{\psi}=\arg \min _{\psi} \sum_{t=2008}^{2014}\left[\frac{\hat{\beta}_{t}^{\text {young }}-\hat{\beta}_{t}^{\text {old }}}{\hat{\beta}_{t}^{y}}-F^{\psi}(\psi, t)\right]^{2}
$$

where $\hat{\beta}_{t}^{y}$ are the estimated coefficients reported in Panel B of Figure 7 of the paper, and $\hat{\beta}_{t}^{\text {young }}-\hat{\beta}_{t}^{\text {old }}$ is the cross-generation employment response obtained with the estimated coefficients reported in Panel A of Figure 7 of the paper.

The minimization problem in (11) yields $\hat{\psi}=0.345$. Figure 3.2 shows the fit of the calibrated model.

Technology-skill specificity: $\eta$. The combination of (3.1) and (7) implies that

$$
\frac{\Delta \log e_{t}^{\text {old }}}{\Delta \log y_{t}} \approx \frac{\eta}{e_{H, 0^{-}}} \frac{1-\frac{\psi}{\chi}\left(1-e^{-\lambda t}\right)}{1+\kappa \eta+\frac{\psi}{\chi}(\theta-1)\left(1-e^{-\lambda t}\right)} .
$$

Using the expression for $\kappa \eta$ in (5),

$$
\frac{\Delta \log e_{t}^{o l d}}{\Delta \log y_{t}} \approx \frac{\eta}{e_{H, 0^{-}}} \frac{1-\frac{(\theta-1)\left(1-e^{-\lambda t}\right)}{\alpha(\rho+\delta)+1}}{1+\psi \alpha-\theta+\frac{(\theta-1)\left(1-e^{-\lambda t}\right)}{\alpha(\rho+\delta)+1}} .
$$

We then define

$$
F^{\eta}(\eta, t) \equiv \frac{\eta}{e_{H, 0^{-}}} \frac{1-\frac{\theta-1}{\hat{\alpha}(\rho+\hat{\delta})+1}\left(1-e^{-\hat{\lambda} t}\right)}{1+\hat{\psi} \hat{\alpha}-\theta+\frac{\theta-1}{\hat{\alpha}(\rho+\hat{\delta})+1}\left(1-e^{-\hat{\lambda} t}\right)} .
$$

where $(\hat{\delta}, \hat{\lambda}, \hat{\psi})$ are the calibrated parameters above and $e_{H, 0^{-}}$is the initial share of employment in cognitive-intensive occupations.

We select the parameter $\eta$ to match the ratio of the employment response of old workers and the payroll response:

$$
\hat{\eta}=\arg \min _{\eta} \sum_{t=2008}^{2014}\left[\frac{\hat{\beta}_{t}^{\text {old }}}{\hat{\beta}_{t}^{y}}-F^{\eta}(\eta, t)\right]^{2}
$$

$\hat{\beta}_{t}^{y}$ are the estimated coefficients reported in Panel B of Figure 7 of the paper, and $\hat{\beta}_{t}^{\text {old }}$ are the estimated coefficients reported in Panel A of Figure 7 of the paper.

The negative point estimates reported in Panel A of Figure 7 of the paper imply that the minimization problem in (14) yields $\hat{\eta}<0$. Since the employment response of old generations is small and nonsignificant, we assume that they are identical to zero, which yields $\hat{\eta}=0$. Hence, we calibrate $\eta=0.01$ and evaluate the model predictions under alternative specifications of this parameter. 


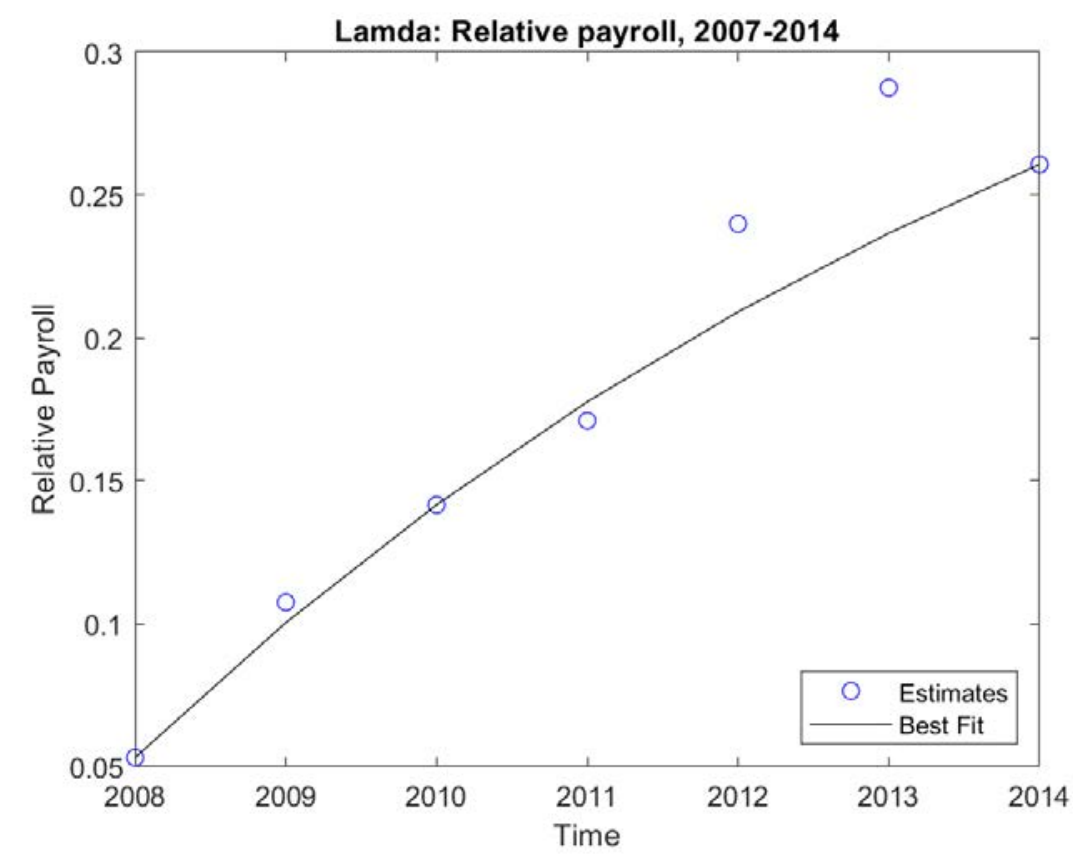

Figure 3.1: Calibration of $\lambda$

Note. Blue dots represent the point estimates reported in Panel B of Figure 7 of the paper. Black solid curve represents the bet fit line with $\lambda=0.135$ obtained from the solution of (4).

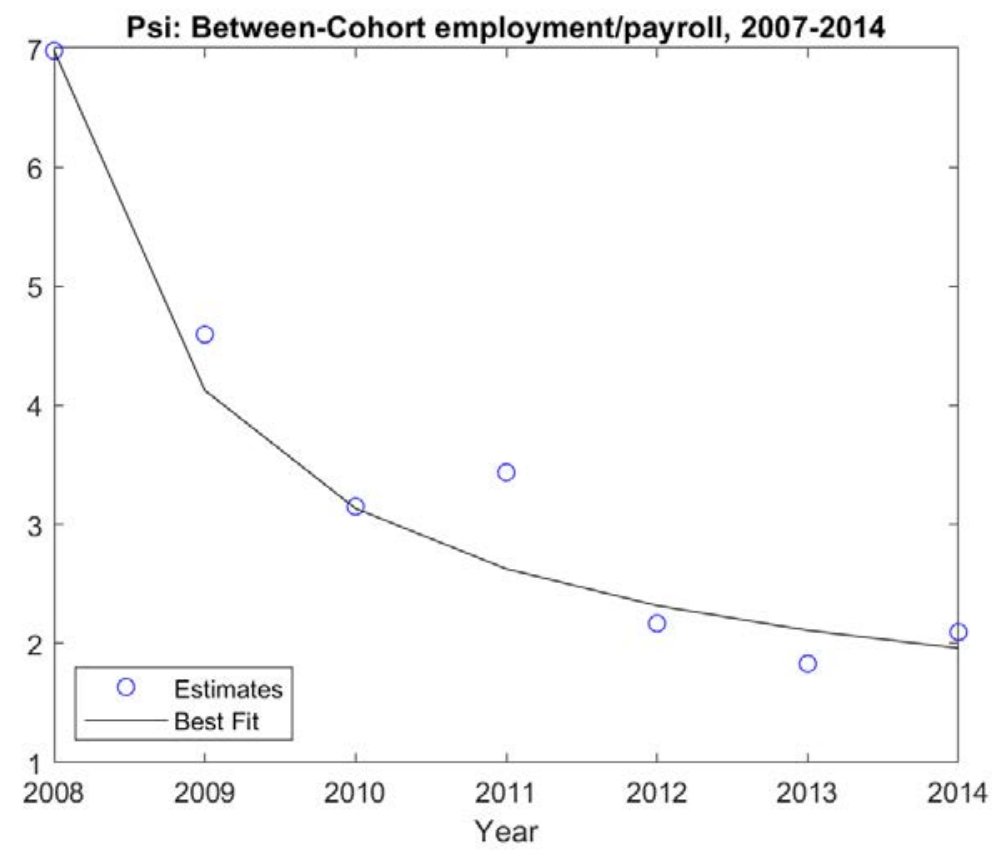

Figure 3.2: Calibration of $\psi$

Note. Blue dots represent the point estimates of $\frac{\hat{\beta}_{t}^{\text {young }}-\hat{\beta}_{t}^{\text {old }}}{\hat{\beta}_{t}^{y}}$ using the estimates reported in Figure 7 of the paper. Black solid curve corresponds to $F^{\psi}(\hat{\psi}, t)$ with $\hat{\psi}=0.354$ obtained from the solution of (11). 


\subsection{Dynamic responses to cognitive-biased technological innovations}

We now present the dynamic responses in our parametrized model. As in Section 4.2 of the paper, we evaluate a shock to $A$ that leads to an increase in the employment share in cognitive-intensive occupations from $20 \%$ to $50 \%$. Figure 3.3 presents the results.

Consider first the response at $t=0$. Given that our theory abstracts from several additional sources of dynamics, it would be wrong to interpret the impact adjustment as happening instantaneously in reality. We view this short-run response as capturing changes over the time window encompassing dynamic forces triggered by other variables that are likely to move faster than the distribution of skills (e.g., physical capital). In other words, we prefer to interpret the "length" of the impact adjustment as related to the time that it takes for such faster moving variables to converge to the new long-run equilibrium. Results show that there is a substantial increase in the relative cognitive-intensive output in the short-run. This large response is a consequence of the large magnitude of the shock. This becomes clear when we take into account that relative employment almost does not change at impact because of the high technology-skill specificity (i.e., $\eta \approx 0$ ). The combination of the large increase in relative output and the small increase in relative employment translates into large changes in lifetime inequality.

Our results also indicate that the responses in all outcomes change substantially over time (measured in terms of worker generations, $1 / \delta \approx 18 y r s$ ). Over the course of the two generations following the shock, the responses in relative output doubles in magnitude due to the reallocation of workers across technologies. Such a reallocation is entirely driven by incoming generations of young workers. This pattern is a consequence of the change in the skill distribution across generations. The bottom right panel shows that the initial spike in lifetime inequality induces young workers to invest in high-i skills allocated to cognitive-intensive occupations. This gives rise to substantial skill heterogeneity across generations. As young generations replace old generations, the economy's skill distribution becomes more biased towards high- $i$ types, leading to a large decline in the present value of the relative wage in cognitive-intensive occupations (which recedes by more than $30 \%$ over the course of two generations). 
Figure 3.3: Dynamic responses to a cognitive-biased innovation at $t=0$
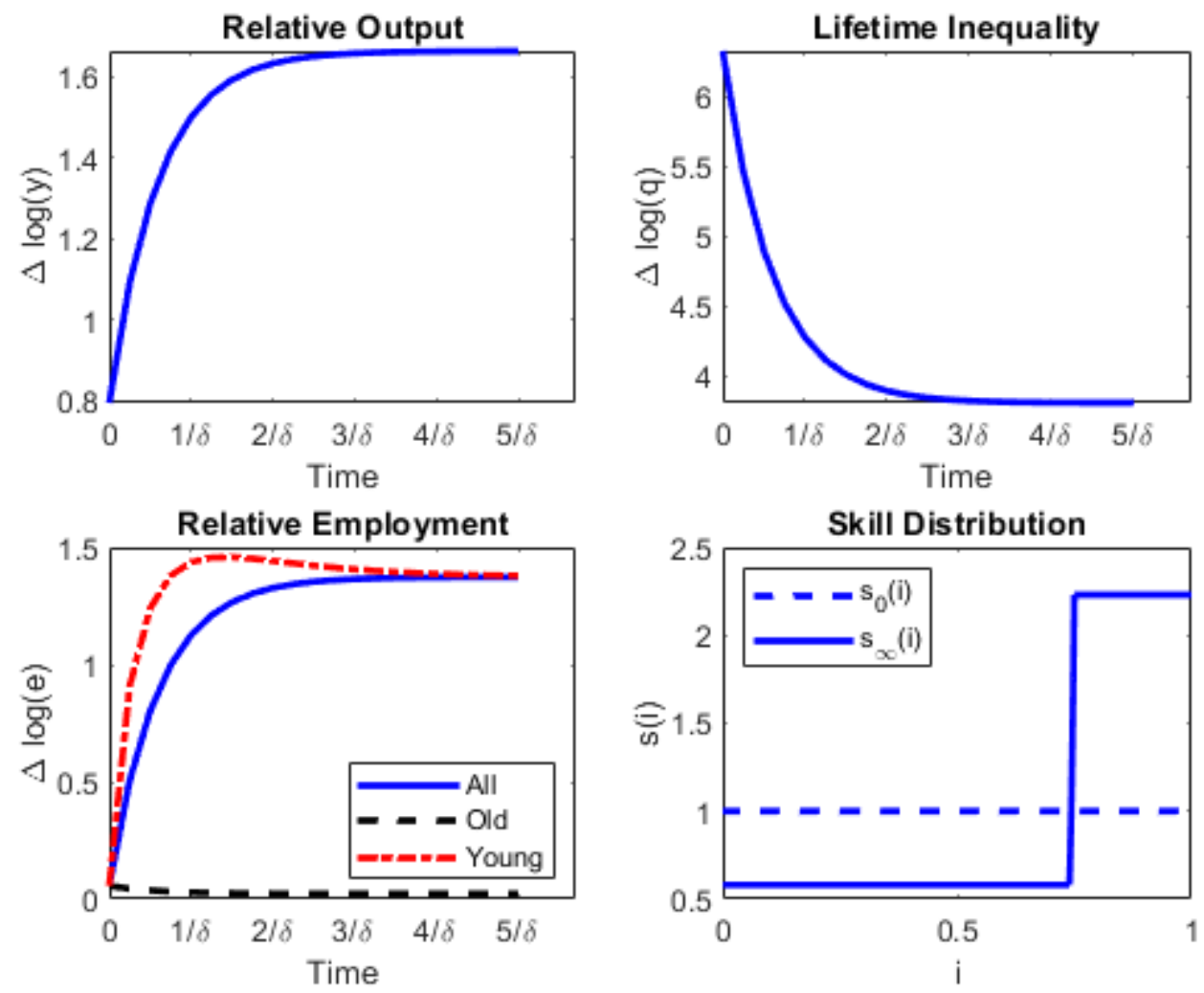

Note. The figure reports the theoretical impulse response function with a shock calibrated to increase the employment share in cognitive-intensive occupations from $20 \%$ to $50 \%$ between stationary equilibria. Baseline calibration described in Appendix 3.3. 